\title{
DRIS PARA AVALIAÇÃO DO ESTADO NUTRICIONAL DA SOJA EM DUAS REGIÕES DO CERRADO BRASILEIRO
}

\section{HAROLDO CORNELIS HOOGERHEIDE}

\author{
Dissertação apresentada à Escola \\ Superior de Agricultura "Luiz de Queiroz", \\ Universidade de São Paulo, para \\ obtenção do título de Mestre em \\ Agronomia, Área de Concentração: Solos \\ e Nutrição de Plantas.
}

PIR A C I C A B A

Estado de São Paulo - Brasil Junho - 2005 


\section{DRIS PARA AVALIAÇÃO DO ESTADO NUTRICIONAL DA SOJA EM DUAS REGIÕES DO CERRADO BRASILEIRO}

\section{HAROLDO CORNELIS HOOGERHEIDE}

Engenheiro Agrônomo

Orientador: Prof. Dr. ANTONIO ROQUE DECHEN

Dissertação apresentada à Escola Superior de Agricultura "Luiz de Queiroz", Universidade de São Paulo, para obtenção do título de Mestre em Agronomia, Área de Concentração: Solos e Nutrição de Plantas.

PIR A C I C A B A

Estado de São Paulo - Brasil Junho - 2005 
Dados Internacionais de Catalogação na Publicação (CIP) DIVISÃO DE BIBLIOTECA E DOCUMENTAÇÃO - ESALQ/USP

\section{Hoogerheide, Haroldo Cornelis}

DRIS para avaliação do estado nutricional da soja em duas regiões do cerrado brasileiro / Haroldo Cornelis Hoogerheide. - - Piracicaba, 2005.

$94 \mathrm{p}$.

Dissertação (mestrado) - - Escola Superior de Agricultura Luiz de Queiroz, 2005.

Bibliografia.

1. Cerrado 2. DRIS - norma 3. Maranhão 4. Mato Grosso 5. Piauí 6. Soja I. Título

CDD 633.34

"Permitida a cópia total ou parcial deste documento, desde que citada a fonte - O autor" 
À minha querida esposa Eulália pela compreensão e amor

Aos meus pais Samuel e Aleida por tudo que fizerem por mim

Às minhas irmãs Very, Carline e Laurina pelo apoio

\section{DEDICO}

À Jesus Cristo o Filho de Deus que me amou dando sua vida por mim "Se confessar com sua boca que Jesus é Senhor e crer em seu coração que Deus o ressuscitou dentre os mortos, será salvo. Pois com o coração se crê para justiça, e com a boca se confessa a salvação" (Rom 6: 9-10) 


\section{AGRADECIMENTOS}

Ao meu orientador Prof. Antonio Roque Dechen, pela amizade, confiança e pela oportunidade em desenvolver este trabalho.

Em especial ao colega Gilmar Ribeiro Nachtigall pelo auxilio nas diversas fases desta pesquisa.

À FUNDAÇÃO MT, SLC Agrícola Ltda, Insolo Soluções Agrícolas, Sementes Petrovina, Grupo Tibagi e Fazenda Serra Vermelha pelos dados cedidos para execução deste estudo.

Ao pesquisador e professor Ondino Bataglia Cleante pelas brilhantes idéias e que muito contribuíram.

Ao professor Carlos Tadeu dos Santos Dias pelo auxílio nas análises estatísticas.

Aos professores do Departamento de Solos e Nutrição de Plantas, em especial àqueles, os quais eu tive a oportunidade de ser aluno.

Aos funcionários do Departamento de Solos e Nutrição de Plantas.

Aos irmãos da Igreja Batista Nova Vida de Piracicaba, que foram a minha família neste período e, em especial ao Márcio Miazaki e aos pastores Marcílio e Sônia Guerra.

Aos meus colegas de curso, Gilberto Nava, José Olimpio de Souza Junior, Zaqueu Fernando Montezano, Karina Batista, Simeire Aparecida Manarin, Luciana Bertolotti, Cristiane Prezotto Silveira, Suzana Pereira de Melo, Edna Maria da Silva Bonfim, e tantos outros.

À CAPES pela concessão da bolsa de estudo. 


\section{SUMÁRIO}

Página

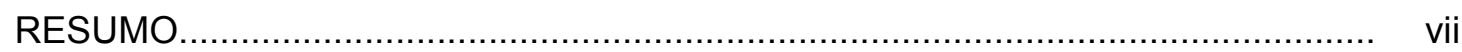

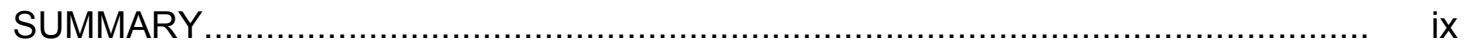

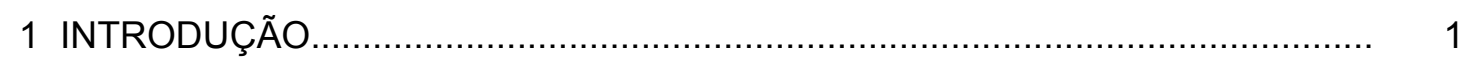

2 REVISÃO DE LITERATURA.................................................................. 3

2.1 A cultura da soja no Brasil........................................................................ 3

2.2 A região dos Cerrados brasileiros........................................................... 5

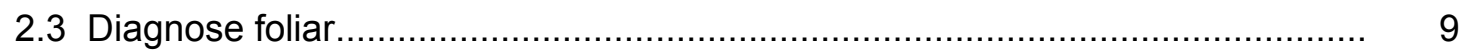

2.4 Sistema Integrado de Diagnose e Recomendação (DRIS)............................ 12

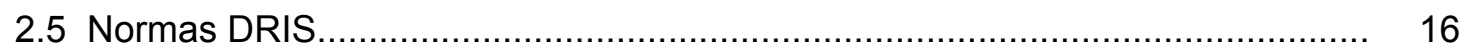

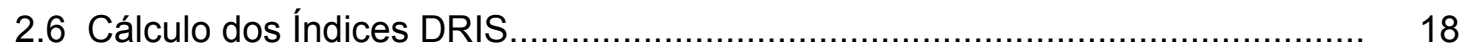

2.7 Aplicação do DRIS em soja ................................................................... 21

3 MATERIAL E MÉTODOS..................................................................... 25

3.1 Dados das regiões do sul do Maranhão e sudoeste do Piauí............................ 26

3.2 Dados do Mato Grosso.............................................................................. 28

3.3 Amostragem e análise de folhas......................................................... $\quad 29$

3.4 Elaboração do banco de dados................................................................ 31

3.5 Aplicação do método DRIS ................................................................. 32

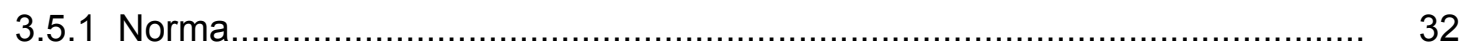

3.5.2 Razão das variâncias....................................................................... 33

3.5.3 Cálculos dos índices DRIS............................................................... 33

3.5.4 Índice de Balanço Nutricional (IBN) .................................................... 35

3.6 Avaliação do estado nutricional............................................................ 36

3.7 Análise estatística.............................................................................. 36 


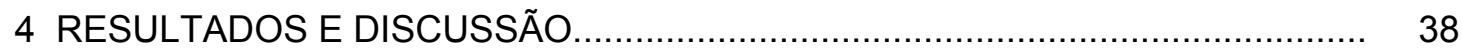

4.1 Banco de amostras das regiões do sul do Maranhão e sudoeste do Piauí........ 38

4.2 Banco de amostras do Mato Grosso......................................................... 43

4.3 Estabelecimento da norma DRIS para as regiões do sul do Maranhão e

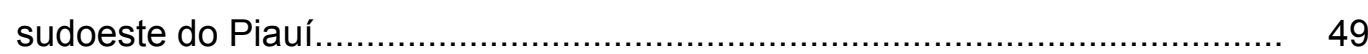

4.3.1 Agrupamento por classe de produtividade.................................................. 49

4.3.2 Seleção da norma DRIS...................................................................... 49

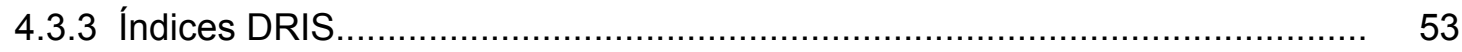

4.4 Estabelecimento da norma DRIS para o Mato Grosso.................................. 59

4.4.1 Agrupamento por classe de produtividade................................................ 59

4.4.2 Seleção da norma DRIS........................................................................ 59

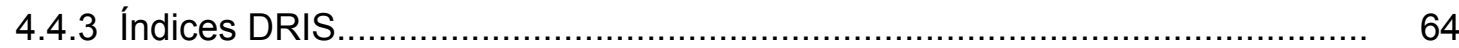

4.5 Estado nutricional da soja nas regiões do sul do Maranhão e sudoeste do

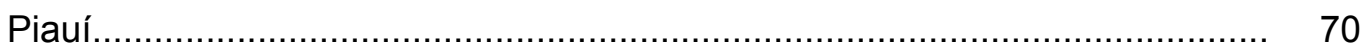

4.6 Estado nutricional da soja no Mato Grosso................................................ 75

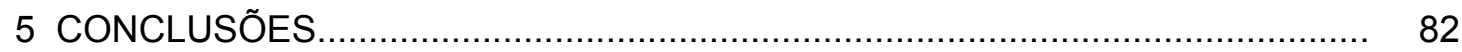

REFERÊNCIAS BIBLIOGRÁFICAS .......................................................... 83 


\title{
DRIS PARA AVALIAÇÃO DO ESTADO NUTRICIONAL DA SOJA EM DUAS REGIÕES DO CERRADO BRASILEIRO
}

\author{
Autor: HAROLDO CORNELIS HOOGERHEIDE \\ Orientador: Prof. Dr. ANTONIO ROQUE DECHEN
}

\section{RESUMO}

A soja é hoje a principal oleaginosa do Brasil, cultivada em todas as latitudes do país é o mais importante produto agrícola de exportação. $O$ alto custo das adubações e a importância da nutrição mineral sobre a produtividade, tornam imprescindível a utilização de técnicas de avaliação do estado nutricional como a diagnose foliar. $\mathrm{O}$ Sistema Integrado de Diagnose e Recomendação (DRIS) utiliza o conceito de balanço de nutrientes e parece estar menos sujeito as interferências de particularidades locais do ambiente e dos sistemas de amostragem das plantas. O presente trabalho teve por objetivo testar diferentes métodos de cálculo das funções DRIS, estabelecer uma norma de referência DRIS e avaliar o estado nutricional da cultura da soja nas regiões compreendidas pelo sul do Maranhão sudoeste do Piauí e Mato Grosso. Foram utilizados 1555 resultados de análise química foliar e produtividade dos campos de produção das regiões do sul do Maranhão e sudoeste do Piauí e 5734 resultados de análise química foliar e produtividade dos campos de pesquisa e produção do Mato Grosso. A amostragem consistiu na coleta da folha diagnóstico, que corresponde à terceira ou quarta folha com pecíolo a partir do ápice de 50 plantas por talhão em pleno florescimento. A sub-população de alta produtividade, nutricionalmente equilibrada, foi determinada pela melhor correlação do Índice de Balanço Nutricional (IBN) com a 
produtividade do banco de amostras. Foram testadas as metodologias DRIS de Beaufils (1973), Jones (1981) e Elwali \& Gascho (1984) para obtenção dos índices DRIS, nos quais as relações foram escolhidas pelo método da razão das variâncias. Os índices DRIS foram classificados em deficiente, normal e excessivo e comparados com o critério das faixas de suficiência. As metodologias de cálculo das funções DRIS (Beaufils, 1973; Jones, 1981; Elwali \& Gascho, 1984) apresentaram resultados semelhantes no diagnóstico nutricional da soja nas regiões estudadas. A relação entre a produtividade e o IBN foi melhor quando as normas DRIS foram estabelecidas utilizando a população de referência com produtividade $\geq 3600 \mathrm{~kg} \mathrm{ha}^{-1}$ para as regiões do sul do Maranhão e sudoeste do Piauí e $\geq 4800 \mathrm{~kg} \mathrm{ha}^{-1}$ para Mato Grosso. O método de cálculo das funções DRIS proposto por Jones (1981) foi escolhido para avaliação do estado nutricional da soja nas regiões do sul do Maranhão e sudoeste do Piauí e Mato Grosso pela sua facilidade de utilização. O cobre foi o nutriente mais limitante para a produtividade da soja nas regiões do sul do Maranhão e sudoeste do Piauí. Fósforo foi o nutriente mais limitante para a produtividade no Mato Grosso. O método DRIS, utilizando normas especificas para as regiões do sul do Maranhão e sudoeste do Piauí e para o Mato Grosso, foi eficiente no diagnóstico nutricional da soja. 


\title{
DRIS TO EVALUATE THE NUTRITIONAL STATUS OF SOYBEAN IN TWO SAVANNA AREAS IN BRAZIL
}

\author{
Author: HAROLDO CORNELIS HOOGERHEIDE \\ Adviser: Prof. Dr. ANTONIO ROQUE DECHEN
}

\section{SUMMARY}

Nowadays, soybean is the main oleaginous plant in Brazil, cultivated in all latitudes of the country it is the most important agricultural product of exportation. The high cost of fertilization and the importance of the mineral nutrition over productivity, make indispensable the use of evaluation techniques for the nutritional status as well as the foliar diagnosis. The Diagnosis and Recommendation Integrated System (DRIS) uses the concept of nutrient balance, it seems to be less subject to the interference of local particularities of the environment and of the systems of plant sampling. The aim of the present work was to test different methods of DRIS calculation functions, to establish a DRIS reference norm, and to evaluate the nutritional status of soybean in the areas comprehended by the south of Maranhão and southwest of Piauí and Mato Grosso. The study used 1555 results of foliar chemical analysis and productivity of production fields in the southern areas of Maranhão and the southwestern areas of Piauí and 5734 results of foliar chemical analysis and productivity of the research fields and production of Mato Grosso. The sampling consisted in collecting the diagnostic leaf corresponding to the third or fourth leaf with petiole, starting from the apex of 50 plants per planting field in full blooming. The sub-population of high productivity, nutritionally 
balanced, was determined by the best correlation of Index of Nutritional Balance (INB) with the productivity of the sampling bank. The methodologies DRIS Beaufils (1973), Jones (1981), and Elwali \& Gascho (1984) were tested in order to obtain the DRIS indices, for which relationships were chosen using the method of variance ratio. The DRIS indices were classified as deficient, normal, and excessive. They were compared with the criterion of the sufficiency ranges. The methodologies of calculation DRIS functions (Beaufils, 1973; Jones, 1981; Elwali \& Gascho, 1984) presented similar results in nutritional diagnosis of soybean in the studied areas. The relation between the productivity and INB was better when DRIS norms were established using the reference population with productivity $\geq 3600 \mathrm{~kg} \mathrm{ha}^{-1}$ for the southern areas of Maranhão and southwestern areas of Piauí and $\geq 4800 \mathrm{~kg} \mathrm{ha}^{-1}$ for Mato Grosso. The method of calculation DRIS functions proposed by Jones (1981) was chosen to evaluate the nutritional status of soybean in the southern areas of Maranhão and southwestern areas of Piauí and Mato Grosso for its usefulness easiness. Copper was the most limiting nutrient for soybean productivity in the southern areas of Maranhão and southwestern areas of Piauí. Phosphorus was the most limiting nutrient for the productivity in Mato Grosso. The DRIS method using specific norms in the southern areas of Maranhão and southwestern areas of Piauí and to Mato Grosso, was efficient in the nutritional diagnosis of soybean. 


\section{INTRODUÇÃO}

A soja é hoje a principal oleaginosa do Brasil, cultivada em todas as latitudes do país é o mais importante produto agrícola de exportação. A região dos Cerrados é responsável por mais de $50 \%$ da produção nacional, principalmente a região CentroOeste.

Os solos sob vegetação de cerrado são naturalmente ácidos e pobres em nutrientes. A produção de soja nestas áreas é dependente de calagens e fertilizações periódicas. Em função do alto custo das adubações e pela importância da nutrição mineral sobre a produtividade, é imprescindível a utilização de técnicas de avaliação do estado nutricional como a diagnose foliar.

A interpretação dos resultados de análise foliar é normalmente feita interpretando-se as faixas de concentração que consideram apenas a concentração do nutriente no material vegetal seco, não identificando qual nutriente é o mais limitante. Métodos de avaliação do estado nutricional das plantas como o Sistema Integrado de Recomendação e Diagnose (DRIS), que considera as relações entre os nutrientes e que os compara com um padrão de alta produtividade, permitem identificar quais os elementos mais limitantes como também pode contribuir para um diagnóstico mais preciso do estado nutricional.

São poucos os estudos de avaliação do estado nutricional da soja pelo DRIS na região de Cerrados do Brasil, inclusive não há referência na literatura da existência de 
normas DRIS para a cultura da soja nas regiões do sul do Maranhão e sudoeste do Piauí, região esta de grande expansão na cultura e favorecida pela condição climática e facilidade de escoamento da produção.

O método DRIS não tem objetivo de substituir as técnicas de avaliação do estado nutricional já existentes, mas vem complementar e auxiliar na identificação dos nutrientes que possam estar limitando a produtividade.

Objetivou-se neste trabalho gerar normas DRIS para avaliação do estado nutricional da cultura da soja nas regiões do sul do Maranhão e sudoeste do Piauí e Mato Grosso, bem como testar metodologias de cálculo das funções DRIS e comparar a diagnose pelo método DRIS escolhido com o critério das faixas de suficiência. 


\section{REVISÃO DE LITERATURA}

\subsection{A cultura da soja no Brasil}

A soja (Glycine max (L.) Merrill) é uma planta originária da China, inicialmente rasteira e cultivada nas margens de rios, domesticada e introduzida provavelmente no período entre 1500 e 1027 AC, é hoje a mais importante oleaginosa cultivada no mundo (Black, 2000).

A soja foi introduzida no Brasil em 1882 por Gustavo Dutra na Imperial Escola Agrícola da Bahia, atual Escola de Agronomia da Universidade Federal da Bahia, trazendo cultivares provenientes dos Estados Unidos (Embrapa, 2004). Em 1891, no Instituto Agronômico de Campinas-SP, foram realizados testes semelhantes com cultivares oriunda também dos Estados Unidos, avaliando sua adaptação às condições brasileiras, com estudos mais voltados para uso como forrageira (Embrapa, 2004).

No Rio Grande do Sul a soja é cultivada desde 1935, concentrada inicialmente na região das missões e depois evoluindo para a região do planalto médio, substituindo a criação de gado e entrando na rotação com trigo. A soja era cultivada pelos colonos nas entrelinhas do milho e o grão utilizado como fonte proteica para suínos (Myasaka, 1986).

A primeira estatística oficial de produção de soja no Estado de São Paulo ocorreu somente no ano agrícola de 1944/45, registrando um total de $31800 \mathrm{~kg}$. Neste período, a produção era proveniente de pequenas áreas espalhadas em todo estado 
cultivadas principalmente por imigrantes japoneses. Em 1951, a firma Anderson Clayton \& Cia Ltda, preocupada com o abastecimento de matéria-prima para sua indústria voltou sua atenção para soja, não somente por ser uma nova opção para produção de óleo, mas também por ser uma cultura interessante para rotação com algodão, que era a sua principal atividade (McClung et al., 1958).

No Estado do Paraná os primeiros registros da cultura são de 1953, quando uma forte geada assolou os cafezais da região norte do Paraná. A cultura foi introduzida para ajudar a custear os tratos exigidos na recuperação dos cafezais afetados. A soja era cultivada nas entre linhas, com boa adaptação e valor de comércio garantido. A empresa exportadora Cereais Paranaense S/A promovia a venda de sementes e oferecia contratos de compra dos grãos (Myasaka, 1986).

O Brasil é o segundo maior produtor e o primeiro exportador mundial de soja, sendo apenas suplantado pelo EUA. A área cultivada brasileira na safra 1990/91 foi de 9742,5 mil hectares, passando a 21243,7 mil hectares na safra $2003 / 04$, o que representa um aumento de $218 \%$ no período. Este aumento de área deve-se principalmente à incorporação de novas áreas de cultivo no Mato Grosso do Sul, Mato Grosso, Goiás, Bahia, Minas Gerais e outros Estados do Norte e Nordeste (Conab, 2005).

Quanto à produção de grãos, observou-se no período de 1990/91 a 2003/04 um crescimento de $322 \%$, passando de 15.394 mil toneladas para 49712,4 mil toneladas. Comparando-se a evolução da área cultivada e da produção, no período de 1990/91 a 2003/04, verifica-se um significativo aumento de rendimento da soja. Na safra 1990/91, o rendimento foi de $1580 \mathrm{~kg} \mathrm{ha}^{-1}$, evoluindo para $2816 \mathrm{~kg} \mathrm{ha}^{-1}$ na safra 2003/04, o que representa um aumento de $78,2 \%$ no período (Conab 2005). 
Na região Centro-Oeste, principalmente os Estados do Mato Grosso, Mato Grosso do Sul e Goiás, a cultura foi introduzida na década de 70 por agricultores da região sul do Brasil em função da disponibilidade de terras a custo mais baixo e o desenvolvimento de tecnologias de produção para a região dos Cerrados.

Hoje a região apresenta a maior produção e a maior área plantada do país. A área plantada na safra 2003/04 foi de 9,56 milhões de hectares e responsável por 49,5\% da produção brasileira (Conab, 2005).

A região Nordeste, apesar de participar apenas com 7\% da produção brasileira, tem apresentado crescimento em área e produção. A região sul do Maranhão teve seu primeiro registro de cultivo no ano de 1970, realizado por agricultores em busca de novas fronteiras agrícolas. A partir desta data, com o avanço da pesquisa para o desenvolvimento de variedades adaptadas, a cultura teve sua expansão também para os Estados do Piauí e Tocantins (Paludzyszyn Filho, 1995; Conab, 2005).

O Brasil exporta mais de $50 \%$ da produção na forma de grãos e processa o restante para fabricação de óleo e farelo para consumo interno e também exportação (Conab, 2005). O emprego de alta tecnologia nas principais regiões produtoras tem possibilitado produtividades médias superiores a $3300 \mathrm{~kg} \mathrm{ha}^{-1}$, tornando o Brasil uma referência na sojicultura mundial (Black, 2000).

\subsection{A região dos Cerrados brasileiros}

Desde a década de 70 tem aumentada a exploração agrícola da região dos cerrados, com progressivos ganhos de produtividade, em boa parte oriundos do avanço no conhecimento sobre o manejo dos solos, principalmente no que se refere à correção da acidez e melhoria na disponibilidade dos nutrientes. 
Com cerca de 200 milhões hectares, aproximadamente $25 \%$ do território nacional, é o segundo maior bioma do país em área, apenas superado pela Floresta Amazônica. Abrange parte dos Estados de Minas Gerais, Bahia, Maranhão, Piauí, Mato Grosso do Sul e Mato Grosso e, totalmente, Goiás e Tocantins (Adámoli et al., 1985).

Trata-se de uma região tropical situada entre $3^{\circ}$ e $24^{\circ}$ latitude sul e entre $41^{\circ} \mathrm{e}$ $63^{\circ}$ longitude oeste. É uma região dominada por amplos planaltos, situando-se metade da área entre 300 e $600 \mathrm{~m}$ de altitude, com apenas $5 \%$ ocorrendo acima de $900 \mathrm{~m}$. A precipitação varia de 750 a $2000 \mathrm{~mm}$ anuais, sendo que em cerca de $65 \%$ da área a precipitação é da ordem de 1200 a 1800 mm. Dois terços da região apresentam cinco a seis meses de seca, função da distribuição estacional das chuvas (Ab'Sáber, 1971).

O clima dominante da região é tropical-quente-subúmido (Aw) caracterizado por forte estacionalidade das chuvas de verão e ausência de estacionalidade da temperatura média diária. Entretanto, as serras e planaltos altos de Minas Gerais, Goiás e Mato Grosso do Sul experimentam sensíveis quedas de temperatura, inclusive geadas, caracterizando áreas de clima tropical de altitude $(\mathrm{Cw})$. Importante fenômeno é a ocorrência de veranicos. Mais de $60 \%$ da região é suscetível a eventos de estresse hídrico causados por veranicos (Dias, 1992).

A vegetação de cerrado é caracterizada pela presença de árvores baixas, inclinadas, tortuosas, com ramificações irregulares e retorcidas, e geralmente com evidências de queimadas. Os arbustos e subarbustos encontram-se espalhados, com algumas espécies apresentando órgãos subterrâneos perenes, xilopódios, que permitem a rebrota após queima ou corte (Ferri, 1969).

Os Latossolos são os solos dominantes da região e correspondem a $46 \%$ da área (Tabela 1), encontram-se subdivididos em três principais classes: Latossolo 
Vermelho, Latossolo Vermelho Amarelo e Latossolo Amarelo. São solos minerais, nãohidromórficos, profundos (normalmente superiores a $2 \mathrm{~m}$ ), com horizonte $B$ muito espesso (> $50 \mathrm{~cm}$ ) e seqüência de horizontes A, B e C pouco diferenciados; as cores variam de vermelhas muito escuras e amareladas, geralmente escuras no A, vivas no B e mais claras no C; apresentam mineralogia rica em caulinita, óxidos de ferro (goethita e hematita) e óxidos de alumínio (gibbsita); estrutura granular muito pequena e são macios quando secos e altamente friáveis quando úmidos (Camargo et al., 1987).

Tabela 1. Solos presentes na região dos Cerrados brasileiros em ordem decrescente de expressão geográfica

\begin{tabular}{lcc}
\hline Classes de solo & Área $\left.\mathbf{( k m}^{2}\right)$ & $\%$ \\
\hline Latossolos & 993.330 & 46 \\
Neossolos Quartzarênicos & 309.715 & 15 \\
Argissolos & 307.677 & 15 \\
Neossolos Litólicos e Cambissolos & 210.077 & 10 \\
Plintossolos Argilúvicos e Háplicos & 122.664 & 6 \\
Solos Concrecionários & 57.460 & 3 \\
Solos Hidromórficos & 40.752 & 2 \\
Outras classes & 19.154 & 1 \\
\hline Fonte: Adámoli et al. (1985) & &
\end{tabular}

São solos muito intemperizados, com pequena reserva de nutrientes e capacidade de troca de cátions (CTC) média à baixa. Mais de $95 \%$ destes solos são distróficos e ácidos, com pH entre 4,0 e 5,5 e teores de fósforo disponível extremamente baixos, quase sempre inferiores a $1 \mathrm{mg} \mathrm{dm}^{-3}$ (Sousa, 1989). São solos passíveis de utilização com culturas anuais, perenes, pastagens e reflorestamento. Normalmente situados em relevo plano a suave-ondulado, com declividade que 
raramente ultrapassa $7 \%$, são profundos, porosos, bem permeáveis mesmo quando muito argilosos, friáveis e de fácil preparo (Goedert, 1980).

As limitações para a produção agrícola dos solos de cerrado do Brasil são principalmente de ordem química, como elevada acidez e toxidez por alumínio, no entanto, a utilização racional de calcário e fertilizantes poderão proporcionar colheitas fartas de diversas culturas (Lopes, 1983).

Os Neossolos Quartzarênicos são solos originários de depósitos arenosos, apresentando textura areia ou areia franca ao longo de pelo menos $2 \mathrm{~m}$ de profundidade. São constituídos essencialmente de grãos de quartzo e praticamente destituídos de minerais primários pouco resistentes ao intemperismo (Oliveira et al., 1992). Por serem muito arenosos, com baixa capacidade de agregação de partículas, condicionados pelos baixos teores de argila e matéria orgânica, são solos muito suscetíveis à erosão. São considerados solos de baixa aptidão agrícola e o cultivo intenso com culturas anuais pode levar estes solos a uma rápida degradação (Silva et al., 1994)

Os Argissolos são solos minerais, não hidromórficos, com horizonte $A$ ou $E$ seguido de horizonte B textural, com nítida diferença entre os horizontes. Apresentam horizonte $\mathrm{B}$ de cor avermelhada até amarelada e teores de óxidos de ferro inferiores à 15\%. Podendo ser eutróficos, distróficos ou álicos, têm profundidades variadas e ampla variabilidade de classes texturais. Nestes solos constata-se grande diversidade nas propriedades de interesse para a fertilidade e uso agrícola (teores variáveis de nutrientes, textura, profundidade, presença ou ausência de cascalhos, ocorrência em diferentes posições na paisagem, entre outras), tornando difícil a generalização das suas qualidades (Oliveira, 1992). Apesar de não ocorrerem em grandes áreas contínuas no cerrado, sua presença é freqüente. Ocupam, na paisagem, a porção 
inferior das encostas onde o relevo se apresenta ondulado com declive entre 8 e $20 \%$ (Camargo et al., 1987).

Com a adaptação das culturas às condições edafoclimáticas do cerrado, a sua ocupação foi intensificada nos últimos anos. O adequado manejo da fertilidade do solo e um mercado internacional em crescimento, tem levado esta região a ser referência na produção de soja e de outras culturas em condicões tropicais.

\subsection{Diagnose foliar}

O crescimento e a produção dos vegetais são diretamente afetados pela sua nutrição, portanto, técnicas de avaliação do estado nutricional das plantas são ferramentas indispensáveis para o monitoramento da oferta em nutrientes pelas adubações realizadas anualmente na maioria das culturas economicamente interessantes.

Malavolta \& Malavolta (1989) definem a diagnose foliar como um método de avaliação do estado nutricional das culturas em que se analisam determinadas folhas em períodos definidos da vida da planta.

A folha, na maioria dos casos, é o órgão da planta onde ocorrem as alterações fisiológicas devido a distúrbios nutricionais. Em função disto, quase sempre o diagnóstico nutricional das plantas é feito pela técnica que, de forma ampla, se denomina diagnose foliar (Bataglia \& Dechen, 1996).

A utilização das folhas para avaliar o estado nutricional das plantas leva em conta que estas são os principais órgãos de metabolismo da planta; que as mudanças no suprimento de nutrientes se refletem na composição mineral das folhas; que as mudanças na composição mineral são mais acentuadas em certos estádios de crescimento do que em outros e; que as concentrações de nutrientes na folha em 
estádios específicos estão relacionados com a performance da cultura (Basso et al., 1986).

O uso correto da diagnose foliar como método de avaliação do estado nutricional da planta depende do conhecimento das limitações da técnica. É preciso questionar a confiabilidade dos dados, a utilização de relação e balanço de nutrientes, o efeito de cultivares e de concentrações variáveis de nutrientes alterando os processos fisiológicos (Jones et al., 1991).

Alguns autores demonstram que as concentrações dos nutrientes na folha variam conforme a idade fisiológica da planta, parte da planta amostrada e a variedade. Em função disto, torna-se imprescindível a padronização da parte da planta a ser amostrada (Olhroge, 1960; Hanway \& Weber, 1971; Mascarenhas et al., 1980).

Beaufils (1971) destaca que a maior vantagem da diagnose foliar está no fato de se considerar a própria planta como o extrator dos nutrientes no solo, permitindo uma avaliação direta de seu estado nutricional pela avaliação das concentrações foliares e assim, de forma indireta, avaliar a fertilidade do solo.

Dentre os critérios de interpretação mais utilizados para avaliação do estado nutricional das plantas destacam-se, o nível crítico, as faixas de suficiência ou concentração e mais recentemente o DRIS (Sistema Integrado de Recomendação e Diagnose) (Beaufils, 1973).

O critério das faixas de suficiência tem sido tradicionalmente o mais utilizado no Brasil, baseando-se na comparação dos resultados obtidos nas amostragens com os valores padrões determinados pela pesquisa.

O nível crítico é definido pela concentração na folha, abaixo da qual a taxa de crescimento, a produção ou a qualidade são significativamente afetadas (Bataglia \& 
Dechen, 1986). Ulrich \& Hills (1967) definem o nível crítico como sendo a concentração do nutriente na planta correspondente a $95 \%$ da produção ótima considerada.

No método das faixas de suficiência, a concentração observada na amostra em teste é comparada com faixas de concentrações consideradas insuficientes, adequadas ou excessivas. Em relação ao nível crítico, a adoção das faixas de suficiência melhora a flexibilidade na diagnose, embora haja perda na exatidão, principalmente quando os limites das faixas são muito amplos (Martinez, 1999).

O emprego dos métodos descritos acima estão sujeitos a algumas limitações, pois, consideram apenas a concentração do nutriente no material vegetal seco, não identificando qual nutriente é mais limitante, bem como as amostras necessitam ser coletadas em estádio fenológico padronizado (Hanson, 1981).

O interesse na utilização de métodos de interpretação que usam relações entre os elementos, tais como o DRIS e suas modificações são cada vez maiores (Malavolta, 1999), pois estes utilizam o conceito de balanço de nutrientes e parecem estar menos sujeito às interferências de particularidades locais do ambiente e dos sistemas de amostragem das plantas (Bataglia \& Dechen, 1996).

Inicialmente, os valores referenciais deveriam ter aplicação universal, entretanto, na prática há uma forte relação com particularidades ambientais, de modo que valores de referência mais fiéis necessitam ser obtidos nas condições locais, embora na inexistência de um padrão local, alguma extrapolação seja possível (Beaufils, 1973).

As recomendações atuais para amostragem de folhas para fins de diagnose nutricional em lavouras de produção de soja no Brasil indicam a coleta das folhas recém maduras da haste principal, correspondente à terceira ou quarta do ápice para a 
base no estádio R2 em pleno florescimento (Bataglia \& Dechen, 1986; Malavolta \& Malavolta, 1989).

$\mathrm{Na}$ Tabela 2 encontram-se os padrões nutricionais sugeridos pela EMBRAPA (2004) para a região central do Brasil.

Tabela 2. Faixas para interpretação de concentrações de macro e micronutrientes em folhas de soja para a região central do Brasil

\begin{tabular}{lccccc}
\hline Elemento & $\begin{array}{c}\text { Deficiente ou } \\
\text { muito baixo }\end{array}$ & Baixo & $\begin{array}{c}\text { Suficiente ou } \\
\text { médio }\end{array}$ & Alto & $\begin{array}{c}\text { Excessivo ou } \\
\text { muito alto }\end{array}$ \\
\hline $\mathrm{N}$ & $<32,5$ & $32,5-45,0$ & $45,1-55,0$ & $55,1-70,0$ & $>70,0$ \\
$\mathrm{P}$ & $<1,6$ & $1,6-2,5$ & $2,6-5,0$ & $5,1-8,0$ & $>8,0$ \\
$\mathrm{~K}$ & $<12,5$ & $12,5-17,0$ & $17,1-25,0$ & $25,1-27,5$ & $>27,5$ \\
$\mathrm{Ca}$ & $<2,0$ & $2,0-3,5$ & $3,6-20,0$ & $20,1-30,0$ & $>30,0$ \\
$\mathrm{Mg}$ & $<1,0$ & $1,0-2,5$ & $2,6-10,0$ & $10,1-15,0$ & $>15,0$ \\
$\mathrm{~S}$ & $<1,5$ & $1,5-2,0$ & $2,1-4,0$ & $>4,0$ & - \\
& $<15$ & $15-20$ & $21-100$ & $101-250$ & $>250$ \\
$\mathrm{Mn}$ & $<30$ & $30-50$ & $51-350$ & $351-500$ & $>500$ \\
$\mathrm{Fe}$ & $<10$ & $10-20$ & $21-55$ & $56-80$ & $>80$ \\
$\mathrm{~B}$ & - & $<6$ & $6-14$ & $>14$ & - \\
$\mathrm{Cu}$ & $<11$ & $11-20$ & $21-50$ & $51-75$ & $>75$ \\
$\mathrm{Zn}$ & $<0,5$ & $0,5-0,9$ & $1-5$ & $5,1-10$ & $>10$ \\
$\mathrm{Mo}$ & $<, 5 \mathrm{~kg}-1$ & & \\
\hline
\end{tabular}

Fonte: Embrapa (2004)

\subsection{Sistema Integrado de Diagnose e Recomendação (DRIS)}

O DRIS foi desenvolvido a partir de um método chamado Diagnose Fisiológica, que tinha por objetivo identificar e estudar a influência de fatores edáficos, climáticos e de manejo sobre a cultura da seringueira no Vietnã e no Camboja (Beaufils, 1971).

Em 1973 foi publicada uma revisão detalhada da proposta DRIS, na qual são 
demonstrados os fundamentos teóricos do método e um exemplo aplicado à cultura do milho na África do Sul (Beaufils, 1973).

A partir de então, Sumner $(1977 a, 1979,1981)$ adapta o método para os Estados Unidos em outras culturas e, em vários outros locais do mundo, o DRIS é testado e utilizado para avaliação do estado nutricional de espécies perenes e anuais: batata (Meldal-Jhonsen \& Sumner, 1980), café (Arboleda et al., 1988; Leite, 1993; Reis Junior et al., 2002), cana-de-açúcar (Zambello Júnior 1979; Elwali \& Gascho, 1984; Reis Junior, 1999), citros (Beverly et al., 1984; Santos, 1997; Salvo, 2001), gramapernambuco (Payne et al., 1990), maçã (Szücs et al., 1990; Nachtigall, 2004), mamão (Costa, 1995), manga (Raghupathi \& Bhargava, 1999), milho (Escano et al., 1981; Elwali et al., 1985), pinheiro (Rathfon \& Burger, 1991) e videira (Schaller et al., 1995).

O DRIS foi originalmente proposto como um modelo para identificação de fatores limitantes à produtividade. Entretanto, com o tempo, tem se mostrado muito mais eficiente como uma forma de interpretação de análise nutricional de plantas do que como modelo de produtividade agrícola (Bataglia, 1989).

No método DRIS, admite-se que as relações entre dois nutrientes são melhores indicadores do estado nutricional das plantas, calculando-se um índice para cada nutriente e considerando a sua relação com os demais (Beaufils, 1973). Utiliza as relações binárias entre os nutrientes, e transforma os valores das concentrações em índices, os quais variam de negativo a positivo. Quanto menor for o índice, se negativo, mais limitante estará o nutriente e quanto maior for o índice, se positivo, menos limitante estará o nutriente. O índice de valor zero indica que o nutriente está nas melhores condições de balanço nutricional (Beverly, 1991; Walworth \& Sumner, 1987).

O método DRIS é baseado em algumas considerações relativas à influência da concentração foliar de nutrientes no rendimento das culturas: a) as relações entre as 
concentrações de nutrientes são freqüentemente, melhores indicadores de deficiências nutricionais do que os valores isolados de concentrações; b) algumas relações entre nutrientes são mais importantes ou significativas do que outras; c) produtividades adequadas são atingidas apenas quando os valores de relações nutricionais importantes aproximam-se de valores ótimos, que são as médias de valores determinados em populações selecionadas, de alta produtividade; d) pelo fato de que relações nutricionais mais importantes devem apresentar valores próximos aos obtidos em populações de alta produtividade, e que a variância de uma relação nutricional importante é menor em uma população de alta produtividade do que em populações de baixa produtividade; e) os índices DRIS podem ser calculados para cada nutriente, baseando-se nos desvios médios de cada relação nutricional deste nutriente com os demais, em relação aos valores ótimos dessa determinada relação nutricional (Jones, 1981).

O método não indica se determinado nutriente encontra-se em concentração de excesso ou deficiência, mas qual nutriente é mais limitante e a ordem desta limitação (Malavolta et al., 1989).

Segundo Baldock \& Shulte (1996), quatro são as vantagens do DRIS: a) a escala de interpretação é continua e fácil de usar; b) o DRIS ordena os nutrientes do mais deficiente para o mais excessivo; c) o DRIS pode identificar casos nos quais a produção está limitada por um desequilíbrio nutricional; d) o Índice de Balanço Nutricional (IBN), que fornece uma medida dos efeitos combinados dos nutrientes na produção.

Por outro lado, o método apresenta algumas desvantagens: a) requer sistema computacional complexo; b) existe interdependência dos índices na qual o índice de 
um nutriente pode ter efeito marcante sobre o outro; c) em alguns casos há sensibilidade à idade da planta (Baldock \& Shulte, 1996).

Em função do uso de relações entre nutrientes e não dos valores absolutos, problemas de diagnose decorrentes de variação na idade fisiológica e parte amostrada são minimizados, vantagens que superam os tradicionais métodos de interpretação como níveis críticos e faixas de concentração (Bataglia \& Dechen, 1996).

O método DRIS foi criado para gerar um diagnóstico independente da idade da planta, local, cultivar, solo, clima e período de amostragem. Por usar relações entre nutrientes, sugere-se que o DRIS é menos sensível que as faixas de suficiência nas diferenças entre posição da folha na planta, idade da folha, clima, solo e cultivar. Uma vez estabelecida a norma de referência, a partir de uma grande população aleatoriamente distribuída, esta poderá ser utilizada universalmente, pois para uma determinada cultura, algumas relações específicas transcendem as condições locais de solo, clima e cultivar para a máxima performance da cultura (Meldal-Jhonsen \& Sumner, 1980; Bailey et al., 1997; Reis Junior, 2002).

Entretanto, a universalidade no uso das normas DRIS tem sido questionada. Diferenças na avaliação do estado nutricional têm sido encontradas na utilização de diferentes normas para a mesma cultura. Estudos realizados para testar o conceito do DRIS, têm demonstrado que este não é totalmente independente das condições locais e período de amostragem (Bataglia \& Santos, 1990; Escano et al., 1981)

Diversas modificações foram propostas para a metodologia apresentada por Beaufils (1973). Jones (1981) sugere uma simplificação do método que não considera se a relação da amostra é maior ou menor que a norma, ponderando a variabilidade das relações através da recíproca do desvio padrão (Bataglia \& Santos, 1990). Elwali \& Gascho (1984) propõem que o balanço entre dois nutrientes ocorre se a razão de suas 
concentrações numa amostra estiverem de acordo com a norma do nutriente em questão mais ou menos seu desvio padrão.

\subsection{Normas DRIS}

Os valores de referência ou normas DRIS correspondem aos valores médios das relações entre os nutrientes de uma população não anormal ou população de referência, bem como os seus respectivos desvios padrões e coeficientes de variação (Beaufils, 1973).

O método DRIS exige que uma determinada população em estudo, da qual deseja-se obter padrões nutricionais seja separada em duas categorias: a) "plantas não anormais", ou população de referência, que não foram afetadas por condições adversas e que possuem uma produtividade superior à um nível estabelecido; e b) plantas anormais, ou população não referência, que foram afetadas por condições adversas, produzindo menos que o nível estabelecido (Beaufils, 1973).

A escolha da população de referência deverá ser baseada na premissa de que existe uma relação significativa entre o suprimento de nutrientes e seus teores na planta, de modo que aumentos ou decréscimos nas suas concentrações proporcionem variação na produtividade.

O tamanho da base de dados para cálculo da norma é bastante variável entre os trabalhos publicados, bem como os critérios para seleção entre a população de alta e baixa produtividade. Walworth et al. (1988) demonstraram que normas desenvolvidas a partir de 10 observações de milho, cultivados a campo com produtividade superior a $18 \mathrm{tha}^{-1}$ foram mais representativas e eficientes que normas provenientes de banco de dados maiores, ao contrário de Letzsch \& Sumner (1984), que observaram que as 
melhores normas tiveram origem em grandes bases de dados em grupo de alta produtividade.

O banco de dados poderá ser oriundo tanto de experimentos de adubação como de áreas comerciais (Schutz \& Villiers, 1987; Leandro, 1998) e devem ser coletados sob as mais variadas condições ambientais possíveis, de maneira que toda a variabilidade de fatores que agem sobre a população de referência esteja nela representada (Sumner, 1979; Beaufils, 1973; Letzsch \& Sumner, 1984).

A qualidade da informação deve ser preponderante sobre o número de informações. Todavia o aumento no número de amostras na população de alta produtividade é importante, pois os valores de referência DRIS tendem a assumir valores constantes, evidenciando a possibilidade de culturas com alta produtividade apresentarem composição mineral dentro de limites definidos (Letzsch \& Sumner, 1984).

Para a subdivisão das duas populações (alta e baixa produtividade) não existe um critério bem definido (Beaufils, 1973). Walworth \& Sumner (1987) sugerem uma definição arbitrária do nível de produtividade considerado para o estabelecimento do ponto de corte entre as duas subpopulações. Letzsch e Sumner (1984) recomendam que o banco de dados seja suficientemente grande e que tenha pelo menos $10 \%$ das observações dentro da sub-população de alta produtividade. Malavolta \& Malavolta (1989) sugerem o rendimento de $80 \%$ do máximo para separar as duas subpopulações.

Após a definição da população de referência, dela são originadas as normas, ou seja, a relação entre todos os pares de nutrientes. A relação ou razão entre um par de nutrientes pode ser tanto direta quanto inversa, por exemplo, $P / K$ e K/P, respectivamente. 
Apenas um tipo de expressão é utilizado para relacionar cada par de nutrientes. Vários critérios têm sido propostos para selecionar a expressão mais adequada, entretanto o mais utilizado tem sido o critério da maior relação de variâncias entre a população de baixa e alta produtividade (Letzsch, 1985, Walworth \& Sumner, 1987). Este critério foi chamado de "valor F" por Nick (1998) e, segundo Santos (1997), o critério da maior relação de variâncias permitiu a escolha da razão que melhor identificasse o parâmetro de interesse.

Bataglia \& Santos (1990) não utilizaram o critério da maior relação de variâncias, mas testaram as relações na ordem direta e inversa e encontraram uma maior dependência da escolha das relações quando utilizaram o método de cálculo Jones (1981).

Definidas as normas e as relações para cada par de nutrientes, é possível calcular os índices DRIS para as concentrações de nutrientes de uma amostra. Desta forma, o método DRIS depende inicialmente de um padrão de referência ou norma criteriosamente estabelecido e da escolha das relações que melhor realçam o parâmetro de interesse.

\subsection{Cálculo dos Índices DRIS}

O índice DRIS de um nutriente é a média aritmética das funções reduzidas dos quocientes da concentração desse nutriente em relação às concentrações dos demais nutrientes determinados na folha.

Os índices DRIS medem o desvio do valor de qualquer parâmetro que uma amostra sob análise possa apresentar em relação aos de uma população de referência, do ponto de vista nutricional e assim estabelecer uma ordem de limitação nutricional diretamente relacionada à produtividade (Walworth \& Sumner, 1987). 
Para calcular as funções das razões dos nutrientes existem três métodos: a) o método original de Beaufils (1973); o método de Jones (1981); c) o método de Beaufils (1973) modificado por Elwali \& Gascho (1984).

O método proposto originalmente por Beaufils (1973) estabelece as funções a partir das relações entre os pares dos nutrientes e impõe restrições quando a relação na amostra é maior ou menor que a relação média da população de referência. As diversas funções são ponderadas através da recíproca dos coeficientes de variação das respectivas relações da população de referência. O valor de cada função é zero quando a relação na amostra é o mesmo da população, independente da sua variabilidade.

O método de Jones (1981) é uma simplificação do método original de Beaufils (1973), na qual não considera se a relação na amostra é maior ou menor que o da população de referência e pondera a variabilidade das relações através da recíproca do desvio padrão. O método apresenta uma base na formalidade estatística, semelhante à utilizada no controle estatístico de qualidade em indústrias (Lourenço Filho, 1982).

A modificação proposta por Elwali \& Gascho (1984), de maneira geral, reduz o valor absoluto do índice DRIS, por não incluir nos cálculos pequenos desvios da razão dos teores de nutrientes na amostra em relação a razão da média das concentrações dos nutrientes na população de referência, levando a uma menor sensibilidade na interpretação do estado nutricional. Considera os nutrientes balanceados se a razão de concentrações numa amostra qualquer estiver dentro da faixa oriunda da norma mais ou menos o seu desvio padrão. Os procedimentos de cálculo são os mesmos propostos por Beaufils (1973). 
Alguns autores têm comparado as metodologias de cálculo dos índices DRIS encontrando diferentes resultados. Bataglia \& Santos (1990) testaram os três métodos para o cálculo dos índices DRIS e concluíram que os métodos Beaufils (1973) e Elwali \& Gascho (1984) apresentaram resultados semelhantes e, o método Jones (1981) mostrou depender da ordem da relação de cada par de nutrientes estudados na cultura da seringueira. Hallmark et al. (1987) compararam os métodos Beaufils (1973) e Jones (1981) quanto à exatidão da diagnose de deficiências de fósforo e potássio na soja, acrescentando a matéria seca no cálculo dos índices. Nestas condições, para o nutriente mais deficiente, o método Jones (1981) foi mais exato que o Beaufils (1973). Santos (1997) comparou o critério de faixas com o DRIS em citros e concluiu que o método Beaufils (1973) proporcionou maior realce para as deficiências; o método de Elwali \& Gascho (1984) levou a menor número de interpretações errôneas; e o método de Jones (1981) apresentou maior facilidade de cálculo. Nick (1998) encontrou maior precisão no método Jones (1981) quando comparou os três métodos na avaliação do estado nutricional do café. Leandro (1998) comparou os três métodos em soja na região de Rio Verde e obteve maior precisão nos resultados quando utilizou a metodologia de Beaufils (1973). Mourão Filho (2000) observou que o método Jones (1981) apresentou melhor correlação com a produtividade quando comparado aos métodos de cálculos baseados em Beaufils (1973) e Elwali \& Gascho (1984) em laranjeira 'Valência' sobre três porta-enxertos.

Os índices DRIS podem assumir valores negativos quando ocorre deficiência do elemento em relação aos demais. Valores positivos indicam excesso e quanto mais próximos de zero estiverem esses índices, mais próximo estará a planta do equilíbrio nutricional para o elemento em estudo, permitindo desse modo, a classificação dos nutrientes em ordem de importância de limitação na produção e fornecendo, ao mesmo 
tempo, uma indicação da intensidade da exigência de determinado nutriente pela planta (Beaufils, 1971).

Um índice adicional e muito importante, obtido com o método DRIS e utilizado por Bataglia \& Santos (1990) e por Leite (1993), é o Índice de Balanço Nutricional (IBN), representado pela soma, em módulo, dos valores dos índices DRIS para cada nutriente, indicando o estado nutricional de cada amostra em estudo.

\subsection{Aplicação do DRIS em soja}

$\mathrm{Na}$ cultura da soja o primeiro trabalho publicado sobre DRIS foi de Sumner (1977a), o qual compilou 1245 resultados de análise foliar para nitrogênio, fósforo e potássio com suas respectivas produtividades e estabeleceu as normas de referência para uma produtividade superior a $2600 \mathrm{~kg} \mathrm{ha}^{-1}$. Seus resultados mostraram que a avaliação do estado nutricional da soja pelo DRIS foi mais precisa quando as concentrações na folha eram maiores ou menores em relação às faixas de suficiência e uma menor dependência quanto à época de amostragem e cultivar.

Hanson (1981) avaliou o estado nutricional da soja em três experimentos com fósforo na região sul do Brasil utilizando a norma publicada por Sumner (1977a). Os índices DRIS gerados no estádio de crescimento R2 indicaram melhor avaliação do equilíbrio nutricional da cultura em função dos tratamentos, quando comparado aos estádios R5 e R7, sugerindo que o método DRIS tem limitação quanto ao uso em diferentes fases da cultura.

Beverly et al. (1986) desenvolveram normas DRIS para nitrogênio, fósforo, potássio, cálcio, magnésio, manganês, ferro, cobre, zinco, molibdênio, boro e alumínio, empregando 3581 resultados de análise foliar e produtividade, provenientes de várias regiões dos EUA e do sul do Brasil. Criaram uma norma global como também normas 
locais com o objetivo de comparar as regiões entre si. O comparativo demonstrou que as condições edafoclimáticas de cada região têm efeito direto sobre os valores de referência, alterando as concentrações na folha e prejudicando o método na avaliação do estado nutricional. Estes autores indicam também a possibilidade de uma avaliação mais precoce do estado nutricional pelo método DRIS perante as faixas de suficiência, o que possibilitaria uma correção da deficiência nutricional antecipadamente.

Halmark et al. (1989) compararam o método das faixas de suficiência e o MDRIS para $\mathrm{Zn}$ e Mn em soja. Observaram superioridade no método das faixas de suficiência sobre o M-DRIS em função dos teores excessivamente elevados para manganês e baixos para zinco nas amostras, a partir dos quais as normas DRIS foram geradas. Os autores alertam sobre a utilização de valores de referência inadequados na avaliação do estado nutricional pelo M-DRIS e ressaltam a necessidade de melhoria na precisão do método DRIS quando se pretende avaliar o estado nutricional em diferentes estádios de crescimento.

Vigier et al. (1989) observaram diagnóstico mais preciso do estado nutricional da soja pelo DRIS em Quebec no Canadá quando compararam o critério das faixas de suficiência com índices DRIS obtidos mediante normas oriundas dos EUA e do Canadá. Utilizando a norma canadense, observaram um leve aumento na precisão do diagnóstico quando comparada à norma norte americana. Apesar disto, descrevem ser desnecessário a regionalização das normas. O ganho em produtividade de grãos pela aplicação do método DRIS, independente da norma utilizada, foi em média $50 \%$ superior ao método das faixas de suficiência.

A literatura indica que o primeiro trabalho com DRIS em amostras foliares de soja no Brasil foi de Oliveira (1993), que calculou os níveis de suficiência pelo método DRIS mediante regressões polinomiais do segundo grau entre os índices e as 
concentrações na folha para um índice zero. Este autor comparou as faixas de suficiência obtidas pelo DRIS com os calculados pelo método convencional, encontrando uma estreita concordância entre as duas metodologias, com exceção para ferro que apresentou uma concentração foliar acima do adequado. Os resultados foram obtidos em 40 fazendas do município de Campo Novo do Parecis, MT.

Leandro (1998) utilizou a metodologia DRIS para avaliação do estado nutricional da soja na região de Rio Verde, GO com amostras de solo e folha. Obteve a norma pela média das concentrações na folha e teores no solo empregando uma subpopulação de alta produtividade $\left(>3000 \mathrm{~kg} \mathrm{ha}^{-1}\right)$. Concluiu que a diagnose de desordens nutricionais foi mais precisa pelo método de Beaufils (1973) e ao aplicar o método DRIS em solo, a norma gerada com extrator Resina para fósforo apresentou maior precisão de diagnóstico que as normas para extrator Mehlich I. Verificou ainda que o fósforo foi o nutriente mais limitante na região de Rio Verde, GO e; que a excessiva adubação potássica provocou um desbalanço nutricional.

Maeda (2002) caracterizou o estado nutricional de lavouras de soja na região sul do Mato Grosso do Sul por meio do critério das faixas de suficiência para solo e folhas e pelo DRIS para folhas durante a safra 2000/2001. Desenvolveu valores de referência DRIS que foram validados por meio de sua aplicação em resultados de amostras foliares que apresentavam sintoma de distúrbio nutricional, principalmente manganês. Ao comparar os valores de referência gerados neste trabalho com normas para soja compilados da literatura obteve resultados distintos, demonstrando a necessidade de desenvolver valores de referência regionalizados.

Lantmann et al. (2002) criaram normas DRIS a partir de uma base de dados com 2400 amostras de folhas dos ensaios da Embrapa Soja em cinco localidades do Paraná. Avaliaram a necessidade de regionalização das normas DRIS testando uma 
norma global e outra local. As normas foram submetidas aos resultados de um experimento com $\mathrm{K}$ em soja conduzido na região de Londrina, verificando um IBN menor quando comparado à norma global, o que sugere uma melhor avaliação do estado nutricional pela norma local. E verificaram também que na dose de potássio correspondente à maior produtividade do experimento, a norma local de Londrina apresentou menor IBN. Assim, sugerem que os bancos de dados sejam regionalizados, pois indicam uma melhor avaliação do estado nutricional pela metodologia DRIS.

Kurihara (2004) estabeleceu níveis críticos, teores ótimos e faixas ótimas de nutrientes para a folha diagnóstico da soja mediante emprego dos Índices Balanceados de Kenworthy e pelo método DRIS. Formou um banco de dados a partir de 254 amostradas coletadas em lavouras comerciais de soja cultivadas em sistema plantio direto, no Mato Grosso do Sul, Mato Grosso e Goiás, e concluíu que os teores ótimos e os níveis críticos definidos a partir da media da população de referência e do limite inferior da faixa ótima estimada pelo DRIS, representam valores associados à uma condição de adequado balanço nutricional. 


\section{MATERIAL E MÉTODOS}

O trabalho foi realizado utilizando-se resultados de análise foliar e de produtividade proveniente de duas regiões do Cerrado brasileiro em concordância com a metodologia DRIS.

Os resultados de análise foliar e produtividade foram fornecidos por fundações de pesquisa e fazendas de produção de soja localizadas no Mato Grosso e nas regiões do sul do Maranhão e sudoeste do Piauí. Na Tabela 3 são apresentados o número de resultados de análise foliar, safras e faixa de produtividade fornecidos pelas empresas e utilizados para a formação do banco de dados.

Tabela 3. Número de amostras, ano e faixa de produtividade do grupo de dados fornecidos pelas empresas participantes

\begin{tabular}{lcccc}
\hline \multicolumn{1}{c}{ Empresa } & Estado & $\mathbf{N .}^{(\mathbf{1})}$ & Safra & $\begin{array}{c}\text { Produtividade } \\
\left(\mathbf{k g ~ h a}^{-1}\right)\end{array}$ \\
\hline Empresa A & PI & 272 & $1996 / 97$ a 2002/03 & 564 a 4.272 \\
Empresa A & MA & 792 & $1996 / 97$ a 2002/03 & 318 a 4.200 \\
Empresa B & MA & 337 & $1994 / 95$ a 2002/03 & 481 a 4.043 \\
Empresa B & MT & 209 & $1994 / 95$ a 2002/03 & 676 a 4314 \\
Empresa C & MA & 123 & $2000 / 01$ a 2002/03 & 1190 a 4526 \\
Empresa D & MA & 44 & $2002 / 03$ & 2279 a 3546 \\
Empresa E & MT & 5323 & $1997 / 98$ a 2001/02 & 164 a 5756 \\
Empresa F & MT & 346 & $1997 / 98$ a 2002/03 & 1674 a 4284 \\
& Total & 7446 & & \\
\hline
\end{tabular}

${ }^{1}$ Número de resultados de análise foliar e produtividade 


\subsection{Dados das regiões do sul do Maranhão e sudoeste do Piauí}

Os resultados de análise foliar e produtividade da soja das regiões do sul do Maranhão e sudoeste do Piauí foram fornecidos pelas empresas:

- INSOLO Soluções Agrícolas;

- SLC Agrícola LTDA;

- Grupo Tibagi e;

- Fazenda Serra Vermelha.

Os resultados de análise foliar e produtividade da empresa A são referentes às fazendas de produção de soja localizadas nas regiões do sul do Maranhão e sudoeste do Piauí, dos quais fazem parte os municípios de Tasso Fragoso, Alto Parnaíba, Balsas, Baixa Grande do Ribeiro, Ribeiro Gonçalves, Santa Filomena e Manoel Emídio.

Os resultados de análise foliar e produtividade da empresa B são referentes às lavouras de produção de soja localizadas no município de Tasso Fragoso-MA e Balsas-MA.

Os resultados de análise foliar e produtividade da empresa $C$ são referentes às lavouras de produção de soja situadas no município de Tasso Fragoso-MA.

Os resultados de análise foliar e produtividade de soja da empresa $D$ são referentes às áreas de produção situadas no município de Sambaíba-MA.

$\mathrm{Na}$ Tabela 4 são apresentados detalhes da localização, altitude, área plantada com soja, índice pluvial e tipo de solo.

As variedades de soja cultivadas nesta região foram: BRS Tracajá, BRSMA Sambaíba, BRSMA Pati, BRSMT Uirapuru, FT-106, FT 107, M_SOY 108, M_SOY 9001, M_SOY 9350 e Suprema. 
Tabela 4. Município, latitude, longitude, altitude, área plantada, índice pluvial e tipo de solo das empresas das regiões do sul do Maranhão e sudoeste do Piauí

\begin{tabular}{|c|c|c|c|c|c|c|c|}
\hline Empresa & Município & Latitude & Longitude & $\begin{array}{l}\text { Altitude } \\
\text { (m) }\end{array}$ & $\begin{array}{l}\text { Área }^{1} \\
\text { (ha) }\end{array}$ & $\begin{array}{l}\text { Índice pluvial }{ }^{2} \\
\text { (mm) }\end{array}$ & Solo $^{3}$ \\
\hline \multirow{7}{*}{ A } & Tasso Fragoso & $08^{\circ} 38^{\prime} 57^{\prime \prime} \mathrm{S}$ & $46^{\circ} 10^{\prime} 44^{\prime \prime} \mathrm{W}$ & - & & 1332 & Latossolo Vermelho Amarelo Distrófico típico \\
\hline & Alto Parnaíba & $09^{\circ} 01^{\prime} 01^{\prime \prime} \mathrm{S}$ & $46^{\circ} 10^{\prime} 31^{\prime \prime} \mathrm{W}$ & - & & 1238 & Latossolo Vermelho Amarelo Distrófico típico \\
\hline & Santa Filomena & $08^{\circ} 55^{\prime} 22^{\prime \prime} \mathrm{S}$ & $45^{\circ} 20^{\prime} 32^{\prime \prime} \mathrm{W}$ & - & & 1085 & Latossolo Vermelho Amarelo Distrófico típico \\
\hline & Balsas & $08^{\circ} 31^{\prime} 55^{\prime \prime} \mathrm{S}$ & $46^{\circ} 45^{\prime} 12^{\prime \prime} \mathrm{W}$ & - & 100.000 & 1519 & Latossolo Vermelho Amarelo Distrófico típico \\
\hline & Ribeiro Gonçalves & $07^{\circ} 18^{\prime} 32^{\prime \prime} \mathrm{S}$ & $45^{\circ} 10^{\prime} 52^{\prime \prime} \mathrm{W}$ & - & & 1013 & Latossolo Vermelho Amarelo Distrófico típico \\
\hline & Baixa Grande do Ribeiro & $08^{\circ} 26^{\prime} 02^{\prime \prime} \mathrm{S}$ & $45^{\circ} 30^{\prime} 16^{\prime \prime} \mathrm{W}$ & - & & 1414 & Latossolo Vermelho Amarelo Distrófico típico \\
\hline & Manoel Emídio & $08^{\circ} 28^{\prime} 19^{\prime \prime} \mathrm{S}$ & $44^{\circ} 23^{\prime} 13^{\prime \prime} \mathrm{W}$ & - & & 950 & Latossolo Vermelho Amarelo Distrófico típico \\
\hline \multirow{2}{*}{ B } & Tasso Fragoso & $08^{\circ} 30^{\prime} 20^{\prime \prime} \mathrm{S}$ & $46^{\circ} 07^{\prime} 19^{\prime \prime} \mathrm{W}$ & 665 & 16.599 & 1437 & Latossolo Vermelho Amarelo Distrófico típico \\
\hline & Balsas & $08^{\circ} 33^{\prime} 09^{\prime \prime} \mathrm{S}$ & $46^{\circ} 51^{\prime} 24^{\prime \prime} \mathrm{W}$ & 608 & 5.633 & 1942 & Latossolo Vermelho Amarelo Distrófico típico \\
\hline C & Balsas & $06^{\circ} 52^{\prime} 12^{\prime \prime} \mathrm{S}$ & $45^{\circ} 18^{\prime} 06^{\prime \prime} \mathrm{W}$ & 505 & 15.225 & 1604 & Latossolo Vermelho Amarelo Distrófico típico \\
\hline $\mathrm{D}$ & Sambaíba & $08^{\circ} 48^{\prime} 25^{\prime \prime} \mathrm{S}$ & $46^{\circ} 21^{\prime} 32^{\prime \prime} \mathrm{W}$ & 497 & 4.972 & 1230 & Latossolo Vermelho Amarelo Distrófico típico \\
\hline
\end{tabular}

${ }_{1}^{1}$ Área cultivada com soja.

${ }^{2}$ Média pluviométrica anual. 


\subsection{Dados do Mato Grosso}

Os resultados de análise foliar e produtividade de soja do Mato Grosso foram fornecidos pelas empresas:

- FUNDAÇÃO MT;

- SLC Agrícola LTDA e;

- Sementes Petrovina.

Os resultados de análise química foliar e produtividade da empresa E foram obtidos em experimentos conduzidos nos municípios de Campo Novo do Parecis, Sapezal e Nova Mutum-MT, conforme descritos a seguir:

a) Experimento de Campo Novo do Parecis-MT: teve como objetivo a calibração dos teores de micronutrientes (zinco, cobre, manganês e boro) para solo e folhas de soja cultivada em diferentes condições de acidez de um Latossolo Vermelho Distrófico típico, o qual foi instalado em setembro de 1997 e conduzido até a safra 2000/01, sendo constituído de 600 parcelas com $60 \mathrm{~m}^{2}$ cada.

b) Experimento de Nova Mutum-MT: teve como objetivo a calibração dos teores de zinco, cobre, manganês e potássio para solo e folhas de soja cultivada em diferentes condições de acidez de um Latossolo Vermelho Amarelo Distrófico típico, o qual foi instalado em setembro de 1997 e conduzido até a safra 2000/01, constituído de 480 parcelas de $60 \mathrm{~m}^{2}$.

c) Experimento de Sapezal-MT: teve por objetivo a calibração dos teores de fósforo no solo e estabelecimento da curva de resposta da soja à adubação fosfatada em um Latossolo Vermelho Distrófico típico o qual foi instalado na safra 1999/00, que ainda está sendo conduzido e foi constituído de 180 parcelas de $405 \mathrm{~m}^{2}$.

Os resultados de análise foliar e produtividade da empresa $F$ são referentes às áreas de produção de soja das fazendas Farroupilha, Rancho Bravo, Planalto e Serra 
da Saudade, localizadas no município de Pedra Preta-MT; da fazenda Leopoldina localizada no município de Pedra Preta e Itiquira-MT; das fazendas Brígida e Da Mata no município de Alto Garças-MT; e Barreiro, Maravilha e Santa Maria localizadas no município de Guiratinga-MT.

Os resultados de análise foliar e produtividade da empresa B são referentes as áreas de produção de soja da fazenda Planorte localizada no município de Sapezal-MT e da fazenda Paiaguás localizada no município de Diamantino-MT.

Na Tabela 5 são apresentados detalhes da localização, altitude, área plantada com soja, índice pluvial e tipo de solo.

As variedades de soja cultivadas nesta região foram: BRSMT Pintado, BRSMT Uirapuru, CAC 1, DM 309, DM Vitória Emgopa 313, FMT Arara Azul, FMT Maritaca, FT Cristalina RCH, MG/BR 46 (Conquista), M_SOY 8914 e MT/BR 45 (Paiaguás).

\subsection{Amostragem e análise de folhas}

A amostragem de folhas consistiu na coleta do terceiro ou quarto trifólio, com pecíolo, do ápice para a base (última folha madura) de aproximadamente 50 plantas por talhão em pleno florescimento da cultura (Embrapa, 2004).

A análise química das folhas para macro e micronutrientes foi realizada em diferentes laboratórios, escolhidas pelas empresas fornecedoras dos resultados.

As empresas $A$ e $D$ obtiveram os resultados de análise química foliar, após secagem e moagem, no laboratório do Instituto Agronômico do Paraná (IAPAR), que segue a metodologia de determinação sugerida pela Embrapa (1999). As empresas B e C obtiveram os resultados de análise química foliar no laboratório Unithal de Campinas-SP, fazendo uso dos procedimentos sugeridos por Sarruge \& Haag (1974) e Bataglia (1983). Os resultados de análise química foliar das empresas E e $F$ foram 
Tabela 5. Município, latitude, longitude, altitude, área plantada, índice pluvial e tipo de solo das empresas do Mato Grosso

\begin{tabular}{|c|c|c|c|c|c|c|c|}
\hline Empresa & Município & Latitude & Longitude & $\begin{array}{l}\text { Altitude } \\
\text { (m) }\end{array}$ & $\begin{array}{l}\text { Área }^{1} \\
\text { (ha) }\end{array}$ & $\begin{array}{c}\text { Índice pluvial }{ }^{2} \\
(\mathrm{~mm})\end{array}$ & Solo $^{3}$ \\
\hline \multirow{2}{*}{ B } & Sapezal & $13^{\circ} 56^{\prime} 33^{\prime \prime} \mathrm{S}$ & $58^{\circ} 53^{\prime} 43^{\prime \prime} \mathrm{W}$ & 695 & 6 & 1920 & Latossolo Vermelho Distrófico típico \\
\hline & Diamantino & $14^{\circ} 04^{\prime} 21^{\prime \prime} \mathrm{S}$ & $57^{\circ} 27^{\prime} 15^{\prime \prime} \mathrm{W}$ & 672 & 4,5 & 2145 & Latossolo Vermelho Amarelo Distrófico típico \\
\hline \multirow{3}{*}{ E } & C. Novo do Parecis & $13^{\circ} 20^{\prime} 15^{\prime \prime} \mathrm{S}$ & $58^{\circ} 02^{\prime} 24^{\prime \prime} \mathrm{W}$ & 646 & 10 & 2092 & Latossolo Vermelho Distrófico típico \\
\hline & Nova Mutum & $13^{\circ} 40^{\prime} 43^{\prime \prime} \mathrm{S}$ & $56^{\circ} 02^{\prime} 52^{\prime \prime} \mathrm{W}$ & 490 & 3386 & 1475 & Latossolo Vermelho Distrófico típico \\
\hline & Sapezal & $13^{\circ} 41^{\prime} 13^{\prime \prime} \mathrm{S}$ & $58^{\circ} 35^{\prime} 41^{\prime \prime} \mathrm{W}$ & 480 & 3482 & 1631 & Latossolo Vermelho Distrófico típico \\
\hline \multirow{5}{*}{$\mathrm{F}$} & Pedra Preta & $16^{\circ} 50^{\prime} 29^{\prime \prime} \mathrm{S}$ & $54^{\circ} 03^{\prime} 36^{\prime \prime} \mathrm{W}$ & 730 & 6161 & 1310 & Neossolo Quartzarênico Örtico típico \\
\hline & Pedra Preta e Itiquira & $17^{\circ} 04^{\prime} 58^{\prime \prime} \mathrm{S}$ & $54^{\circ} 13^{\prime} 13^{\prime \prime} \mathrm{W}$ & 636 & 2019 & 1660 & Latossolo Vermelho Distrófico típico \\
\hline & Alto Garças & $16^{\circ} 59^{\prime} 50^{\prime \prime} \mathrm{S}$ & $53^{\circ} 57^{\prime} 24^{\prime \prime} \mathrm{W}$ & 726 & 1814 & 1568 & Latossolo Vermelho Distrófico típico \\
\hline & Alto Garças & $16^{\circ} 41^{\prime} 44^{\prime \prime} \mathrm{S}$ & $53^{\circ} 40^{\prime} 43^{\prime \prime} \mathrm{W}$ & 726 & 6180 & 2168 & Latossolo Vermelho Distrófico típico \\
\hline & Guiratinga & $16^{\circ} 41^{\prime} 44^{\prime \prime} \mathrm{S}$ & $53^{\circ} 40^{\prime} 43^{\prime \prime} \mathrm{W}$ & 726 & 12249 & 2042 & Latossolo Vermelho Distrófico típico \\
\hline
\end{tabular}

${ }_{2}^{1}$ Área cultivada com soja.
${ }_{3}$ Média pluviométrica anual.

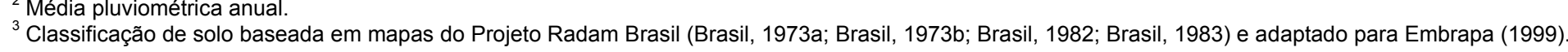


obtidos no laboratório AgroAnálise, sediada em Cuiabá-MT, o qual segue a metodologia sugerida por Malavolta et al. (1997).

\subsection{Elaboração do banco de dados}

Os resultados de análise química foliar para nitrogênio, fósforo, potássio, cálcio, magnésio, enxofre, boro, cobre, ferro, manganês e zinco, juntamente com os respectivos resultados de produtividade em $\mathrm{kg} \mathrm{ha}^{-1}$, foram plotados em planilha eletrônica Microsoft Excel ${ }^{\mathrm{TM}}$ e organizados por região de origem e safra.

Os dados foram submetidos inicialmente a uma avaliação visual com o objetivo de identificação de possíveis erros de digitação ou contaminações. Ferro e manganês apresentaram diversos resultados com suspeita de contaminação, de modo que foram mantidos na base de dados somente os valores abaixo de $500 \mathrm{mg} \mathrm{kg}^{-1}$ para ferro e 250 mg kg-1 para manganês em ambas as regiões. Para os demais nutrientes verificou-se poucos resultados com valores duvidosos, representando um número insignificante de exclusões.

O banco de dados de cada região foi dividido em uma população de alta e outra de baixa produtividade, para estabelecimento das normas. O critério de escolha do nível de produtividade para separação entre as duas subpopulações (alta e baixa) será discutido no item posterior.

Em função do elevado número de dados em cada região, optou-se pelo agrupamento em classes de produtividade de $300 \mathrm{~kg} \mathrm{ha}^{-1}$. As concentrações médias dos nutrientes de cada classe de produtividade foram utilizadas para a diagnose nutricional pelo DRIS e pelo critério das faixas de suficiência. 


\subsection{Aplicação do método DRIS}

\subsubsection{Norma}

A norma foi estabelecida para cada região utilizando as concentrações dos nutrientes da população de alta produtividade. O critério adotado para separação entre as duas sub-populações foi semelhante ao adotado por Creste (1996), sendo escolhida a população na qual a norma oriunda de determinado nível de produtividade apresente a melhor relação entre o Índice de Balanço Nutricional (IBN) e a produtividade.

O critério para determinar a produtividade mínima para divisão entre as populações de alta e baixa produtividade foi baseado no nível de produtividade considerado alto nas fazendas de produção de soja de cada região. Para as regiões do sul do Maranhão e sudoeste do Piauí adotou-se a produtividade $\geq 3000 \mathrm{~kg} \mathrm{ha}^{-1}$ e para o Mato Grosso $\geq 3600 \mathrm{~kg} \mathrm{ha}^{-1}$.

A partir destas produtividades foram estabelecidas as classes de população de alta produtividade, dentre as quais foi escolhida a que apresentou melhor relação com a produtividade no estabelecimento da norma. Para as regiões do sul do Maranhão e sudoeste do Piauí foram estabelecidos três classes: $\geq 3000 \mathrm{~kg} \mathrm{ha}^{-1}, \geq 3300 \mathrm{~kg} \mathrm{ha}^{-1} \mathrm{e}$ $\geq 3600 \mathrm{~kg} \mathrm{ha}^{-1}$, e para o Mato Grosso foram estabelecidos cinco classes de produtividade: $\geq 3600 \mathrm{~kg} \mathrm{ha}^{-1}, \geq 3900 \mathrm{~kg} \mathrm{ha}^{-1}, \geq 4200 \mathrm{~kg} \mathrm{ha}^{-1}, \geq 4500 \mathrm{~kg} \mathrm{ha}^{-1}$ e $\geq 4800 \mathrm{~kg}$ $\mathrm{ha}^{-1}$.

Dentro da população de cada classe de produtividade estabeleceu-se a população nutricionalmente equilibrada (Beaufils, 1956, citado por Beaufils 1971). O critério adota como população nutricionalmente equilibrada somente as observações que tiverem suas concentrações dentro do limite $2 / 3$ desvio padrão mais ou menos a média. 
Foram calculadas todas as relações possíveis, média, desvios padrões, variância e coeficiente de variação de todas as populações consideradas de alta produtividade. Para cada uma das populações foram calculados os índices DRIS e o IBN para estudo da relação com a produtividade. Foi selecionada a norma que apresentou a melhor relação entre o IBN e a produtividade.

\subsubsection{Razão das variâncias}

As relações foram escolhidas pelo método da razão das variâncias (Walworth \& Sumner, 1987), também denominado valor "F", que consiste no calculo da razão de variância das relações entre nutrientes da sub-população de alta e baixa produtividade, tanto na relação direta como inversa. É escolhida a relação que apresente a maior razão de variância entre a população de alta e baixa produtividade.

\subsubsection{Cálculos dos Índices DRIS}

As funções das relações dos nutrientes foram calculadas utilizando-se as metodologias propostas por Beaufils (1973), Jones (1981) e Elwali \& Gascho (1984):

a) Beaufils (1973):

se: $Y / X_{a}<Y / X_{n}$

então: $\int(Y / X)=\left[1-\left(Y / X_{n} / Y / X_{a}\right)\right] \cdot(100 \cdot k / C V)$

se: $Y / X_{a}=Y / X_{n}$

então: $\quad \int(Y / X)=O($ zero $)$

se: $Y / X_{a} \geq Y / X_{n}$ 
então: $\int(Y / X)=\left[\left(Y / X_{a} / Y / X_{n}\right)-1\right] \cdot(100 \cdot k / C V)$

b) Jones (1981):

$$
\int(Y / X)=\left(Y / X_{a}-Y / X_{n}\right) \cdot(k / s)
$$

c) Elwali e Gascho (1984):

se: $Y / X_{a}<Y / X_{n}-s$

então: $\int(Y / X)=\left[1-\left(Y / X_{n} / Y / X_{a}\right)\right] \cdot(100 \cdot k / C V)$

se: $Y / X_{n}-s \leq Y / X_{a} \leq Y / X_{n}+s$

então: $\quad \int(Y / X)=0$

se: $Y / X_{a}>Y / X_{n}+s$

então: $\int(Y / X)=\left[\left(Y / X_{a} / Y / X_{n}\right)-1\right] \cdot(100 \cdot k / C V)$

Onde:

$\int(Y / X)$ : Função calculada da relação de nutrientes $Y$ e $X$

$Y / X_{a}$ : relação de nutrientes da amostra

$Y / X_{n}:$ relação de nutrientes da norma

S: desvio padrão da relação da $Y / X_{n}$

$C V$ : coeficiente de variação (\%) da relação $Y / X_{n}$

$k$ : constante de sensibilidade 
Os índices DRIS $I_{y}$, para o nutriente $Y$ foram determinados pela fórmula geral:

$$
I_{y}=\frac{\sum_{i=1}^{m} f\left(Y / X_{i}\right)-\sum_{j=1}^{n} f\left(X_{j} / Y\right)}{m+n}
$$

Onde:

$$
\begin{array}{ll}
I_{y}: & \text { índice DRIS para o nutriente } Y \\
Y: & \text { nutriente para cálculo do índice } \\
X: & \text { outro nutriente } \\
m: & \text { número de funções cujo nutriente } Y \text { encontra-se no denominador } \\
& \text { da função } \\
n: & \text { número de funções cujo nutriente } Y \text { encontra-se no numerador da } \\
& \text { função }
\end{array}
$$

\subsection{4 Índice de Balanço Nutricional (IBN)}

Foi calculado através da soma dos valores absolutos de todos os índices gerados para a amostra (Leite, 1993):

$$
I B N=\mid \text { Índice } A|+| \text { Índice } B|+K+| \text { Índice } N \mid
$$

Foi também calculado o Índice de Balanço Nutricional médio, obtido através do somatório de todos os valores gerados para a amostra, dividido pelo número de nutrientes que participam do cálculo (Wadt, 1996).

$$
I B N m=(\mid \text { Índice } A|+| \text { Índice } B|+K+| \text { Índice } N \mid) / N
$$




\subsection{Avaliação do estado nutricional}

Foram estabelecidas três classes nutricionais para cada um dos nutrientes, considerando os índices DRIS. As classes limitante, normal e excessivo foram estabelecidas semelhantemente ao método do potencial de resposta à adubação (PRA) proposto por Wadt (1996).

O nutriente foi considerado limitante, quando apresentou índice DRIS negativo e que em módulo apresentou valor maior que o IBNm. A classe normal abrangeu os nutrientes que apresentaram índices DRIS negativos ou positivos porém em módulo menores que o IBNm. Na classe excessiva foram considerados aqueles que apresentaram índices DRIS positivos em módulo maiores que o IBNm.

A diagnose em classes obtida pelo método DRIS foi comparada com a diagnose obtida pelo critério das faixas de suficiência (Tabela 2) sugerida pela Embrapa (2004).

\subsection{Análise estatística}

As concentrações dos nutrientes e a produtividade foram submetidos à distribuição de freqüência, com aplicação do teste Kolmogorov-Smirnov para verificação de significância a 5\% de probabilidade.

Em função do elevado número de dados, utilizou-se de alguns parâmetros da estatística descritiva para uma melhor descrição dos resultados (média artimética, mediana, moda, maior, menor, desvio padrão, variância da amostra, coeficiente de variação, curtose, assimetria).

Para avaliar o efeito de safras sobre a concentração de nutrientes, os resultados foram submetidos à analise de variância e teste de médias Tukey a $5 \%$ de probabilidade. 
Para demonstrar a variabilidade da concentração dos nutrientes dentro das classes de produtividade submeteram-se os dados ao erro padrão da média, conforme:

$$
s(\bar{x})=\frac{s}{\sqrt{n}}
$$

Onde:

$$
\begin{aligned}
& s(\bar{x}): \text { erro padrão da média da concentração de um determinado } \\
& \text { nutriente por classe de produtividade } \\
& s: \text { desvio padrão das concentrações de um nutriente por classe de } \\
& \quad \text { produtividade } \\
& n: \text { número de concentrações por classe de produtividade }
\end{aligned}
$$

Para avaliar o efeito da concentração sobre os Índices DRIS e o efeito dos índices DRIS sobre a produtividade, submeteu-se os dados ao teste t a $5 \%$ de probabilidade e a análise de regressão linear.

Parte das análises estatísticas foram efetuadas mediante pacote estatístico SAS, através dos procedimentos "UNIVARIATE", "FREQ", "gCHART", "REG" e "GLM" (SAS INSTITUTE, 1999) e, a estatística descritiva, teste t e erro padrão da média em planilha eletrônica Microsoft Excel ${ }^{\mathrm{TM}}$. 


\section{RESULTADOS E DISCUSSÃO}

\subsection{Banco de amostras das regiões do sul do Maranhão e sudoeste do Piauí}

A distribuição de freqüência para macro e micronutrientes para toda população das regiões do sul do Maranhão e sudoeste do Piaui (1287 amostras) seguiu uma distribuição próxima à normalidade (Figuras 1 e 2).

Na Tabela 6 é apresentada a estatística descritiva de todos os nutrientes, o que permite uma melhor visualização dos resultados, inclusive da sua variabilidade. Os micronutrientes apresentaram um coeficiente de variação maior perante os macronutrientes, principalmente para cobre, manganês e ferro. A distribuição normal é afetada e refletida nos valores de curtose e assimetria.

Com exceção de cobre, todas as concentrações médias dos nutrientes na folha se encontram na classe suficiente de acordo com o critério das faixas de suficiência sugeridos pela Embrapa (2004).

Para cobre a concentração foliar média é considerada baixa segundo o critério das faixas de suficiência da Embrapa (2004). Os valores de mediana e moda para cobre são inferiores à média indicando que é superior o número de resultados com concentrações mais baixas neste nutriente. Este comportamento também pode ser observado na distribuição de freqüência das concentrações para cobre (Tabela 6). 
Tabela 6. Estatística descritiva das concentrações de nitrogênio, fósforo, potássio, cálcio, magnésio, enxofre, boro, cobre, ferro, manganês e zinco nas folhas de soja das regiões do sul do Maranhão e sudoeste do Piauí (Safras 1994/95 a 2002/03)

\begin{tabular}{lrrrrrrrrrr}
\hline Nutriente & Média & Mediana & Moda & Min. & Max. & $\begin{array}{r}\text { Desvio } \\
\text { padrão }\end{array}$ & Variância & CV (\%) & Curtose & Assimetria \\
\hline $\mathrm{N}\left(\mathrm{g} \mathrm{kg}^{-1}\right)$ & 45,6 & 45,1 & 39,6 & 19,4 & 69,6 & 9,3 & 86,1 & 20,3 & $-0,28$ & 0,09 \\
$\mathrm{P}\left(\mathrm{g} \mathrm{kg}^{-1}\right)$ & 3,6 & 3,5 & 3,2 & 1,3 & 7,8 & 0,9 & 0,9 & 26,3 & 1,23 & 0,69 \\
$\mathrm{~K}\left(\mathrm{~g} \mathrm{~kg}^{-1}\right)$ & 22,5 & 22,7 & 22,7 & 8,2 & 33,9 & 4,2 & 17,4 & 18,5 & 0,03 & $-0,18$ \\
$\mathrm{Ca}\left(\mathrm{g} \mathrm{kg}^{-1}\right)$ & 8,5 & 8,3 & 6,4 & 1,5 & 17,3 & 2,3 & 5,2 & 27,0 & 0,78 & 0,38 \\
$\mathrm{Mg}\left(\mathrm{g} \mathrm{kg}^{-1}\right)$ & 4,3 & 4,3 & 4,0 & 1,7 & 7,7 & 0,9 & 0,8 & 20,8 & 0,58 & 0,23 \\
$\mathrm{~S}\left(\mathrm{~g} \mathrm{~kg}^{-1}\right)$ & 2,8 & 2,8 & 1,9 & 1,1 & 5,8 & 0,7 & 0,5 & 25,6 & 0,77 & 0,45 \\
$\mathrm{~B}\left(\mathrm{mg} \mathrm{kg}^{-1}\right)$ & 49 & 48 & 43 & 26 & 97 & 10,1 & 102,3 & 20,6 & 1,49 & 0,65 \\
$\mathrm{Cu}\left(\mathrm{mg} \mathrm{kg}^{-1}\right)$ & 5 & 4 & 7 & 1 & 14 & 2,6 & 6,5 & 54,2 & 0,49 & 0,99 \\
$\mathrm{Fe}\left(\mathrm{mg} \mathrm{kg}^{-1}\right)$ & 173 & 152 & 115 & 51 & 495 & 78,4 & 6151,5 & 45,2 & 3,38 & 1,75 \\
$\mathrm{Mn}\left(\mathrm{mg} \mathrm{kg}^{-1}\right)$ & 60 & 48 & 40 & 18 & 246 & 38,5 & 1485,1 & 64,1 & 5,40 & 2,16 \\
$\mathrm{Zn}\left(\mathrm{mg} \mathrm{kg}^{-1}\right)$ & 48 & 46 & 50 & 10 & 96 & 13,9 & 195,5 & 29,4 & 0,75 & 0,67 \\
\hline
\end{tabular}



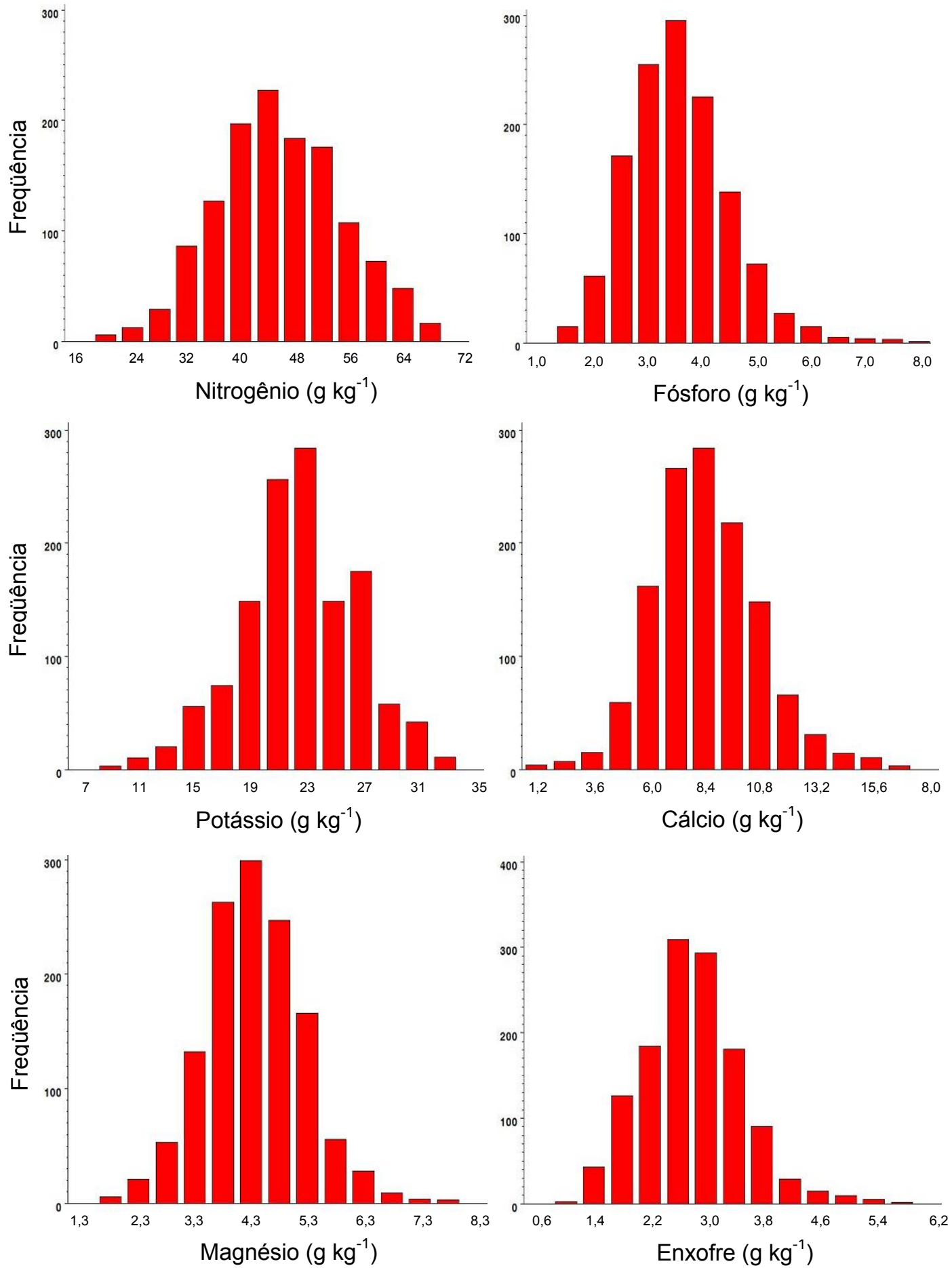

Figura 1 - Distribuição de freqüência da concentração de nitrogênio, fósforo, potássio, cálcio, magnésio e enxofre nas folhas de soja das regiões do sul do Maranhão e sudoeste do Piauí 

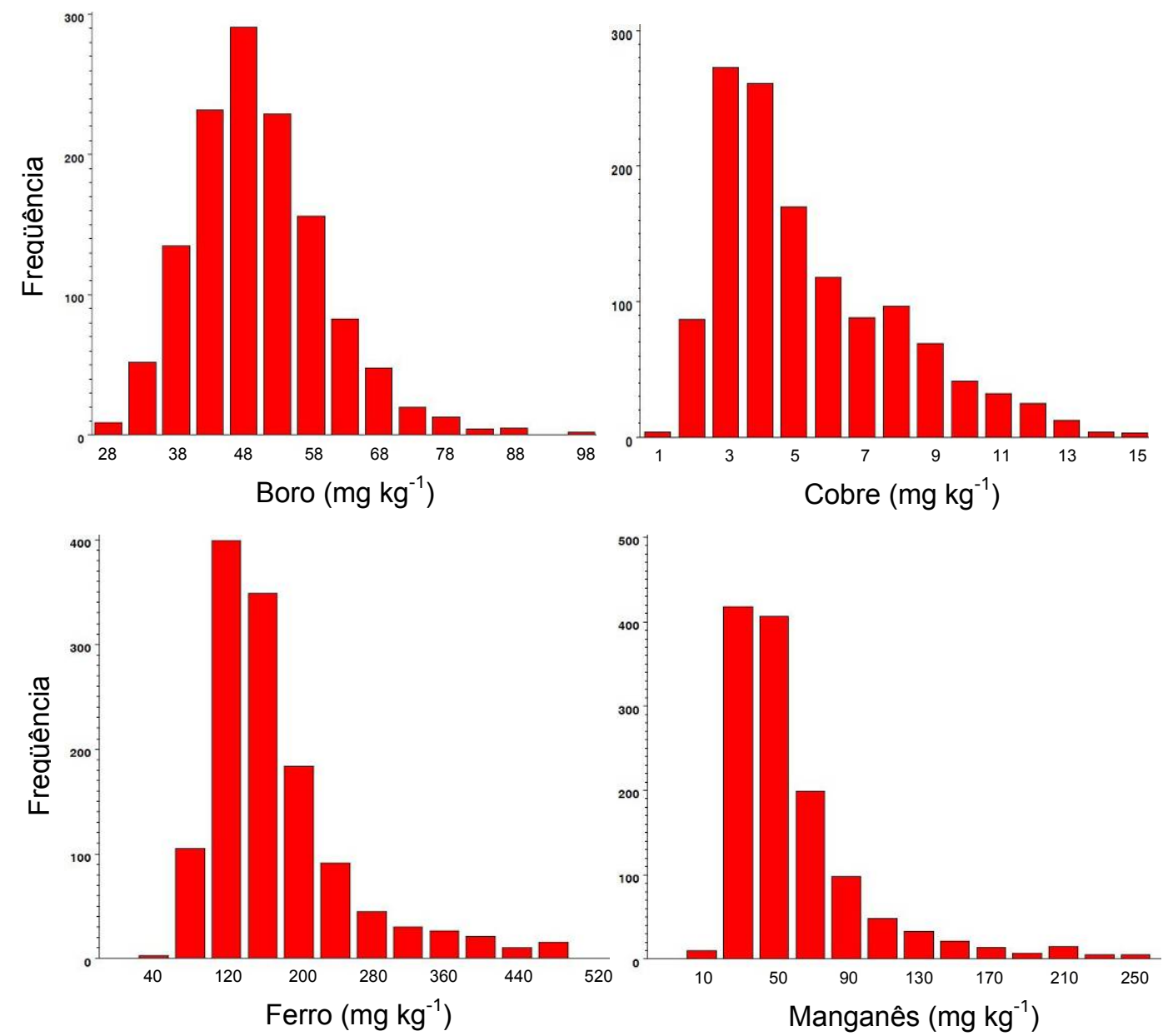

Ferro $\left(\mathrm{mg} \mathrm{kg}^{-1}\right)$

Manganês $\left(\mathrm{mg} \mathrm{kg}^{-1}\right)$

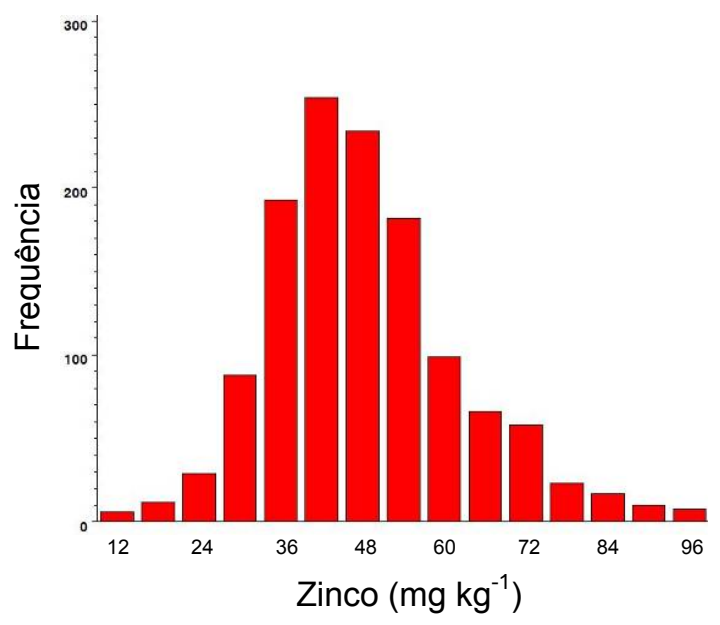

Figura 2 - Distribuição de freqüência da concentração de boro, cobre, ferro, manganês e zinco nas folhas de soja das regiões do sul do Maranhão e sudoeste do Piauí 
A concentração da maioria dos nutrientes nas amostras das regiões do sul do Maranhão e sudoeste do Piauí foi influenciada pela safra de cultivo da soja (Tabela 7). Com exceção de ferro e manganês, os demais nutrientes apresentaram uma concentração na folha significativamente diferente entre as safras 1994/95 e 2002/03.

Para nitrogênio e cobre verificou-se uma maior amplitude entre as concentrações, cujos valores variaram entre 39,8 e $55,3 \mathrm{~g} \mathrm{~kg}^{-1}$ e 2 e $9 \mathrm{mg} \mathrm{kg}^{-1}$, respectivamente. Para ferro e manganês não foi observado diferença significativa $(p<0,05)$ entre as safras pelo teste de Tukey. Os demais nutrientes apresentaram diferenças significativas pelo teste de médias, porém, em menor grau.

Tabela 7. Safra, número de amostras, concentração média de nitrogênio, fósforo, potássio, cálcio, magnésio, enxofre, boro, cobre, ferro, manganês e zinco nas amostras das regiões do sul do Maranhão e sudoeste do Piauí

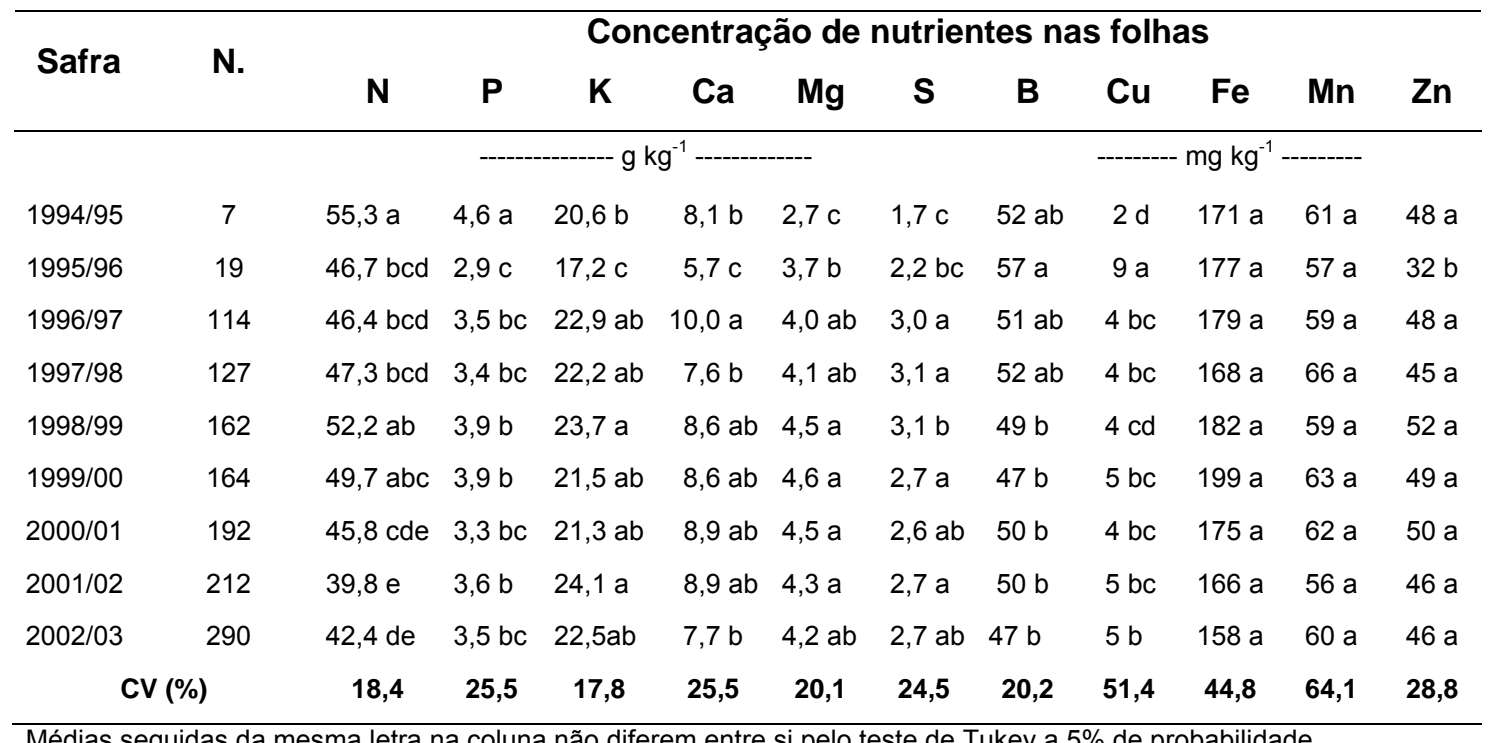

Médias seguidas da mesma letra na coluna não diferem entre si pelo teste de Tukey a $5 \%$ de probabilidade.

As diferenças verificadas nas concentrações dos nutrientes em função das safras podem ser atribuídas provavelmente à condição climática nos quais as plantas foram expostas no período. Como se trata da região de Cerrados, provavelmente a 
distribuição das chuvas foi o principal fator que influenciou na absorção de nutrientes e, consequentemente, a produtividade.

$\mathrm{Na}$ Tabela 8 é apresentada a estatística descritiva da produtividade por safra nas regiões do sul do Maranhão e sudoeste do Piauí. As produtividades médias por safra variaram entre 2069 e $3094 \mathrm{~kg} \mathrm{ha}^{-1}$, onde se observa que as maiores produtividades médias ocorreram nas safras 1999/00 e 2002/03 e as menores nas safras 1994/95, 1996/97, 1997/98 e 2001/02. A produtividade mínima foi de $318 \mathrm{~kg} \mathrm{ha}^{-1}$ ocorrido na safra 1997/98 e a máxima de $4526 \mathrm{~kg} \mathrm{ha}^{-1}$ na safra 2002/03.

Tabela 8. Estatística descritiva da produtividade de soja $\left(\mathrm{kg} \mathrm{ha}^{-1}\right)$ por safra nas regiões do sul do Maranhão e sudoeste do Piauí

\begin{tabular}{lcllcccccc}
\hline Safra & N. & Média & Mínimo & Máximo & $\begin{array}{c}\text { Desvio } \\
\text { padrão }\end{array}$ & Variância & CV (\%) & Curtose & Assimetria \\
\hline $1994 / 95$ & 7 & 2487 bcd & 1318 & 3190 & 805,5 & 648823,1 & 32,4 & $-0,97$ & $-1,07$ \\
$1995 / 96$ & 19 & 2529 bc & 1864 & 3138 & 404,5 & 163611,7 & 16,0 & $-1,12$ & $-0,02$ \\
$1996 / 97$ & 114 & $2069 \mathrm{~d}$ & 443 & 3478 & 614,8 & 377942,2 & 29,7 & 0,00 & $-0,40$ \\
$1997 / 98$ & 127 & $2162 \mathrm{~cd}$ & 318 & 3234 & 615,6 & 379007,2 & 28,5 & 0,42 & $-0,79$ \\
$1998 / 99$ & 162 & $2515 \mathrm{bc}$ & 5.40 & 3585 & 642,9 & 413351,1 & 25,6 & 0,54 & $-0,83$ \\
$1999 / 00$ & 164 & 2752 ab & 1243 & 4020 & 564,3 & 318409,7 & 20,5 & $-0,53$ & $-0,37$ \\
$2000 / 01$ & 192 & $2632 \mathrm{~b}$ & 1190 & 3941 & 571,2 & 326273,3 & 21,7 & 0,34 & $-0,55$ \\
$2001 / 02$ & 212 & $2489 \mathrm{bcd}$ & 564 & 3926 & 734,7 & 539748,9 & 29,5 & $-0,32$ & $-0,53$ \\
$2002 / 03$ & 290 & $3098 \mathrm{a}$ & 955 & 4526 & 522,2 & 272672,4 & 16,9 & 1,59 & $-0,75$ \\
\hline
\end{tabular}

Médias seguidas da mesma letra na coluna não diferem entre si pelo teste de Tukey a $5 \%$ de probabilidade.

\subsection{Banco de amostras do Mato Grosso}

Da mesma forma que para as regiões do sul do Maranhão e sudoeste do Piauí, as concentrações foliares de nitrogênio, fósforo, potássio, cálcio, magnésio, enxofre, boro, cobre, ferro manganês e zinco apresentaram tendência à normalidade (Figuras 3 e 4). Embora também não apresentem significância pelo teste de Kolmogorov-Smirnov a $5 \%$ de probabilidade. 

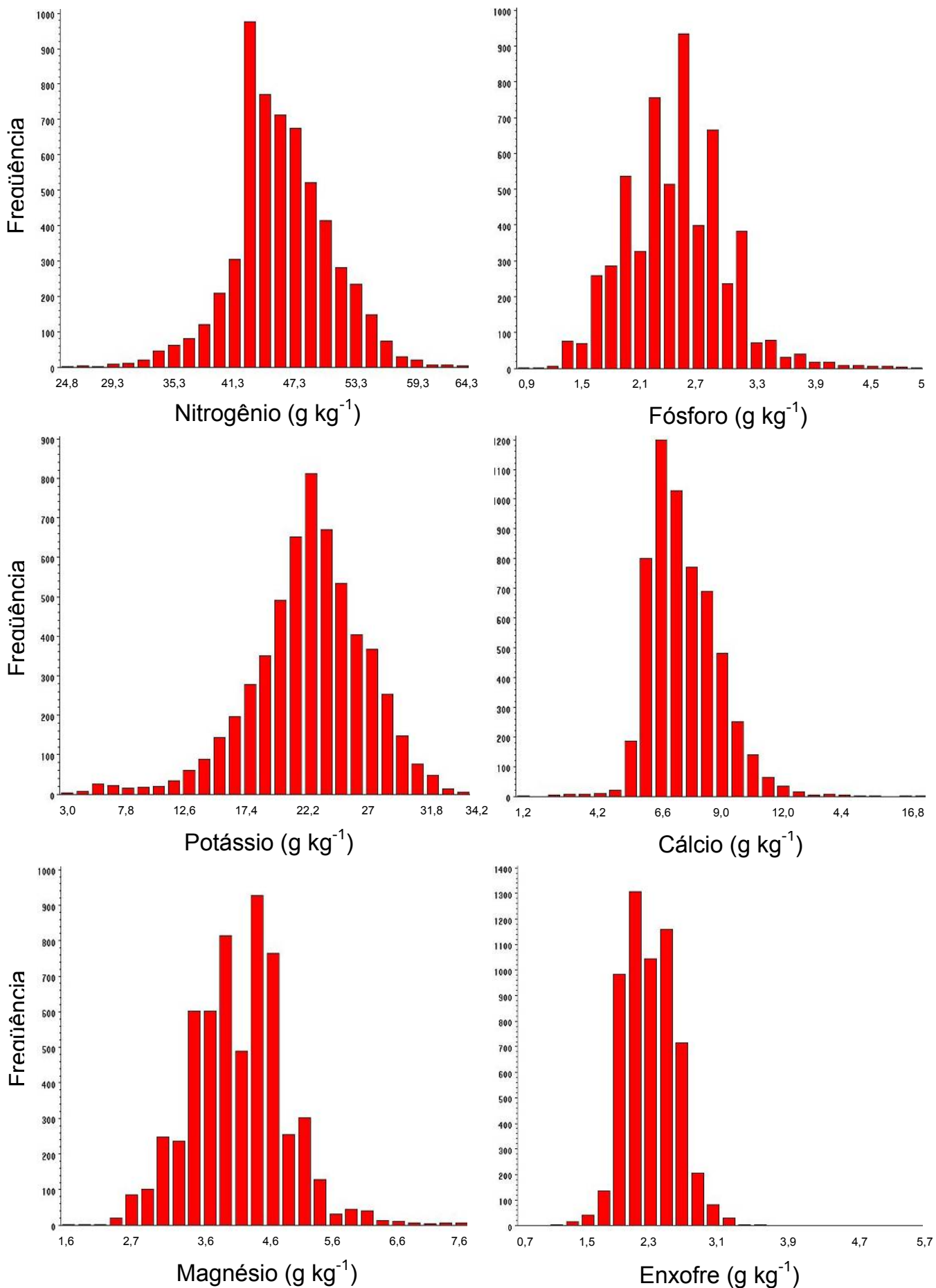

Figura 3 - Distribuição de freqüência da concentração de nitrogênio, fósforo, potássio, cálcio, magnésio e enxofre nas folhas de soja do Mato Grosso 

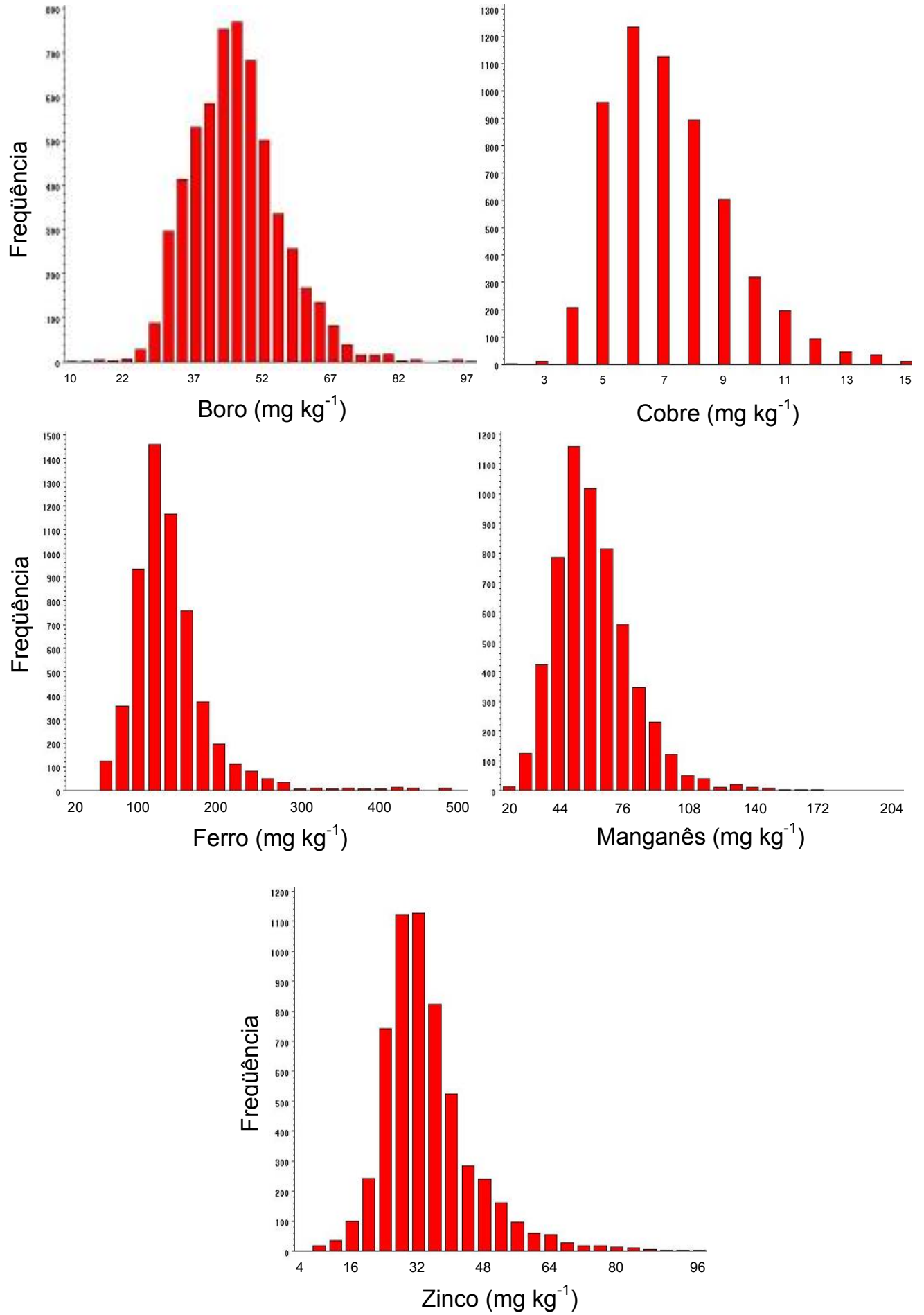

Figura 4 - Distribuição de freqüência da concentração de boro, cobre, ferro, manganês e zinco nas folhas de soja do Mato Grosso 
Na Tabela 9 é apresentada a estatística descritiva das concentrações dos nutrientes do Mato Grosso.

Tabela 9. Estatística descritiva das concentrações de nitrogênio, fósforo, potássio, cálcio, magnésio, enxofre, boro, cobre, ferro, manganês e zinco nas folhas de soja do Mato Grosso (Safras 1994/95 a 2002/03)

\begin{tabular}{lrrrrrrrrrr}
\hline Nutriente & Média & Mediana & Moda & Min. & Max. & $\begin{array}{r}\text { Desvio } \\
\text { padrão }\end{array}$ & Variância & CV (\%) & Curtose & Assimetria \\
\hline $\mathrm{N}$ & 46,0 & 46,2 & 44,8 & 24,2 & 63,7 & 4,8 & 23,2 & 10,5 & 0,60 & $-0,13$ \\
$\mathrm{P}$ & 2,5 & 2,5 & 2,4 & 0,9 & 5,0 & 0,5 & 0,3 & 20,8 & 0,90 & 0,41 \\
$\mathrm{~K}$ & 21,9 & 22,2 & 21,6 & 2,8 & 34,6 & 4,5 & 20,2 & 20,5 & 1,37 & $-0,66$ \\
$\mathrm{Ca}$ & 7,4 & 7,2 & 6,6 & 0,9 & 17,0 & 1,4 & 1,9 & 18,4 & 2,41 & 0,84 \\
$\mathrm{Mg}$ & 4,3 & 4,4 & 4,5 & 1,7 & 7,9 & 0,8 & 0,6 & 17,9 & 1,41 & 0,33 \\
$\mathrm{~S}$ & 2,2 & 2,2 & 2,0 & 0,6 & 5,7 & 0,3 & 0,1 & 14,9 & 3,19 & 0,57 \\
$\mathrm{~B}$ & 46 & 45 & 42 & 11 & 98 & 9,7 & 94,2 & 21,3 & 1,08 & 0,59 \\
$\mathrm{Cu}$ & 7 & 7 & 6 & 2 & 15 & 2,0 & 4,0 & 27,8 & 6,11 & 1,20 \\
$\mathrm{Fe}$ & 138 & 129 & 138 & 16 & 497 & 50,1 & 2512,8 & 36,2 & 11,47 & 2,56 \\
$\mathrm{Mn}$ & 61 & 58 & 54 & 18 & 213 & 19,3 & 371,6 & 31,6 & 4,04 & 1,27 \\
$\mathrm{Zn}$ & 34 & 31 & 30 & 3 & 99 & 10,9 & 119,2 & 32,4 & 3,81 & 1,41 \\
\hline
\end{tabular}

Com exceção de fósforo, os demais nutrientes apresentaram uma concentração média na folha dentro da classe suficiente de acordo com as faixas de suficiência da Embrapa (2004). O fósforo apresenta uma concentração média considerada baixa segundo o critério de faixas, os limites entre a concentração mínima e máxima é de 0,9 e $5,0 \mathrm{~g} \mathrm{~kg}^{-1}$, considerado baixo e suficiente, respectivamente. Não foi observado nenhum resultado com concentração foliar alto em fósforo segundo o critério de faixas.

O coeficiente de variação para a concentração de micronutrientes foi superior ao observado para macronutrientes, indicando uma maior oscilação na concentração de ferro, zinco e manganês perante os demais (Tabela 9), similar ao verificado por Maeda (2002), que obteve um coeficiente de variação alto para ferro $(40,4 \%)$, zinco $(51,0 \%)$ e manganês $(43,6 \%)$ em folhas de soja no Mato Grosso do Sul. 
A concentração dos nutrientes nas amostras do Mato Grosso foram influenciadas pelas safras de cultivo de soja (Tabela 10). Observa-se que a concentração foliar de nitrogênio diferiu significativamente $(p<0,05)$ entre as safras 1994/95 e 2002/03, representando a menor e a maior concentração. A concentração de fósforo para as safras 1995/96, 1997/98, diferiu significativamente $(p<0,05)$ das safras 1994/95, 1999/00, 2000/01 e 2002/03, sendo que as safras 1994/95, 1999/00 e 2000/01 não diferiram entre si. Para potássio a maior concentração é observada na safra 2000/01 que diferiu significativamente $(p<0,05)$ da safra 1994/95 com 26,2 $\mathrm{g} \mathrm{kg}^{-1}$ e $15,9 \mathrm{~g} \mathrm{~kg}^{-1}$ respectivamente. Houve diferenças significativas $(p<0,05)$ entre as safras para cálcio e magnésio com as maiores concentrações nas safras 1994/95 e 2000/01 respectivamente. Para a concentração de enxofre verificou-se que as safras 1994/95, 1997/98, 1999/00, 2000/01 e 2002/03 apresentaram diferenças significativas $(p<0,05)$ em relação às safras 1995/96 e 2001/02.

Tabela 10. Concentração média de nitrogênio, fósforo, potássio, cálcio, magnésio, enxofre, boro, cobre, ferro, manganês e zinco nas amostras do Mato Grosso em função de safra

\begin{tabular}{|c|c|c|c|c|c|c|c|c|c|c|c|c|}
\hline \multirow{2}{*}{ Safra } & \multirow{2}{*}{ N. } & \multicolumn{11}{|c|}{ Concentração de nutrientes nas folhas } \\
\hline & & $\mathbf{N}$ & $\mathbf{P}$ & $\mathbf{K}$ & $\mathbf{C a}$ & Mg & $\mathbf{S}$ & B & Cu & $\mathrm{Fe}$ & Mn & Zn \\
\hline & & \multicolumn{6}{|c|}{$\mathrm{g} \mathrm{kg}^{-1}$} & \multicolumn{5}{|c|}{$\mathrm{mg} \mathrm{kg}^{-1}$} \\
\hline $1994 / 95$ & 8 & $43,1 \mathrm{c}$ & $2,5 b c$ & 15,9 e & $9,7 \mathrm{a}$ & $4,3 \mathrm{bc}$ & $2,3 a$ & $27 \mathrm{e}$ & $8 \mathrm{~cd}$ & $128 \mathrm{~cd}$ & $34 \mathrm{~d}$ & $38 \mathrm{~b}$ \\
\hline $1995 / 96$ & 11 & $43,9 \mathrm{c}$ & $2,0 \mathrm{~d}$ & 16,9 e & $3,6 \mathrm{~d}$ & $3,7 \mathrm{~d}$ & $1,3 \mathrm{c}$ & $40 \mathrm{~cd}$ & $11 a$ & $144 \mathrm{bc}$ & $48 c$ & $22 \mathrm{c}$ \\
\hline $1997 / 98$ & 1072 & $43,3 \mathrm{c}$ & $2,1 \mathrm{~d}$ & $17,8 \mathrm{de}$ & $7,1 \mathrm{c}$ & $3,8 \mathrm{~cd}$ & $2,3 \mathrm{a}$ & $45 \mathrm{abc}$ & 7 cde & $108 d$ & $69 a$ & $31 \mathrm{~b}$ \\
\hline $1998 / 99$ & 1100 & $47,9 a b$ & $2,3 \mathrm{~cd}$ & $20,2 \mathrm{~cd}$ & $8,3 \mathrm{~b}$ & $4,0 \mathrm{~cd}$ & $2,2 a b$ & $37 d$ & $7 \mathrm{de}$ & $159 \mathrm{~b}$ & $65 a b$ & $34 \mathrm{~b}$ \\
\hline 1999/00 & 1328 & $46,1 \mathrm{abc}$ & $2,7 \mathrm{~b}$ & $22,9 \mathrm{~b}$ & $7,0 \mathrm{c}$ & $4,6 a b$ & $2,4 \mathrm{a}$ & $49 a b$ & $8 c$ & 139 bc & $60 \mathrm{abc}$ & $37 \mathrm{~b}$ \\
\hline 2000/01 & 1245 & $45,2 \mathrm{bc}$ & $2,7 \mathrm{~b}$ & $26,2 \mathrm{a}$ & 7,6 bc & $4,8 \mathrm{a}$ & $2,2 \mathrm{a}$ & $51 a$ & $8 \mathrm{~cd}$ & $134 \mathrm{bcd}$ & $58 \mathrm{abc}$ & $33 \mathrm{~b}$ \\
\hline 2001/02 & 869 & $47,7 \mathrm{ab}$ & $2,3 \mathrm{~cd}$ & $21,9 \mathrm{bc}$ & $6,9 \mathrm{c}$ & $4,3 \mathrm{bc}$ & $2,0 \mathrm{~b}$ & $44 \mathrm{bc}$ & $6 \mathrm{e}$ & $132 \mathrm{bcd}$ & $53 \mathrm{bc}$ & $31 \mathrm{~b}$ \\
\hline $2002 / 03$ & 101 & 48,9 a & $3,1 \mathrm{a}$ & $21,4 \mathrm{bc}$ & $8,4 \mathrm{~b}$ & $4,1 \mathrm{~cd}$ & $2,3 \mathrm{a}$ & $51 a$ & $10 \mathrm{~b}$ & 326 a & $63 a b$ & $46 a$ \\
\hline \multicolumn{2}{|c|}{ CV (\%) } & 9,8 & 18,1 & 15,8 & 16,8 & 15,5 & 13,7 & 18,1 & 25,2 & 29,2 & 30,4 & 31,2 \\
\hline
\end{tabular}

Médias seguidas da mesma letra na coluna não diferem entre si pelo teste de Tukey a $5 \%$ de probabilidade. 
A maior concentração de Boro foi $51 \mathrm{mg} \mathrm{kg}^{-1}$ na safra 2000/01 que diferiu estatisticamente $(p<0,05)$ das safras $1994 / 95,1995 / 96,1998 / 99$ e 2000/01. Verificouse a menor concentração de cobre $\left(6 \mathrm{mg} \mathrm{kg}^{-1}\right)$ na safra 2001/02 que diferiu significativamente $(p<0,05)$ da concentração média de todas as safras. A maior concentração de ferro ocorreu na safra 2002/03, e foi estatisticamente diferente $(p<0,05)$ de todas as demais safras. A menor concentração de manganês ocorreu na safra 1994/95 e diferiu estatisticamente $(p<0,05)$ das demais safras. Zinco foi $o$ nutriente que apresentou o maior número de safras sem diferenças significativas $(p<0,05)$ entre as concentrações. As maiores concentrações, considerando todos os nutrientes, não foram relacionados a uma safra específica.

A produtividade média de soja, por safra, no Mato Grosso é apresentada na Tabela 11. A maior produtividade foi observada na safra $2000 / 01 \mathrm{com} 3.744 \mathrm{~kg} \mathrm{ha}^{-1}$ e a menor na safra 1995/96 com $2.272 \mathrm{~kg} \mathrm{ha}^{-1}$. A amplitude de variação na produtividade, considerando todas as safras foi entre 164 e $5.756 \mathrm{~kg} \mathrm{ha}^{-1}$.

Tabela 11. Estatística descritiva da produtividade de soja $\left(\mathrm{kg} \mathrm{ha}^{-1}\right)$ por safra no Mato Grosso

\begin{tabular}{lccccccccc}
\hline Safra & N. & Média & Mínimo & Máximo & $\begin{array}{c}\text { Desvio } \\
\text { padrão }\end{array}$ & Variância & CV (\%) & Curtose & Assimetria \\
\hline $1994 / 95$ & 8 & $2304 \mathrm{~d}$ & 1.741 & 3167 & 575,5 & 331184,4 & 25,0 & $-1,24$ & 0,76 \\
$1995 / 96$ & 11 & $2272 \mathrm{~d}$ & 1.847 & 2841 & 297,6 & 88540,4 & 13,1 & $-0,25$ & 0,30 \\
$1997 / 98$ & 1072 & $2899 \mathrm{c}$ & 441 & 5275 & 597,1 & 356492,0 & 20,6 & 0,56 & 0,09 \\
$1998 / 99$ & 1100 & $3006 \mathrm{bc}$ & 808 & 4671 & 523,0 & 273556,6 & 17,4 & 0,36 & 0,03 \\
$1999 / 00$ & 1328 & $3365 \mathrm{ab}$ & 417 & 4712 & 532,6 & 283634,7 & 15,8 & 4,91 & $-1,70$ \\
$2000 / 01$ & 1245 & $3744 \mathrm{a}$ & 164 & 5756 & 694,7 & 482602,2 & 18,6 & 4,00 & $-1,44$ \\
$2001 / 02$ & 869 & $3108 \mathrm{bc}$ & 256 & 4314 & 716,2 & 512989,9 & 23,0 & 1,65 & $-1,31$ \\
$2002 / 03$ & 101 & $3216 \mathrm{bc}$ & 676 & 4282 & 533,9 & 285071,4 & 16,6 & 4,90 & $-1,47$ \\
\hline
\end{tabular}

Médias seguidas da mesma letra na coluna não diferem entre si pelo teste de Tukey a $5 \%$ de probabilidade. 


\subsection{Estabelecimento da norma DRIS para as regiões do sul do Maranhão e sudoeste do Piauí}

\subsubsection{Agrupamento por classes de produtividade}

Em função de elevado número de resultados de análise química foliar, agrupouse os dados por classes de produtividade visando facilitar a visualização dos resultados (Tabela 12). O erro padrão da média da concentração dos nutrientes foi calculado para cada classe de produtividade, descrevendo a variabilidade na concentração foliar de cada um dos nutrientes.

Observa-se que houve variações nas concentrações dos nutrientes na folha em função da classe de produtividade. Nutrientes como nitrogênio e magnésio apresentaram erro padrão da média menos variável se comparado à ferro e manganês (Tabela 12).

Para cobre observou-se uma concentração na folha crescente com o aumento da produtividade, ao contrário da concentração de enxofre que diminuiu com o aumento da produtividade. Para os demais nutrientes não foi observada uma tendência definida em relação ao aumento ou diminuição da produtividade da cultura da soja nas regiões do sul do Maranhão e sudoeste do Piauí (Tabela 12).

\subsubsection{Seleção da norma DRIS}

A população de referência foi definida pela população de alta produtividade cujo método de cálculo DRIS apresentou melhor relação entre o IBN e a produtividade. As concentrações médias dos nutrientes por classe de produtividade, foram submetidas aos diferentes cálculos de funções DRIS (Beaufils, 1973; Jones, 1981; Elwali \& Gascho, 1984), utilizando as normas obtidas para cada nível de produtividade. 
Tabela 12. Classes de produtividade, número de amostras, concentração na folha e erro padrão da média da concentração foliar dos nutrientes na soja das regiões do sul do Maranhão e sudoeste do Piauí

\begin{tabular}{|c|c|c|c|c|c|c|c|c|c|c|c|c|c|c|c|c|c|c|c|c|c|c|c|}
\hline $\begin{array}{c}\text { Classes de } \\
\text { produtividade } \\
\mathrm{kg} \mathrm{ha}^{-1}\end{array}$ & $\mathrm{~N}^{1}$ & & $\mathbf{N}$ & & $\mathbf{P}$ & r & $\mathrm{K} \mathrm{kg}^{-1}$ & & $\mathrm{Ca}$ & & $\mathrm{Mg}$ & & $\mathbf{s}$ & & B & & Su & & $\begin{array}{l}\mathrm{Fe} \\
\mathrm{ng} \mathrm{kg}^{-1}\end{array}$ & & Mn & & $n$ \\
\hline $3901-4200$ & 11 & $44,2^{*}$ & $\pm 2,3^{* \star}$ & 3,2 & $\pm 0,2$ & 22,3 & $\pm 1,9$ & 7,5 & $\pm 0,8$ & 4,4 & $\pm 0,1$ & 2,7 & $\pm 0,2$ & 52 & $\pm 1,4$ & $7 \pm$ & $\pm 0,7$ & 165 & $\pm 18,9$ & 56 & $\pm 14,2$ & 47 & $\pm 5,4$ \\
\hline $3601-3900$ & 46 & 44,0 & $\pm 1,3$ & 3,4 & $\pm 0,1$ & 23,5 & $\pm 0,7$ & 7,3 & $\pm 0,3$ & 3,9 & $\pm 0,1$ & 2,4 & $\pm 0,1$ & 45 & $\pm 1,3$ & $6 \pm$ & $\pm 0,4$ & 155 & $\pm 8,3$ & 46 & $\pm 4,4$ & 44 & $\pm 2,3$ \\
\hline $3301-3600$ & 114 & 43,8 & $\pm 0,8$ & 3,4 & $\pm 0,1$ & 22,8 & $\pm 0,4$ & 8,0 & $\pm 0,3$ & 4,2 & $\pm 0,1$ & 2,5 & $\pm 0,1$ & 47 & $\pm 0,8$ & $6 \pm$ & $\pm 0,2$ & 151 & $\pm 5,7$ & 50 & $\pm 3,4$ & 46 & $\pm 1,4$ \\
\hline $3001-3300$ & 223 & 46,8 & $\pm 0,7$ & 3,8 & $\pm 0,1$ & 23,2 & $\pm 0,3$ & 8,6 & $\pm 0,2$ & 4,3 & $\pm 0,1$ & 2,7 & $\pm 0,0$ & 48 & $\pm 0,6$ & $5 \pm$ & $+0,2$ & 156 & $\pm 4,9$ & 53 & $\pm 2,1$ & 47 & $\pm 1,0$ \\
\hline $2701-3000$ & 239 & 46,7 & $\pm 0,6$ & 3,7 & $\pm 0,1$ & 22,1 & $\pm 0,3$ & 8,7 & $\pm 0,1$ & 4,3 & $\pm 0,1$ & 2,8 & $\pm 0,1$ & 48 & $\pm 0,7$ & $5 \pm$ & $\pm 0,2$ & 171 & $\pm 5,0$ & 58 & $\pm 2,5$ & 49 & $\pm 1,0$ \\
\hline $2401-2700$ & 197 & 45,5 & $\pm 0,8$ & 3,6 & $\pm 0,1$ & 22,8 & $\pm 0,3$ & 8,7 & $\pm 0,2$ & 4,3 & $\pm 0,1$ & 2,9 & $\pm 0,0$ & 49 & $\pm 0,8$ & $4 \pm$ & $\pm 0,2$ & 179 & $\pm 5,8$ & 66 & $\pm 2,7$ & 49 & $\pm 0,9$ \\
\hline $2101-2400$ & 180 & 44,9 & $\pm 0,7$ & 3,4 & $\pm 0,1$ & 22,1 & $\pm 0,3$ & 8,5 & $\pm 0,2$ & 4,3 & $\pm 0,1$ & 2,9 & $\pm 0,0$ & 51 & $\pm 0,7$ & $4 \pm$ & $\pm 0,2$ & 185 & $\pm 6,1$ & 63 & $\pm 2,6$ & 49 & $\pm 1,1$ \\
\hline $1801-2100$ & 111 & 44,8 & $\pm 0,7$ & 3,4 & $\pm 0,1$ & 22,6 & $\pm 0,4$ & 8,6 & $\pm 0,2$ & 4,1 & $\pm 0,1$ & 2,9 & $\pm 0,1$ & 49 & $\pm 0,9$ & $4 \pm$ & $\pm 0,2$ & 189 & $\pm 8,1$ & 69 & $\pm 4,4$ & 48 & $\pm 1,1$ \\
\hline $1501-1800$ & 79 & 45,2 & $\pm 1,1$ & 3,5 & $\pm 0,1$ & 21,6 & $\pm 0,5$ & 8,6 & $\pm 0,3$ & 4,3 & $\pm 0,1$ & 2,9 & $\pm 0,1$ & 52 & $\pm 1,2$ & $4 \pm$ & $\pm 0,2$ & 186 & $\pm 9,8$ & 65 & $\pm 4,3$ & 47 & $\pm 1,2$ \\
\hline $1201-1500$ & 36 & 45,2 & $\pm 1,5$ & 3,5 & $\pm 0,2$ & 21,9 & $\pm 0,7$ & 8,5 & $\pm 0,2$ & 4,5 & $\pm 0,2$ & 2,9 & $\pm 0,1$ & 52 & $\pm 1,9$ & $4 \pm$ & $\pm 0,3$ & 182 & $\pm 12,7$ & 82 & $\pm 8,3$ & 45 & $\pm 1,9$ \\
\hline $901-1200$ & 32 & 47,9 & $\pm 1,3$ & 3,3 & $\pm 0,1$ & 22,1 & $\pm 0,5$ & 8,7 & $\pm 0,3$ & 4,6 & $\pm 0,1$ & 2,9 & $\pm 0,1$ & 48 & $\pm 1,4$ & $4 \pm$ & $\pm 0,4$ & 179 & $\pm 10,9$ & 68 & $\pm 7,8$ & 44 & $\pm 2,0$ \\
\hline $601-900$ & 19 & 48,0 & $\pm 2,2$ & 3,5 & $\pm 0,2$ & 22,6 & $\pm 1,0$ & 8,2 & $\pm 0,7$ & 4,5 & $\pm 0,2$ & 3,3 & $\pm 0,2$ & 49 & $\pm 2,1$ & $3 \pm$ & $\pm 0,4$ & 229 & $\pm 24,2$ & 63 & $\pm 9,2$ & 48 & $\pm 4,5$ \\
\hline
\end{tabular}


Observou-se que houve relação significativa $(p<0,01)$ entre a produtividade e o IBN para todos os níveis de produtividade e para os métodos de cálculo das funções DRIS (Tabela 13). Entretanto, observou-se um valor crescente do coeficiente de determinação com o aumento da produtividade na norma, o que mostra que houve uma melhora na relação entre as duas variáveis com o aumento do nível de produtividade da população.

Tabela 13. Relação entre a produtividade e o IBN para os níveis de produtividade da sub-população de alta produtividade pelos diferentes cálculos de funções DRIS para a cultura da soja das regiões do sul do Maranhão e sudoeste do Piauí (Safras 1994/95 a 2002/03)

\begin{tabular}{|c|c|c|c|c|c|c|}
\hline \multirow{2}{*}{ Norma } & \multicolumn{2}{|l|}{ Beaufils (1973) } & \multicolumn{2}{|l|}{ Jones (1981) } & \multicolumn{2}{|c|}{ Elwali \& Gascho (1984) } \\
\hline & Equação & $\mathbf{R}^{2}$ & Equação & $\mathbf{R}^{2}$ & Equação & $\mathbf{R}^{2}$ \\
\hline$\geq 3000 \mathrm{~kg} \mathrm{ha}^{-1}$ & $y=4386,13-653,47^{* *} x$ & 0,62 & $y=4425,66-342,44^{* *} x$ & 0,70 & $y=3561,67-521,64^{* *} x$ & 0,65 \\
\hline$\geq 3300 \mathrm{~kg} \mathrm{ha}^{-1}$ & $y=4531,85-574,50^{* *} x$ & 0,84 & $y=4517,13-288,88^{* *} x$ & 0,86 & $y=3796,77-486,29^{* *} x$ & 0,84 \\
\hline$\geq 3600 \mathrm{~kg} \mathrm{ha}^{-1}$ & $y=4722,95-486,42^{* *} x$ & 0,92 & $y=4712,71-243,45^{\star *} x$ & 0,92 & $y=4147,48-430,64^{* *} x$ & 0,91 \\
\hline
\end{tabular}

Os métodos de cálculo das funções DRIS apresentam coeficientes de determinação semelhantes para um mesmo nível de produtividade da norma, demonstrando que os três métodos foram muito próximos nos seus resultados, apesar das modificações propostas a partir do método original proposto por Beaufils (1973).

Assim, a norma obtida com população de produtividade $\geq 3600 \mathrm{~kg} \mathrm{ha}^{-1}$ apresentou a melhor relação entre o IBN e a produtividade nos três métodos de cálculo das funções DRIS, sendo então adotada para os estudos do DRIS para as regiões do sul do Maranhão e sudoeste do Piauí (Tabela 14). 
Tabela 14. Norma DRIS para a cultura da soja nas regiões do sul do Maranhão e sudoeste do Piauí

\begin{tabular}{|c|c|c|c|c|c|c|c|c|c|c|c|}
\hline Relação & $x$ & $s^{2}$ & s & C.v. & $\mathbf{N}$ & Relação & $x$ & $s^{2}$ & $\mathbf{s}$ & c.v. & $\mathbf{N}$ \\
\hline $\mathrm{N}$ & 42,49 & 7,39 & 2,72 & 6,40 & 42 & $\mathrm{Mg} / \mathrm{N}$ & 0,09 & 0,00 & 0,01 & 12,48 & 25 \\
\hline$P$ & 3,17 & 0,11 & 0,33 & 10,41 & 37 & $\mathrm{Mg} / \mathrm{K}$ & 0,17 & 0,00 & 0,02 & 13,78 & 27 \\
\hline $\mathrm{K}$ & 23,02 & 3,70 & 1,92 & 8,36 & 39 & $\mathrm{Mg} / \mathrm{B}$ & 0,09 & 0,00 & 0,01 & 8,38 & 26 \\
\hline $\mathrm{Ca}$ & 7,16 & 0,76 & 0,87 & 12,16 & 40 & $\mathrm{Mg} / \mathrm{Cu}$ & 0,60 & 0,02 & 0,12 & 20,63 & 27 \\
\hline $\mathrm{Mg}$ & 3,97 & 0,13 & 0,36 & 9,15 & 46 & $S / K$ & 0,11 & 0,00 & 0,02 & 13,68 & 14 \\
\hline$S$ & 2,45 & 0,08 & 0,28 & 11,21 & 37 & $\mathrm{~S} / \mathrm{Mg}$ & 0,64 & 0,01 & 0,08 & 12,56 & 19 \\
\hline B & 47,16 & 8,92 & 2,99 & 6,33 & 42 & S/B & 0,06 & 0,00 & 0,01 & 10,85 & 16 \\
\hline $\mathrm{Cu}$ & 6,78 & 1,04 & 1,02 & 15,04 & 41 & $\mathrm{~S} / \mathrm{Cu}$ & 0,34 & 0,01 & 0,07 & 20,42 & 20 \\
\hline $\mathrm{Fe}$ & 149,76 & 466,16 & 21,59 & 14,42 & 44 & $\mathrm{~B} / \mathrm{Cu}$ & 7,15 & 2,14 & 1,46 & 20,49 & 22 \\
\hline $\mathrm{Mn}$ & 38,69 & 94,10 & 9,70 & 25,07 & 56 & $\mathrm{Fe} / \mathrm{N}$ & 3,48 & 0,42 & 0,65 & 18,68 & 24 \\
\hline $\mathrm{Zn}$ & 43,04 & 34,46 & 5,87 & 13,64 & 36 & $\mathrm{Fe} / \mathrm{P}$ & 47,03 & 55,74 & 7,47 & 15,88 & 20 \\
\hline$N / K$ & 1,83 & 0,03 & 0,17 & 9,38 & 19 & $\mathrm{Fe} / \mathrm{K}$ & 6,71 & 1,58 & 1,26 & 18,75 & 24 \\
\hline$N / S$ & 17,36 & 3,96 & 1,99 & 11,46 & 24 & $\mathrm{Fe} / \mathrm{Mg}$ & 36,21 & 28,97 & 5,38 & 14,86 & 26 \\
\hline N/B & 0,91 & 0,01 & 0,09 & 9,59 & 24 & $\mathrm{Fe} / \mathrm{S}$ & 62,11 & 110,76 & 10,52 & 16,94 & 23 \\
\hline $\mathrm{N} / \mathrm{Cu}$ & 6,50 & 1,24 & 1,11 & 17,12 & 24 & $\mathrm{Fe} / \mathrm{B}$ & 3,16 & 0,23 & 0,48 & 15,03 & 26 \\
\hline$N / Z n$ & 1,02 & 0,03 & 0,17 & 16,14 & 21 & $\mathrm{Fe} / \mathrm{Cu}$ & 22,66 & 38,45 & 6,20 & 27,36 & 25 \\
\hline $\mathrm{P} / \mathrm{N}$ & 0,07 & 0,00 & 0,01 & 14,20 & 25 & $\mathrm{Fe} / \mathrm{Zn}$ & 3,56 & 0,55 & 0,74 & 20,84 & 22 \\
\hline $\mathrm{P} / \mathrm{K}$ & 0,14 & 0,00 & 0,02 & 13,17 & 22 & $\mathrm{Mn} / \mathrm{N}$ & 0,86 & 0,05 & 0,23 & 26,40 & 31 \\
\hline $\mathrm{P} / \mathrm{Ca}$ & 0,43 & 0,01 & 0,08 & 17,71 & 22 & $\mathrm{Mn} / \mathrm{P}$ & 11,50 & 9,59 & 3,10 & 26,93 & 27 \\
\hline $\mathrm{P} / \mathrm{Mg}$ & 0,78 & 0,01 & 0,09 & 11,29 & 23 & $\mathrm{Mn} / \mathrm{K}$ & 1,60 & 0,14 & 0,38 & 23,49 & 27 \\
\hline $\mathrm{P} / \mathrm{S}$ & 1,26 & 0,02 & 0,15 & 11,76 & 22 & $\mathrm{Mn} / \mathrm{Ca}$ & 5,55 & 2,98 & 1,73 & 31,10 & 29 \\
\hline $\mathrm{P} / \mathrm{Cu}$ & 0,48 & 0,01 & 0,11 & 23,06 & 20 & $\mathrm{Mn} / \mathrm{Mg}$ & 10,02 & 6,51 & 2,55 & 25,46 & 35 \\
\hline $\mathrm{P} / \mathrm{B}$ & 0,07 & 0,00 & 0,01 & 10,02 & 20 & $\mathrm{Mn} / \mathrm{S}$ & 15,77 & 14,62 & 3,82 & 24,25 & 28 \\
\hline $\mathrm{K} / \mathrm{B}$ & 0,50 & 0,00 & 0,05 & 9,72 & 23 & $\mathrm{Mn} / \mathrm{Fe}$ & 0,27 & 0,01 & 0,08 & 30,79 & 31 \\
\hline $\mathrm{K} / \mathrm{Cu}$ & 3,50 & 0,34 & 0,58 & 16,57 & 22 & $\mathrm{Mn} / \mathrm{Zn}$ & 0,92 & 0,07 & 0,26 & 27,87 & 28 \\
\hline $\mathrm{Ca} / \mathrm{N}$ & 0,17 & 0,00 & 0,02 & 13,29 & 16 & $\mathrm{Mn} / \mathrm{Cu}$ & 5,43 & 1,77 & 1,33 & 24,52 & 33 \\
\hline $\mathrm{Ca} / \mathrm{K}$ & 0,33 & 0,00 & 0,05 & 13,84 & 19 & $\mathrm{Mn} / \mathrm{B}$ & 0,86 & 0,04 & 0,21 & 23,99 & 29 \\
\hline $\mathrm{Ca} / \mathrm{Mg}$ & 1,76 & 0,04 & 0,20 & 11,12 & 25 & $\mathrm{Zn} / \mathrm{P}$ & 13,70 & 4,40 & 2,10 & 15,30 & 21 \\
\hline $\mathrm{Ca} / \mathrm{S}$ & 2,88 & 0,19 & 0,44 & 15,31 & 19 & $\mathrm{Zn} / \mathrm{K}$ & 1,94 & 0,08 & 0,28 & 14,45 & 15 \\
\hline $\mathrm{Ca} / \mathrm{B}$ & 0,15 & 0,00 & 0,02 & 13,55 & 23 & $\mathrm{Zn} / \mathrm{Mg}$ & 10,74 & 1,41 & 1,19 & 11,06 & 24 \\
\hline $\mathrm{Ca} / \mathrm{Cu}$ & 1,07 & 0,07 & 0,26 & 24,48 & 19 & $\mathrm{Zn} / \mathrm{S}$ & 16,53 & 5,39 & 2,32 & 14,04 & 19 \\
\hline $\mathrm{Ca} / \mathrm{Fe}$ & 0,05 & 0,00 & 0,01 & 15,34 & 22 & $\mathrm{Zn} / \mathrm{B}$ & 0,90 & 0,02 & 0,13 & 14,11 & 22 \\
\hline $\mathrm{Ca} / \mathrm{Zn}$ & 0,16 & 0,00 & 0,02 & 11,59 & 23 & $\mathrm{Zn} / \mathrm{Cu}$ & 6,65 & 3,23 & 1,80 & 27,00 & 17 \\
\hline
\end{tabular}


A produtividade estabelecida para a população de referência é variável na literatura. A sua definição é normalmente feita de forma arbitrária e, utilizando um nível de produtividade considerado elevado para a região em estudo. Sumner (1977a) apresentou a primeira norma para a cultura da soja nos Estados Unidos e, estabeleceu uma produtividade de grãos de soja $>2600 \mathrm{~kg} \mathrm{ha}^{-1}$ para divisão entre a população de alta e baixa produtividade. Hanson (1981) estabeleceu norma DRIS para soja no Rio Grande do Sul com produtividade $>3000 \mathrm{~kg} \mathrm{ha}^{-1}$ e comparou com a norma de Sumner (1977).

Maeda (2002) estabeleceu norma DRIS para a soja na região sul do Mato Grosso do Sul, empregando uma população de referência superior à $3500 \mathrm{~kg} \mathrm{ha}^{-1}$. Kurihara (2004) estabeleceu norma DRIS para o Mato Grosso e Mato Grosso do Sul com produtividade superior à $3900 \mathrm{~kg} \mathrm{ha}^{-1}$, equivalente à $130 \%$ da produtividade média do seu banco de dados.

Os trabalhos mais recentes apresentam produtividade da população de referência mais elevados, semelhante ao obtido para as regiões do sul do Maranhão e sudoeste do Piauí.

\subsection{3 Índices DRIS}

Observou-se que para todos os índices DRIS houve relação significativa com as respectivas concentrações na folha dos nutrientes (Tabela 15), mostrando que o Índice DRIS foi fortemente dependente da concentração do nutriente na folha.

O valor do coeficiente de determinação foi semelhante para os três métodos de cálculo das funções. O método de Elwali \& Gascho (1984) para alguns nutrientes tendeu a mostrar uma relação mais baixa, provavelmente por considerar no cálculo das 
funções o desvio padrão da norma, o que faz este método ser menos rigoroso perante os demais.

Tabela 15. Relação entre índices DRIS e a concentração foliar dos nutrientes na cultura da soja das regiões do sul do Maranhão e sudoeste do Piauí

\begin{tabular}{|c|c|c|c|c|c|c|c|}
\hline \multirow{2}{*}{\multicolumn{2}{|c|}{ Variável }} & \multicolumn{2}{|c|}{ Beaufils (1973) } & \multicolumn{2}{|l|}{ Jones (1981) } & \multicolumn{2}{|c|}{ Elwali \& Gascho (1984) } \\
\hline & & \multirow{2}{*}{$\frac{\text { Equação }}{y=-3,55+0,08^{* *} x}$} & \multirow{2}{*}{$\frac{\mathbf{R}^{2}}{0,67}$} & \multirow{2}{*}{$\begin{array}{c}\text { Equação } \\
y=-7,12+0,16^{* *} x\end{array}$} & \multirow{2}{*}{$\frac{\mathbf{R}^{2}}{0,69}$} & \multirow{2}{*}{$\begin{array}{c}\text { Equação } \\
y=-2,86+0,06^{* *} x\end{array}$} & \multirow{2}{*}{$\frac{\mathbf{R}^{2}}{0,75}$} \\
\hline $\bar{N}$ & $\overline{I_{N}}$ & & & & & & \\
\hline$P$ & $\mathrm{I}_{\mathrm{P}}$ & $y=-3,65+1,07^{* *} x$ & 0,81 & $y=-7,17+2,11^{* *} x$ & 0,83 & $y=-2,41+0,71^{* *} x$ & 0,83 \\
\hline K & $\mathrm{I}_{\mathrm{K}}$ & $y=-7,42+0,31^{* *} x$ & 0,84 & $y=-14,40+0,61^{* *} x$ & 0,84 & $y=-7,58+0,32^{* *} x$ & 0,86 \\
\hline $\mathrm{Ca}$ & $\mathrm{I}_{\mathrm{Ca}}$ & $y=-2,83+0,38^{* \star} x$ & 0,90 & $y=-5,58+0,75^{\star \star} x$ & 0,91 & $y=-2,38+0,31^{* *} x$ & 0,85 \\
\hline Mg & $\mathrm{I}_{\mathrm{Mg}}$ & $y=-3,07+0,72^{* *} x$ & 0,77 & $y=-6,09+1,42^{* *} x$ & 0,77 & $y=-1,99+0,47^{* *} x$ & 0,61 \\
\hline$S$ & $I_{S}$ & $y=-3,53+1,34^{\star *} x$ & 0,96 & $y=-6,84+2,60^{* *} x$ & 0,96 & $y=-2,78+1,07^{* *} x$ & 0,83 \\
\hline B & $\mathrm{I}_{\mathrm{B}}$ & $y=-3,26+0,06^{* *} x$ & 0,72 & $y=-6,23+0,12^{* *} x$ & 0,71 & $y=-1,72+0,03^{*} x$ & 0,34 \\
\hline $\mathrm{Cu}$ & $\mathrm{I}_{\mathrm{Cu}}$ & $y=-5,52+0,82^{* *} x$ & 0,93 & $y=-11,04+1,64^{* *} x$ & 0,93 & $y=-5,62+0,85^{* *} x$ & 0,92 \\
\hline $\mathrm{Fe}$ & $\mathrm{I}_{\mathrm{Fe}}$ & $y=-2,77+0,02^{* *} x$ & 0,98 & $y=-5,42+0,03^{* *} x$ & 0,98 & $y=-2,52+0,02^{* *} x$ & 0,89 \\
\hline $\mathrm{Mn}$ & $\mathrm{I}_{\mathrm{Mn}}$ & $y=-2,06+0,05^{* *} x$ & 0,99 & $y=-4,12+0,10^{* *} x$ & 0,99 & $y=-2,64+0,06^{* *} x$ & 0,99 \\
\hline $\mathrm{Zn}$ & $\mathrm{I}_{\mathrm{Zn}}$ & $y=-2,52+0,05^{\star \star} x$ & 0,53 & $y=-4,92+0,11^{\star *} x$ & 0,54 & $y=-1,60+0,03^{* *} x$ & 0,59 \\
\hline
\end{tabular}

Para nitrogênio e zinco, observou-se uma relação menor entre os índices DRIS e a concentração na folha, o que sugere uma menor dependência destes índices DRIS com a sua concentração foliar e, por outro lado, uma maior interação com as relações dos demais nutrientes que compõem o índice DRIS.

Em estudo de diagnose nutricional da soja, Kurihara (2004) obteve significância $(p<0,01)$ entre o índice DRIS e a concentração para nitrogênio na cultura da soja, usando a metodologia proposta por Alvarez \& Leite (1999). Nachtigall (2004) não obteve significância $(p<0,05)$ entre o índice DRIS nitrogênio e a sua concentração para a cultura da maçã, usando a metodologia de cálculo proposta por Elwali \& Gascho 
(1984). Leandro (1998) obteve maior precisão no diagnóstico de desordens nutricionais pelo método proposto por Beaufils (1973).

$\mathrm{Na}$ avaliação da relação entre a produtividade e os índices DRIS nos diferentes métodos de cálculo das funções DRIS para cultura da soja nas regiões do sul do Maranhão e sudoeste do Piauí (Tabela 16), são observadas algumas diferenças para o método Elwali \& Gascho (1984). Para nitrogênio, nos métodos Beaufils (1973) e Jones (1981) não foi observada significância estatística pelo teste t, para o modelo aplicado (linear), porém quando utilizado o método proposto por Elwali \& Gascho (1984) verificou-se relação linear significativa $(p<0,05)$ entre o índice DRIS para nitrogênio e a produtividade.

Para cálcio, magnésio, boro e zinco não foi verificada relação significativa entre a produtividade e o IBN, para os três métodos de cálculo das funções DRIS.

Tabela 16. Relação entre a produtividade da soja e índices DRIS para as regiões do sul do Maranhão e sudoeste do Piauí

\begin{tabular}{|c|c|c|c|c|c|c|}
\hline \multirow{2}{*}{ Variável } & \multicolumn{2}{|l|}{ Beaufils (1973) } & \multicolumn{2}{|l|}{ Jones (1981) } & \multicolumn{2}{|c|}{ Elwali \& Gascho (1984) } \\
\hline & Equação & $\mathbf{R}^{2}$ & Equação & $\mathbf{R}^{2}$ & Equação & $\mathbf{R}^{2}$ \\
\hline$I_{N}$ & $y=2367,7-2982,7^{N S} x$ & 0,15 & $y=2380,18-1567,38^{\mathrm{NS}} x$ & 0,16 & $y=2765,4-6064,0^{*} x$ & 0,36 \\
\hline$I_{P}$ & $y=2349,5+1089,1^{N S} x$ & 0,05 & $y=2346,60+541,28^{N S} x$ & 0,05 & $y=2389,5+649,0^{\mathrm{NS}} x$ & 0,01 \\
\hline $\mathrm{I}_{\mathrm{K}}$ & $y=3844,8+3494,4^{*} x$ & 0,37 & $y=3883,94+1823,31^{*} x$ & 0,38 & $y=3424,8+3355,2^{*} x$ & 0,36 \\
\hline $\mathrm{I}_{\mathrm{Ca}}$ & $y=3314,4-2864,5^{\mathrm{NS}} x$ & 0,26 & $y=3384,38-1534,26^{\mathrm{NS}} x$ & 0,29 & $y=3153,4-3349,9^{N S} x$ & 0,26 \\
\hline $\mathrm{I}_{\mathrm{Mg}}$ & $y=2489,6-2804,0^{N S} x$ & 0,17 & $y=2487,00-1430,09^{N S} x$ & 0,18 & $y=2598,0-4248,2^{N S} x$ & 0,22 \\
\hline $\mathrm{I}_{\mathrm{S}}$ & $y=3120,8-2937,5^{\star *} x$ & 0,72 & $y=3127,00-1523,86^{\star *} x$ & 0,72 & $y=3124,0-3213,8^{* *} x$ & 0,63 \\
\hline $\mathrm{I}_{\mathrm{B}}$ & $y=2431,3+83,6^{N S} x$ & 0,00 & $y=2437,31+69,06^{N S} x$ & 0,00 & $y=2454,0+1227,5^{\mathrm{NS}} x$ & 0,02 \\
\hline $\mathrm{I}_{\mathrm{Cu}}$ & $y=4015,3+1007,7^{* *} x$ & 0,91 & $y=4017,60+504,37^{\star *} x$ & 0,91 & $y=3924,5+965,9^{* *} x$ & 0,90 \\
\hline $\mathrm{I}_{\mathrm{Fe}}$ & $y=3123,1-2274,3^{\star *} x$ & 0,63 & $y=3137,91-1165,96^{\star *} x$ & 0,63 & $y=2964,9-2162,5^{\star *} x$ & 0,51 \\
\hline $\mathrm{I}_{\mathrm{Mn}}$ & $y=4283,6-1685,5^{\star *} x$ & 0,66 & $y=4283,63-842,74^{* *} x$ & 0,66 & $y=3908,2-1453,6^{* *} x$ & 0,66 \\
\hline $\mathrm{I}_{\mathrm{Zn}}$ & $y=2212,7+4557,4^{N S} x$ & 0,27 & $y=2208,38+2296,26^{\mathrm{NS}} x$ & 0,26 & $y=2386,9+1870,7^{N S} x$ & 0,02 \\
\hline
\end{tabular}


A relação entre a produtividade e o índice DRIS para potássio foi significativa ao nível de $5 \%$ de probabilidade, enquanto que as relações entre a produtividade e os índices DRIS para enxofre, cobre, ferro e manganês foram significativas ao nível de $1 \%$ de probabilidade (Tabela 16).

As melhores relações entre a produtividade e os índices DRIS foram observadas para enxofre, cobre, ferro e manganês. Para enxofre observou-se relação linear negativa, onde as menores produtividades estiveram relacionadas à índices DRIS enxofre positivos mais distantes de zero (Figura $5 \mathrm{~A}$ ), indicando que na população avaliada, a produtividade foi afetada negativamente por altas concentrações de enxofre.
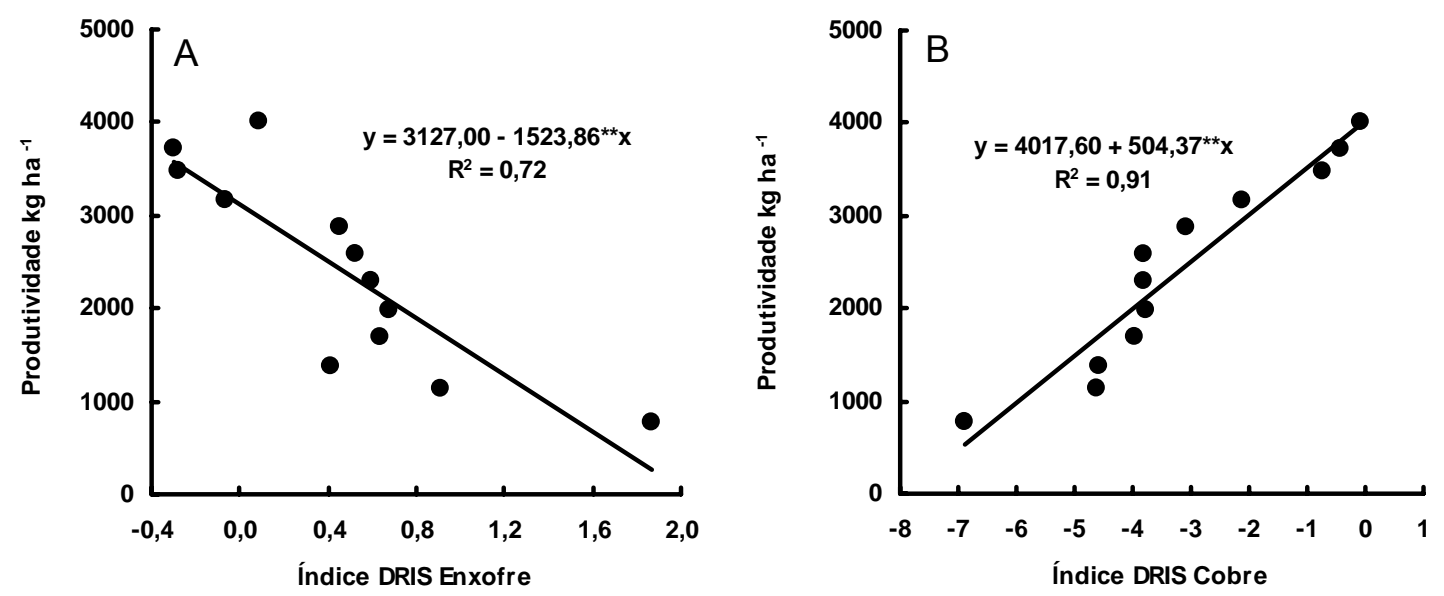

Figura 5 - Relação entre a produtividade da soja e os índices DRIS (Jones, 1981) para enxofre (A) e cobre (B) nas regiões do sul do Maranhão e sudoeste do Piauí

Para cobre observou-se relação linear positiva, na qual as menores produtividades estiveram relacionadas à índices DRIS negativos mais distantes de zero (Figura 5B), indicando que na população avaliada, a produtividade foi afetada positivamente por altas concentrações de cobre. 
Quanto à comparação entre os métodos de cálculo das funções DRIS, com exceção de nitrogênio, o resultados obtidos foram semelhantes entre os métodos DRIS utilizados. Verifica-se também, que a relação a produtividade e o IBN apresentou coeficientes de determinação semelhantes entre os métodos (Figura 6).

Este resultado, aliado ao fato de que o método DRIS proposto por Jones (1981) apresenta maior facilidade de utilização, levou a escolha deste método para a avaliação do estado nutricional da soja nas regiões do sul do Maranhão e sudoeste do Piauí. 

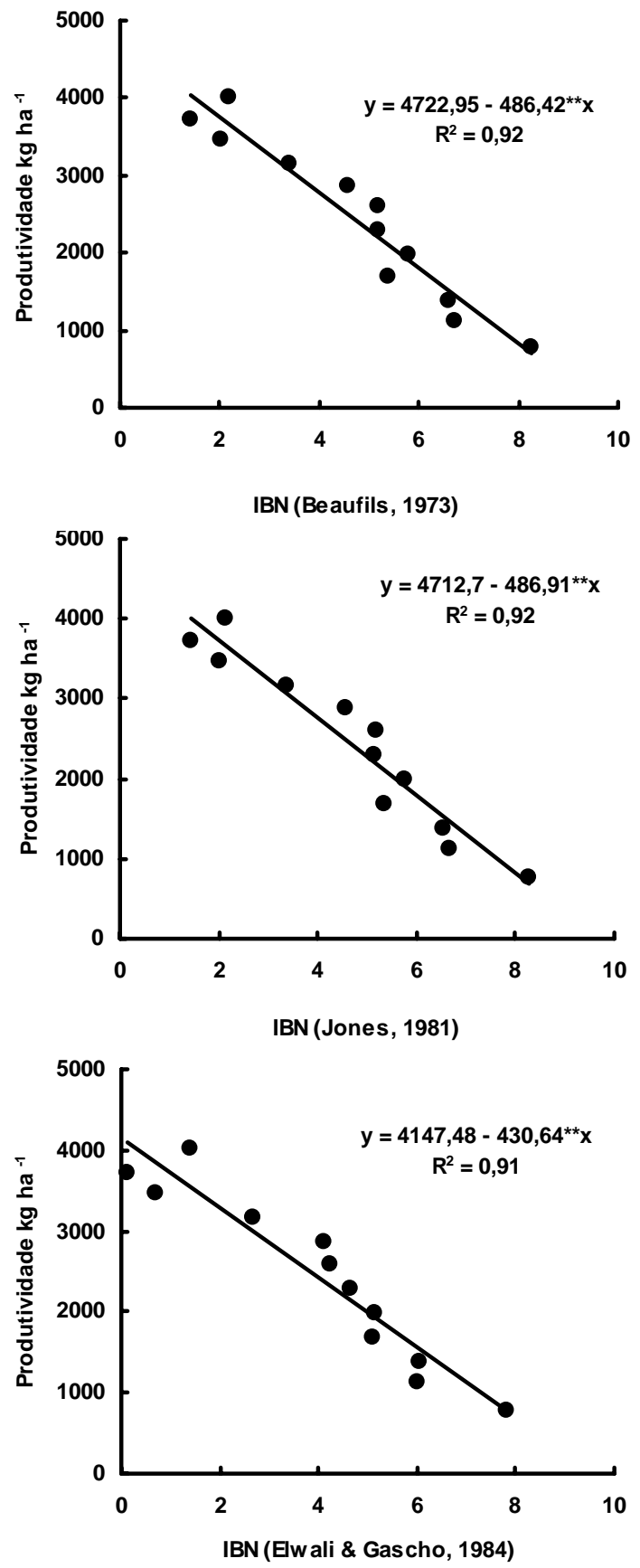

Figura 6 - Relação entre a produtividade da soja e IBN, obtidos pelos métodos Beaufils (1973), Jones (1981) e Elwali \& Gascho (1984) para as regiões do sul do Maranhão e sudoeste do Piauí 


\subsection{Estabelecimento da norma DRIS para o Mato Grosso}

\subsubsection{Agrupamento por classes de produtividade}

Em função do maior número de resultados de análise química foliar, foi estabelecido um maior número de classes de produtividade em relação às regiões do sul do Maranhão e sudoeste do Piauí (Tabela 17).

A concentração dos nutrientes foi variável em função da classe de produtividade, como também o erro padrão da média. O erro padrão da média foi superior nos extremos da tabela, indicando uma maior variabilidade na concentração dos nutrientes. As concentrações foliares de fósforo e potássio tenderam a aumentar com o aumento da produtividade, o que não ocorre tão evidentemente para os demais nutrientes. De maneira geral observou-se uma maior variabilidade das concentrações médias nas folhas para micronutrientes, principalmente para ferro e manganês (Tabela 17).

\subsubsection{Seleção da norma DRIS}

Os critérios para estabelecimento da norma DRIS para o Mato Grosso foram os mesmos empregados para as regiões do sul do Maranhão e sudoeste do Piauí. As concentrações médias foram submetidas ao cálculo das funções DRIS nas metodologias Beaufils (1973), Jones (1981) e Elwali \& Gascho (1984), mediante as normas estabelecidas a partir das cinco classes de produtividade da população de referência (Tabela 18). 
Tabela 17. Classes de produtividade, número de amostras, concentração na folha e erro padrão da média da concentração foliar dos nutrientes na soja do Mato Grosso

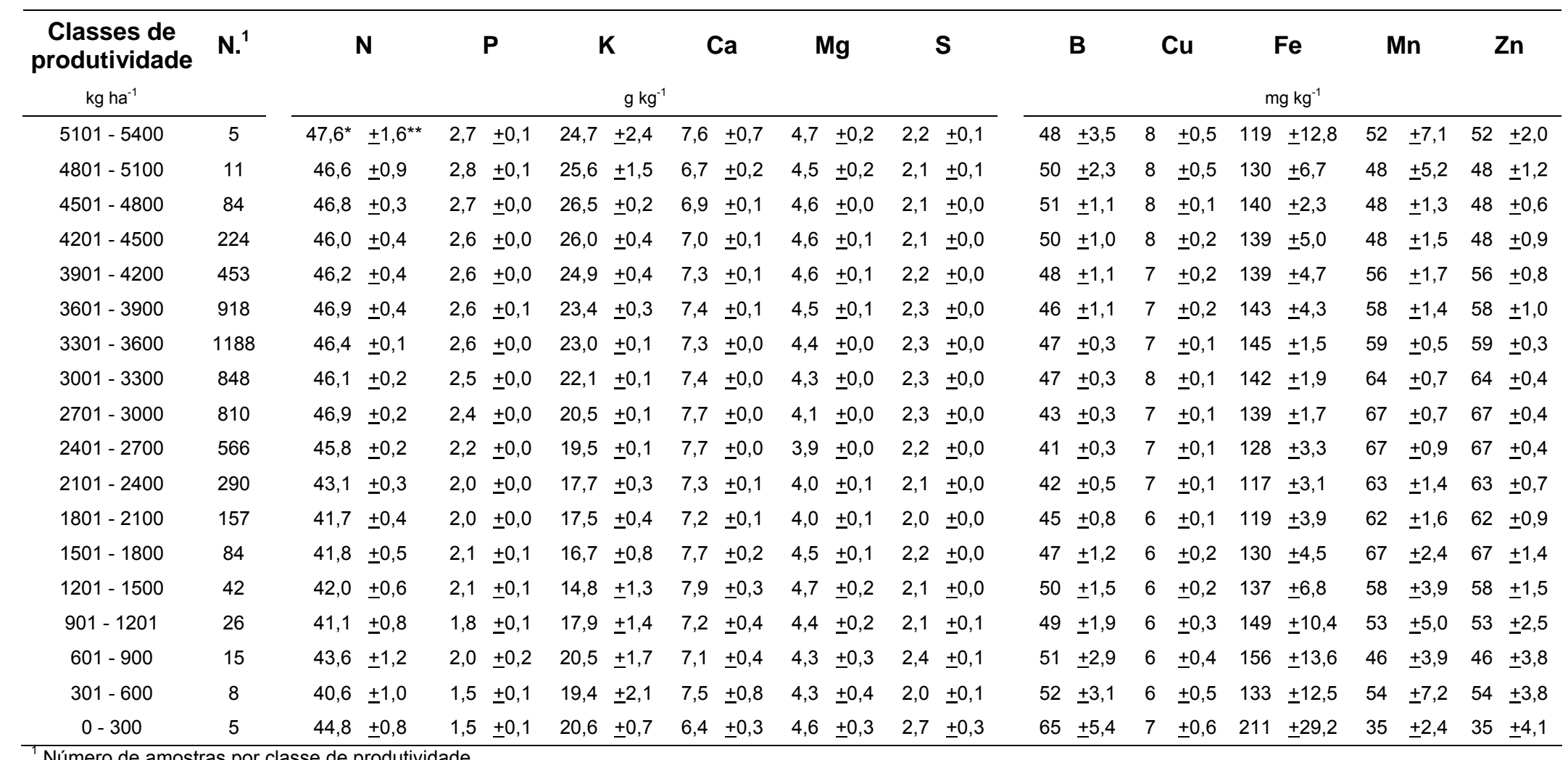

Número de amostras por classe de produtividade

${ }^{* *}$ Concentração na folha 
Tabela 18. Relação entre a produtividade e o IBN para as populações de alta produtividade estabelecidas nos diferentes métodos DRIS para a cultura da soja no Mato Grosso (Safras 1994/95 a 2002/03)

\begin{tabular}{|c|c|c|c|c|c|c|}
\hline \multirow{2}{*}{ Norma } & \multicolumn{2}{|l|}{ Beaufils (1973) } & \multicolumn{2}{|l|}{ Jones (1981) } & \multicolumn{2}{|c|}{ Elwali \& Gascho (1984) } \\
\hline & Equação & $\mathbf{R}^{2}$ & Equação & $\mathbf{R}^{2}$ & Equação & $\mathbf{R}^{2}$ \\
\hline$\geq 3600 \mathrm{~kg} \mathrm{ha}^{-1}$ & $y=4496,83-292,72^{* *} x$ & 0,68 & $y=4833,05-190,54^{* *} x$ & 0,76 & $y=4231,15-277,70^{* *} x$ & 0,71 \\
\hline$\geq 3900 \mathrm{~kg} \mathrm{ha}^{-1}$ & $y=4722,75-274,63^{* *} x$ & 0,80 & $y=4932,12-159,57^{* *} x$ & 0,85 & $y=4434,92-255,54^{* *} x$ & 0,82 \\
\hline$\geq 4200 \mathrm{~kg} \mathrm{ha}^{-1}$ & $y=4966,58-241,33^{* *} x$ & 0,84 & $y=5096,29-132,16^{* *} x$ & 0,86 & $y=4806,33-232,08^{* *} x$ & 0,84 \\
\hline$\geq 4500 \mathrm{~kg} \mathrm{ha}^{-1}$ & $y=5081,83-198,20^{* *} x$ & 0,86 & $y=5219,12-108,36^{\star *} x$ & 0,87 & $y=4924,72-189,41^{* *} x$ & 0,85 \\
\hline$\geq 4800 \mathrm{~kg} \mathrm{ha}^{-1}$ & $y=5063,25-178,36^{* *} x$ & 0,86 & $y=5221,15-98,25^{\star *} x$ & 0,88 & $y=4955,70-173,17^{\star *} x$ & 0,86 \\
\hline
\end{tabular}

A relação entre a produtividade e o IBN apresentou maior coeficiente de determinação com o aumento do nível de produtividade da população de referência no cálculo da norma, semelhantemente ao que ocorreu na escolha da população de referência para as regiões do sul do Maranhão e sudoeste do Piauí. Houve significância estatística entre a produtividade e o IBN em todos os níveis de produtividade da norma (Tabela 18).

A relação entre a produtividade e o IBN apresentou maior coeficiente de determinação com o aumento da produtividade para os três métodos de cálculo. Os coeficientes de determinação foram próximos em cada nível de produtividade da norma, mostrando que os métodos foram semelhantemente eficientes para mostrar a relação entre as duas variáveis.

A população de referência escolhida para cálculo da norma DRIS para o Mato Grosso foi a população com produtividade $\geq 4800 \mathrm{~kg} \mathrm{ha}^{-1}$. As relações entre nutrientes, variância, desvio padrão, coeficiente de variação e número de observações são apresentados na Tabela 19. 
Tabela 19. Norma DRIS para a cultura da soja no Mato Grosso

\begin{tabular}{|c|c|c|c|c|c|c|c|c|c|c|c|}
\hline Relação & $x$ & $\mathrm{~s}^{2}$ & $\mathbf{s}$ & C.v. & $\mathbf{n}$ & Relação & $x$ & $\mathrm{~s}^{2}$ & s & c.v. & $\mathbf{n}$ \\
\hline $\mathrm{N}$ & 45,92 & 1,56 & 1,25 & 2,72 & 11 & S/B & 0,05 & 0,00 & 0,00 & 5,57 & 4 \\
\hline$P$ & 2,70 & 0,01 & 0,09 & 3,37 & 11 & $\mathrm{~B} / \mathrm{K}$ & 1,83 & 0,02 & 0,14 & 7,57 & 7 \\
\hline K & 26,06 & 2,19 & 1,48 & 5,68 & 17 & $\mathrm{~B} / \mathrm{Mg}$ & 10,42 & 0,25 & 0,50 & 4,80 & 6 \\
\hline $\mathrm{Ca}$ & 6,87 & 0,22 & 0,47 & 6,89 & 16 & $\mathrm{Cu} / \mathrm{P}$ & 2,79 & 0,02 & 0,15 & 5,25 & 6 \\
\hline $\mathrm{Mg}$ & 4,58 & 0,03 & 0,16 & 3,53 & 15 & $\mathrm{Cu} / \mathrm{K}$ & 0,29 & 0,00 & 0,02 & 7,34 & 10 \\
\hline$S$ & 2,12 & 0,00 & 0,05 & 2,45 & 9 & $\mathrm{Cu} / \mathrm{Mg}$ & 1,69 & 0,01 & 0,11 & 6,22 & 7 \\
\hline B & 48,65 & 9,70 & 3,11 & 6,40 & 12 & $\mathrm{Cu} / \mathrm{B}$ & 0,15 & 0,00 & 0,02 & 9,48 & 8 \\
\hline $\mathrm{Cu}$ & 7,50 & 0,22 & 0,47 & 6,23 & 15 & $\mathrm{Fe} / \mathrm{N}$ & 2,72 & 0,03 & 0,17 & 6,14 & 6 \\
\hline $\mathrm{Fe}$ & 126,92 & 56,74 & 7,53 & 5,94 & 13 & $\mathrm{Fe} / \mathrm{P}$ & 46,82 & 6,49 & 2,55 & 5,44 & 6 \\
\hline $\mathrm{Mn}$ & 46,62 & 38,26 & 6,19 & 13,27 & 13 & $\mathrm{Fe} / \mathrm{K}$ & 4,89 & 0,13 & 0,36 & 7,38 & 7 \\
\hline $\mathrm{Zn}$ & 28,68 & 2,14 & 1,46 & 5,10 & 13 & $\mathrm{Fe} / \mathrm{Ca}$ & 18,61 & 1,37 & 1,17 & 6,28 & 8 \\
\hline$N / P$ & 16,89 & 0,16 & 0,40 & 2,35 & 4 & $\mathrm{Fe} / \mathrm{Mg}$ & 27,70 & 2,31 & 1,52 & 5,49 & 9 \\
\hline$N / K$ & 1,75 & 0,01 & 0,08 & 4,63 & 7 & $\mathrm{Fe} / \mathrm{S}$ & 60,60 & 6,86 & 2,62 & 4,32 & 4 \\
\hline $\mathrm{N} / \mathrm{Ca}$ & 6,67 & 0,24 & 0,49 & 7,28 & 8 & $\mathrm{Fe} / \mathrm{Zn}$ & 4,46 & 0,06 & 0,25 & 5,58 & 6 \\
\hline $\mathrm{N} / \mathrm{Mg}$ & 10,10 & 0,10 & 0,31 & 3,05 & 8 & $\mathrm{Fe} / \mathrm{Cu}$ & 16,20 & 1,40 & 1,18 & 7,29 & 7 \\
\hline $\mathrm{N} / \mathrm{Cu}$ & 6,16 & 0,12 & 0,34 & 5,54 & 5 & $\mathrm{Fe} / \mathrm{B}$ & 2,62 & 0,06 & 0,24 & 9,25 & 8 \\
\hline N/B & 0,97 & 0,00 & 0,04 & 4,18 & 4 & $\mathrm{Mn} / \mathrm{N}$ & 1,01 & 0,02 & 0,14 & 14,21 & 4 \\
\hline $\mathrm{P} / \mathrm{K}$ & 0,11 & 0,00 & 0,00 & 3,86 & 6 & $\mathrm{Mn} / \mathrm{P}$ & 17,44 & 2,73 & 1,65 & 9,47 & 5 \\
\hline $\mathrm{P} / \mathrm{Mg}$ & 0,59 & 0,00 & 0,02 & 3,72 & 5 & $\mathrm{Mn} / \mathrm{K}$ & 1,71 & 0,03 & 0,16 & 9,47 & 8 \\
\hline $\mathrm{P} / \mathrm{B}$ & 0,06 & 0,00 & 0,00 & 6,46 & 9 & $\mathrm{Mn} / \mathrm{Ca}$ & 6,66 & 0,41 & 0,64 & 9,61 & 8 \\
\hline $\mathrm{Ca} / \mathrm{P}$ & 2,56 & 0,01 & 0,12 & 4,68 & 4 & $\mathrm{Mn} / \mathrm{Mg}$ & 9,79 & 1,93 & 1,39 & 14,17 & 8 \\
\hline $\mathrm{Ca} / \mathrm{K}$ & 0,25 & 0,00 & 0,01 & 4,51 & 10 & $\mathrm{Mn} / \mathrm{S}$ & 20,24 & 11,54 & 3,40 & 16,79 & 6 \\
\hline $\mathrm{Ca} / \mathrm{Mg}$ & 1,46 & 0,01 & 0,07 & 4,74 & 9 & $\mathrm{Mn} / \mathrm{Fe}$ & 0,37 & 0,00 & 0,05 & 12,95 & 7 \\
\hline $\mathrm{Ca} / \mathrm{Zn}$ & 0,24 & 0,00 & 0,03 & 11,05 & 9 & $\mathrm{Mn} / \mathrm{Zn}$ & 1,56 & 0,04 & 0,20 & 12,82 & 6 \\
\hline $\mathrm{Ca} / \mathrm{Cu}$ & 0,93 & 0,01 & 0,11 & 11,86 & 9 & $\mathrm{Mn} / \mathrm{Cu}$ & 6,25 & 0,90 & 0,95 & 15,13 & 10 \\
\hline $\mathrm{Ca} / \mathrm{B}$ & 0,15 & 0,00 & 0,01 & 4,32 & 5 & $\mathrm{Mn} / \mathrm{B}$ & 0,98 & 0,01 & 0,11 & 10,94 & 8 \\
\hline $\mathrm{Mg} / \mathrm{K}$ & 0,18 & 0,00 & 0,01 & 6,89 & 12 & $\mathrm{Zn} / \mathrm{N}$ & 0,62 & 0,00 & 0,05 & 7,39 & 6 \\
\hline$S / N$ & 0,05 & 0,00 & 0,00 & 2,49 & 4 & $\mathrm{Zn} / \mathrm{P}$ & 10,52 & 0,83 & 0,91 & 8,67 & 6 \\
\hline $\mathrm{S} / \mathrm{P}$ & 0,78 & 0,00 & 0,03 & 3,71 & 3 & $\mathrm{Zn} / \mathrm{K}$ & 1,09 & 0,01 & 0,11 & 10,38 & 8 \\
\hline$S / K$ & 0,08 & 0,00 & 0,01 & 7,92 & 7 & $\mathrm{Zn} / \mathrm{Mg}$ & 6,32 & 0,09 & 0,30 & 4,68 & 7 \\
\hline $\mathrm{S} / \mathrm{Ca}$ & 0,30 & 0,00 & 0,03 & 9,25 & 6 & $\mathrm{Zn} / \mathrm{S}$ & 13,46 & 0,46 & 0,67 & 5,01 & 4 \\
\hline $\mathrm{S} / \mathrm{Mg}$ & 0,46 & 0,00 & 0,01 & 2,81 & 6 & $\mathrm{Zn} / \mathrm{Cu}$ & 3,69 & 0,10 & 0,31 & 8,40 & 7 \\
\hline $\mathrm{S} / \mathrm{Cu}$ & 0,28 & 0,00 & 0,01 & 3,81 & 7 & $\mathrm{Zn} / \mathrm{B}$ & 0,59 & 0,00 & 0,04 & 7,07 & 6 \\
\hline
\end{tabular}


O coeficiente de variação das relações apresentou valores relativamente baixos quando comparados à outros trabalhos (Maeda, 2002; Kurihara, 2004). Um menor coeficiente de variação é desejavel na obtenção da norma, já que seu valor influência diretamente no cálculo das funções DRIS, aumentando ou diminuindo a precisão do diagnóstico. Segundo Maia et al. (1999), para que uma relação possa ser potencialmente útil na avaliação do estado nutricional pelo DRIS, este deverá apresentar um coeficiente de variação inferior a $25 \%$.

O número de observações empregados na obtenção da norma foi baixo em função do corte na população de referência, de acordo com o critério da população nutricionalmente equilibrada (Beaufils, 1956 citado por Beaufils, 1971). Entretanto, observa-se que a melhor relação entre a produtividade e o IBN foi obtida com um número reduzido de observações, mostrando que a precisão de diagnóstico da norma não foi dependente do número de observações que compõem sua população, mas sim de uma população de referência nutricionalmente equilibrada.

Autores defendem a criação de uma norma que ultrapasse inclusive o limite de fronteiras entre continentes (Beaufils, 1973; Sumner, 1977b; Beverly et al., 1986; Halmark et al.,1987). Entretanto, outros têm contestado esta idéia (Escano et al., 1981; Vigier et al., 1989; Leandro, 1998; Reis Junior, 2002; Maeda, 2002; Lantmann, 2002).

Neste trabalho optou-se pela regionalização das normas, visto que o número de resultados de análise química foliar foi suficientemente grande e também por acreditar que as diferenças regionais possam afetar a norma, ao ponto de gerar falsos diagnósticos e não expressar o verdadeiro estado nutricional da soja nas respectivas regiões. 


\subsection{3 Índices DRIS}

$\mathrm{Na}$ Tabela 20 são apresentadas as relações entre os índices DRIS e as concentrações foliares dos nutrientes. Com exceção de nitrogênio, para os demais nutrientes houve significância entre o índice DRIS e a concentração foliar, indicando a influência da concentração foliar dos nutrientes sobre os índices DRIS, semelhante ao encontrado para as regiões do sul do Maranhão. Também observado por Nachtigall (2004) em macieira, não obtendo signficância estatística entre o índice DRIS e a concentração de nitrogênio na folha, porém significativa para os demais nutrientes.

Tabela 20. Relação entre índices DRIS e a concentração foliar dos nutrientes para a cultura da soja no Mato Grosso

\begin{tabular}{|c|c|c|c|c|c|c|c|}
\hline \multirow{2}{*}{\multicolumn{2}{|c|}{ Variável }} & \multicolumn{2}{|c|}{ Beaufils (1973) } & \multicolumn{2}{|l|}{ Jones (1981) } & \multicolumn{2}{|c|}{ Elwali \& Gascho (1984) } \\
\hline & & Equação & $\mathbf{R}^{2}$ & Equação & $\mathbf{R}^{2}$ & Equação & $\mathbf{R}^{2}$ \\
\hline$\overline{\mathrm{N}}$ & $\mathrm{I}_{\mathrm{N}}$ & $y=-0,72+0,02^{N S} x$ & 0,01 & $y=-0,46+0,01^{\mathrm{NS}} x$ & 0,00 & $y=-0,97+0,02^{N S} x$ & 0,02 \\
\hline$P$ & $I_{P}$ & $y=-16,83+6,31^{* *} x$ & 0,86 & $y=-30,43+11,35^{* *} x$ & 0,88 & $y=-16,90+6,36^{* *} x$ & 0,86 \\
\hline K & $\mathrm{I}_{\mathrm{K}}$ & $y=-11,26+0,43^{* *} x$ & 0,92 & $y=-22,6+10,86^{\star *} x$ & 0,93 & $y=-11,48+0,44^{\star *} x$ & 0,93 \\
\hline $\mathrm{Ca}$ & $\mathrm{I}_{\mathrm{Ca}}$ & $y=-13,29+1,95^{\star *} x$ & 0,68 & $y=-24,20+3,57^{* *} x$ & 0,64 & $y=-12,94+1,90^{* *} x$ & 0,66 \\
\hline $\mathrm{Mg}$ & $\mathrm{I}_{\mathrm{Mg}}$ & $y=-8,40+1,80^{* *} x$ & 0,42 & $y=-16,09+3,41^{* *} x$ & 0,42 & $y=-8,55+1,84^{* *} x$ & 0,43 \\
\hline S & $\mathrm{I}_{\mathrm{S}}$ & $y=-7,36+3,74^{\star *} x$ & 0,50 & $y=-14,37+7,32^{* *} x$ & 0,49 & $y=-7,21+3,68^{* *} x$ & 0,50 \\
\hline B & $\mathrm{I}_{\mathrm{B}}$ & $y=-9,11+0,19^{* *} x$ & 0,87 & $y=-13,81+0,29^{* *} x$ & 0,82 & $y=-9,03+0,19^{* *} x$ & 0,87 \\
\hline $\mathrm{Cu}$ & $\mathrm{I}_{\mathrm{Cu}}$ & $y=-6,04+0,78^{* *} x$ & 0,74 & $y=-11,56+1,49^{* *} x$ & 0,73 & $y=-5,90+0,76^{* \star} x$ & 0,70 \\
\hline $\mathrm{Fe}$ & $\mathrm{I}_{\mathrm{Fe}}$ & $y=-7,95+0,06^{* *} x$ & 0,91 & $y=-15,03+0,12^{* *} x$ & 0,90 & $y=-7,97+0,06^{\star *} x$ & 0,90 \\
\hline $\mathrm{Mn}$ & $\mathrm{I}_{\mathrm{Mn}}$ & $y=-5,61+0,12^{* *} x$ & 0,92 & $y=-9,59+0,21^{* *} x$ & 0,90 & $y=-5,80+0,12^{* *} x$ & 0,92 \\
\hline $\mathrm{Zn}$ & $\mathrm{I}_{\mathrm{Zn}}$ & $y=-7,27+0,26^{* *} x$ & 0,90 & $y=-13,53+0,49^{* *} x$ & 0,88 & $y=-7,42+0,26^{* *} x$ & 0,90 \\
\hline
\end{tabular}

Fósforo, potássio, boro, cobre, ferro, manganês e zinco se destacaram pelo elevado coeficiente de determinação e, portanto, índices DRIS altamente dependentes de sua própria concentração. Cálcio, magnésio e enxofre apresentaram uma maior 
interferência da concentração dos outros nutrientes e, portanto foram menos dependentes de sua própria concentração na folha.

A relação obtida entre os índices DRIS e a concentração foliar foi muito próxima para os métodos Beaufils (1973), Jones (1981) e Elwali \& Gascho (1984). Não houve diferenças quanto à significância e os coeficientes de determinação foram semelhantes.

Os métodos de cálculo das funções DRIS apresentaram resultados de significância estatística idênticas na relação da produtividade com os índices DRIS (Tabela 21). A relação entre o índice DRIS para nitrogênio e a produtividade não apresentou significância nas três metodologias de cálculo das funções DRIS, semelhante ao ocorrido nas regiões do sul do Maranhão e sudoeste do Piauí e observado também por Maeda (2002) em lavouras de soja no Mato Grosso do Sul.

Tabela 21. Relação entre a produtividade da soja e índices DRIS para o Mato Grosso

\begin{tabular}{|c|c|c|c|c|c|c|}
\hline \multirow{2}{*}{ Variável } & \multicolumn{2}{|l|}{ Beaufils (1973) } & \multicolumn{2}{|l|}{ Jones (1981) } & \multicolumn{2}{|c|}{ Elwali \& Gascho (1984) } \\
\hline & Equação & $\mathbf{R}^{2}$ & Equação & $\mathbf{R}^{2}$ & Equação & $\mathbf{R}^{2}$ \\
\hline $\mathrm{I}_{\mathrm{N}}$ & $y=2707,3+426,3^{N S} x$ & $\overline{0,01}$ & $y=2725,87+19,49^{N S} x$ & 0,00 & $y=2689,0+655,4^{N S} x$ & 0,02 \\
\hline$I_{P}$ & $y=3989,3+507,7^{\star \star} x$ & 0,73 & $y=4086,33+291,63^{* *} x$ & 0,75 & $y=3968,4+505,2^{* *} x$ & 0,73 \\
\hline $\mathrm{I}_{\mathrm{K}}$ & $y=4242,8+697,6^{* *} x$ & 0,48 & $y=4283,18+355,70^{* *} x$ & 0,50 & $y=4208,6+691,4^{* *} x$ & 0,49 \\
\hline $\mathrm{I}_{\mathrm{Ca}}$ & $y=3379,0-719,6^{\mathrm{NS}} x$ & 0,17 & $y=3529,18-436,58^{*} x$ & 0,22 & $y=3398,3-744,1^{\mathrm{NS}} x$ & 0,18 \\
\hline $\mathrm{I}_{\mathrm{Mg}}$ & $y=2555,9-348,0^{N S} x$ & 0,02 & $y=2737,95+7,83^{\mathrm{NS}} x$ & 0,00 & $y=2600,3-274,6^{\mathrm{NS}} x$ & 0,01 \\
\hline $\mathrm{I}_{\mathrm{S}}$ & $y=4082,7-1482,3^{* *} x$ & 0,54 & $y=4112,52-759,78^{* *} x$ & 0,55 & $y=4137,8-1512,1^{* *} x$ & 0,54 \\
\hline $\mathrm{I}_{\mathrm{B}}$ & $y=2898,6-815,5^{\star} x$ & 0,31 & $y=2809,07-484,10^{*} x$ & 0,26 & $y=2892,9-845,6^{*} x$ & 0,32 \\
\hline $\mathrm{I}_{\mathrm{Cu}}$ & $y=4.85,0+2284,6^{* *} x$ & 0,69 & $y=4197,37+1186,75^{\star *} x$ & 0,69 & $y=4160,9+2241,8^{* *} x$ & 0,67 \\
\hline $\mathrm{I}_{\mathrm{Fe}}$ & $y=3518,6-745,1^{* *} x$ & 0,43 & $y=3574,26-397,63^{\star *} x$ & 0,44 & $y=3511,6-752,9^{* *} x$ & 0,44 \\
\hline $\mathrm{I}_{\mathrm{Mn}}$ & $y=2866,7-123,7^{N S} x$ & 0,01 & $y=3062,20-143,28^{N S} x$ & 0,03 & $y=2919,2-178,3^{N S} x$ & 0,02 \\
\hline $\mathrm{I}_{\mathrm{Zn}}$ & $y=4450,9-1120,0^{* *} x$ & 0,86 & $y=4511,84-595,46^{* *} x$ & 0,87 & $y=4397,5-1106,9^{* *} x$ & 0,86 \\
\hline
\end{tabular}


Os índices DRIS para fósforo, potássio, enxofre, boro, cobre, ferro, manganês e zinco apresentaram relação significativa com a produtividade para todas as metodologias de cálculo das funções DRIS. Para cálcio houve significância entre o índice DRIS e produtividade somente na metodologia proposta por Jones (1981), embora seu coeficiente de determinação apresente um valor muito próximo dos obtidos para Beaufils (1973) e Elwali \& Gascho (1984) (Tabela 21).

Para magnésio e manganês não foi verificada relação significativa entre a produtividade e o IBN, para os três métodos de cálculo das funções DRIS.

A relação entre produtividade e os índices DRIS procura explicar o efeito da variação no valor do índice sobre a produtividade. Quando ocorre uma relação significativa e um alto coeficiente de determinação entre estas variáveis, é possível verificar se há limitação na produtividade por determinado nutriente, seja por falta ou excesso.

Fósforo e enxofre se destacaram entre os macronutrientes na relação da produtividade e índices DRIS para o Mato Grosso (Figura 7A e B).
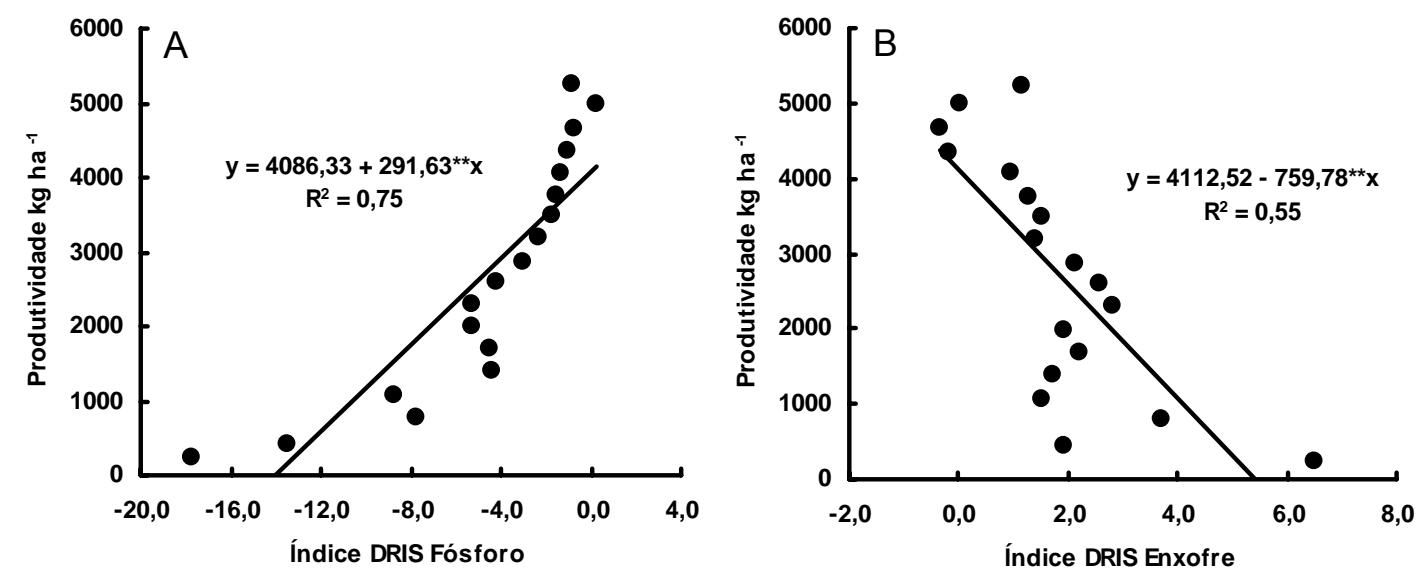

Figura 7 - Relação entre a produtividade da soja e os Índices DRIS (Jones, 1981) para fósforo e enxofre no Mato Grosso 
Para fósforo observou-se que houve uma relação positiva entre os parâmetros na medida em que os índices DRIS tenderam a zero. O que indicou déficit do nutriente nas menores produtividades e um suprimento adequado nas produtividades maiores.

Ao contrário do enxofre, o qual apresentou relação negativa, a produtividade aumentou com a diminuição dos valores dos índices, indicando excesso nas menores produtividades e um melhor equilíbrio nutricional nas produtividades superiores.

Dentre os micronutrientes, merecem destaque cobre e zinco (Figura 8A e B).
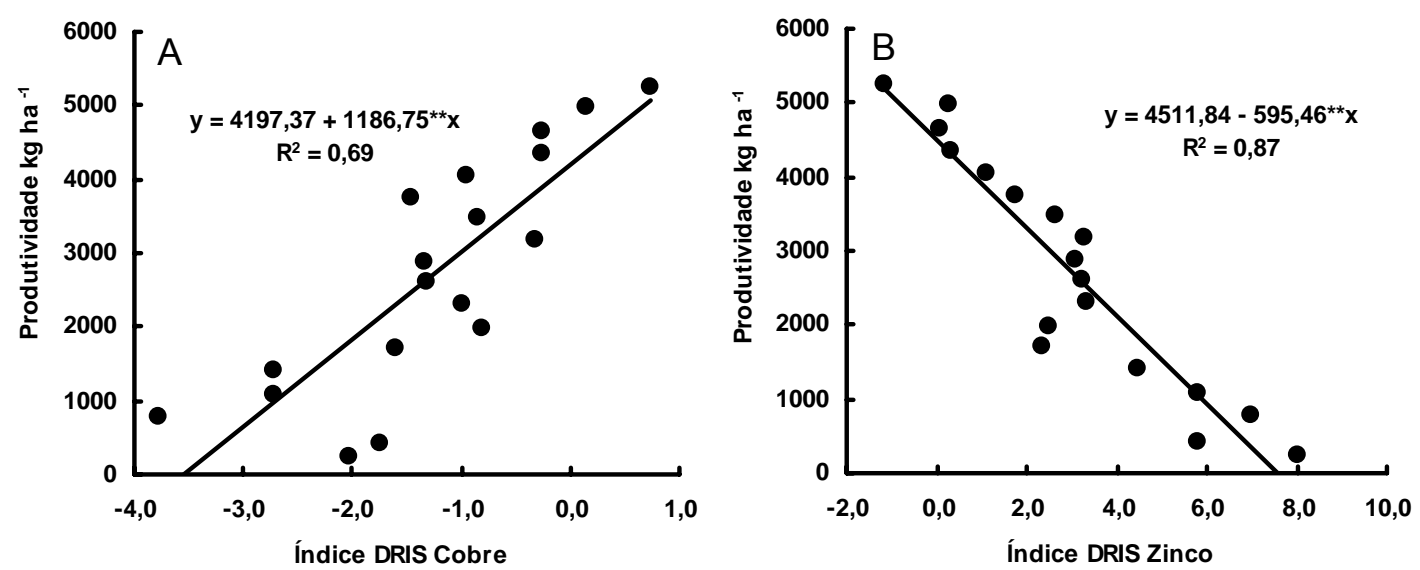

Figura 8 - Relação entre a produtividade da soja e os Índices DRIS (Jones, 1981) para cobre e zinco no Mato Grosso

Para cobre foi observado um aumento nos valores dos índices com o aumento da produtividade, ou seja, uma relação positiva, demonstrando limitação na produtividade, da mesma forma que para fósforo. Os índices DRIS para zinco tiveram comportamento semelhante ao enxofre, apresentando uma relação negativa, com índices DRIS positivos nas menores produtividades.

$\mathrm{Na}$ escolha da população de referência foi observada uma ligeira superioridade do método Jones (1981) na relação entre a produtividade e o IBN para o Mato Grosso. Semelhantemente ao observado nas regiões do sul do Maranhão e sudoeste do Piauí 
e também por Mourão Filho (2000), que observou uma melhor correlação com a produtividade de laranjeira 'Valencia' empregando o método proposto por Jones (1981). Portanto, foi escolhido o método modificado proposto por Jones (1981) para cálculo das funções DRIS na avaliação do estado nutricional da soja no Mato Grosso (Figura 9). 

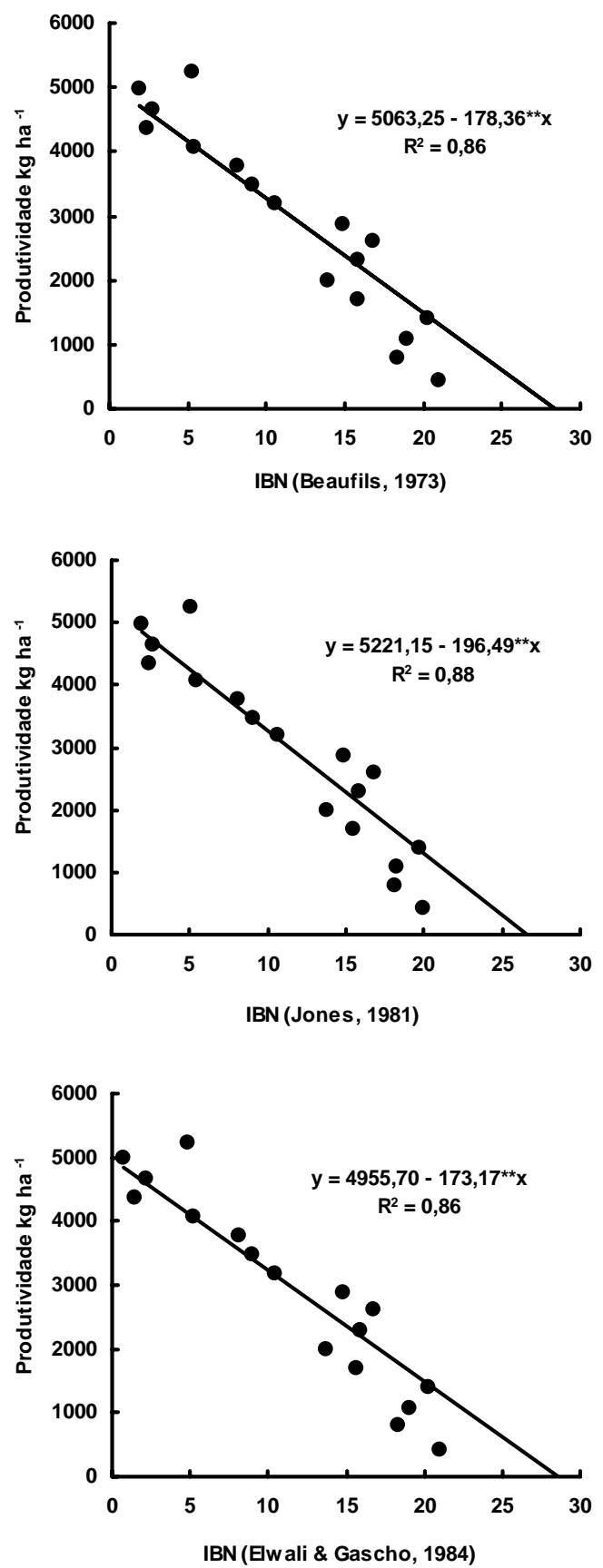

Figura 9 - Relação entre a produtividade da soja e IBN, obtidos pelos métodos Beaufils (1973), Jones (1981) e Elwali \& Gascho (1984) para o Mato Grosso 
4.5 Estado nutricional da soja nas regiões do sul do Maranhão e sudoeste do Piauí

Para avaliar o estado nutricional da soja em amostras distribuídas em classes de produtividade, para as condições das regiões do sul do Maranhão e sudeste do Piauí, foram calculados os índices DRIS e os valores de IBN. A interpretação dos índices considerou que valores negativos foram deficientes, valores positivos como excessivos e, iguais a zero como equilibrados nutricionalmente (Tabela 22).

Tabela 22. Índices DRIS (Jones, 1981), Índice de Balanço Nutricional (IBN), Índice de Balanço Nutricional Médio (IBNm) por classe de produtividade da soja nas regiões do sul do Maranhão e sudoeste do Piauí

\begin{tabular}{|c|c|c|c|c|c|c|c|c|c|c|c|c|c|}
\hline \multirow{2}{*}{$\begin{array}{c}\text { Classes de } \\
\text { produtividade } \\
\left(\mathrm{kg} \mathrm{ha}^{-1}\right)\end{array}$} & \multicolumn{13}{|c|}{ Índices DRIS (Jones, 1981) } \\
\hline & $\mathbf{N}$ & $\mathbf{P}$ & $\mathbf{K}$ & $\mathrm{Ca}$ & Mg & $\mathbf{S}$ & B & $\mathrm{Cu}$ & $\mathrm{Fe}$ & Mn & $\mathrm{Zn}$ & IBN & IBNm \\
\hline $3901-4200$ & $-0,4$ & $-0,6$ & $-0,9$ & $-0,2$ & 0,3 & 0,1 & 0,2 & $-0,1$ & 0,1 & 1,4 & 0,1 & 4,3 & 0,4 \\
\hline $3601-3900$ & 0,1 & 0,4 & 0,0 & 0,0 & $-0,3$ & $-0,3$ & $-0,4$ & $-0,4$ & 0,1 & 0,7 & 0,1 & 2,9 & 0,3 \\
\hline $3301-3600$ & $-0,1$ & 0,2 & $-0,4$ & 0,5 & 0,0 & $-0,3$ & $-0,3$ & $-0,7$ & $-0,2$ & 1,1 & 0,2 & 4,1 & 0,4 \\
\hline $3001-3300$ & 0,2 & 1,0 & $-0,5$ & 0,9 & 0,0 & $-0,1$ & $-0,4$ & $-2,1$ & $-0,2$ & 1,2 & 0,1 & 6,7 & 0,6 \\
\hline $2701-3000$ & 0,1 & 0,7 & $-1,0$ & 0,9 & 0,0 & 0,5 & $-0,5$ & $-3,1$ & 0,3 & 1,8 & 0,4 & 9,2 & 0,8 \\
\hline $2401-2700$ & $-0,2$ & 0,4 & $-0,8$ & 0,9 & $-0,1$ & 0,5 & $-0,3$ & $-3,8$ & 0,6 & 2,6 & 0,2 & 10,4 & 0,9 \\
\hline $2101-2400$ & $-0,2$ & $-0,1$ & -1 & 0,8 & $-0,1$ & 0,6 & 0,1 & $-3,8$ & 0,9 & 2,4 & 0,4 & 10,3 & 0,9 \\
\hline $1801-2100$ & $-0,2$ & $-0,2$ & $-0,8$ & 0,9 & $-0,5$ & 0,7 & $-0,2$ & $-3,8$ & 1,0 & 3,0 & 0,2 & 11,5 & 1,0 \\
\hline $1501-1800$ & $-0,2$ & 0,2 & $-1,2$ & 0,8 & 0,0 & 0,6 & 0,2 & $-4,0$ & 0,9 & 2,6 & 0,0 & 10,7 & 1,0 \\
\hline $1201-1500$ & $-0,3$ & 0,0 & $-1,3$ & 0,7 & 0,3 & 0,4 & 0,2 & $-4,6$ & 0,6 & 4,3 & $-0,3$ & 13,1 & 1,2 \\
\hline $901-1200$ & 0,5 & $-0,2$ & $-1,0$ & 1,0 & 0,6 & 0,9 & $-0,5$ & $-4,6$ & 0,7 & 3,0 & $-0,4$ & 13,3 & 1,2 \\
\hline $601-900$ & 0,4 & 0,1 & $-0,9$ & 0,4 & 0,4 & 1,9 & $-0,5$ & $-6,9$ & 2,5 & 2,5 & 0,1 & 16,5 & 1,5 \\
\hline
\end{tabular}

O nitrogênio apresentou um comportamento variável em função da classe de produtividade, não sendo verificada relação com índice DRIS nitrogênio e produtividade. Dentre os nutrientes, o nitrogênio é o elemento de maior requerimento à cultura da soja, sua demanda é de aproximadamente $83 \mathrm{~kg} \mathrm{ton}^{-1}$ de grãos a produzir e sua principal fonte tem sido a fixação simbiótica pelas bactérias do gênero 
Bradyrhizobium, que dependendo da sua eficiência podem fornecer todo nitrogênio necessário ao desenvolvimento da soja (Embrapa, 2004). Os índices DRIS próximos de zero indicam bom estado nutricional da soja em nitrogênio e mostra que a fixação simbiótica foi eficiente no suprimento.

O fósforo apresentou índices DRIS negativos, mais próximos de zero nas produtividades menores e uma limitação mais acentuada na classe de maior produtividade. As classes com produtividades intermediárias e altas apresentaram índices positivos, mas também próximos de zero. Deve-se salientar que índices DRIS para fósforo não apresentaram uma relação significativa com a produtividade, contrariando o esperado e demonstrando que apesar dos baixos teores de fósforo em solos de cerrado, o suprimento mediante fertilizações tem sido satisfatório.

Os índices DRIS para potássio foram em sua maioria negativos, indicando déficit deste nutriente em praticamente todas as classes, justificando a relação negativa e significativa deste nutriente com a produtividade e indicando deficiência. Potássio é o segundo elemento mais requerido pela cultura da soja e sua absorção é normalmente influenciada pela presença de fósforo (Miller et al., 1961), o potássio esta relacionado como ativador de um grande número de enzimas e na sua deficiência pode ocorrer acúmulo de carboidratos solúveis e aminoácidos livres ou amidas e diminuição de amido e síntese de proteína (Bataglia \& Mascarenhas, 1982).

O cálcio apresentou índices DRIS positivos, principalmente nas produtividades mais baixas, indicando um desbalanço para excesso nestas produtividades, porém não foi verificada relação significativa dos índices DRIS para cálcio com a produtividade.

Para magnésio foram obtidos índices DRIS positivos e negativos, entretanto sempre próximos de zero. Os índices indicaram que não houve desbalanço para 
magnésio em qualquer classe de produtividade. Os índices DRIS para magnésio não apresentaram relação significativa para produtividade (Tabela 22).

O enxofre apresentou índices DRIS decrescentes com o aumento da produtividade e uma relação significativa entre os dois parâmetros. Os índices apontaram um significativo excesso nas produtividades mais baixas e uma tendência ao equilíbrio nutricional com o aumento da produtividade.

Os índices DRIS para boro não apresentaram tendência definida em função da produtividade. Para cobre os índices DRIS diminuiram linearmente com o aumento da produtividade. É notável a diminuição linear do índice DRIS para cobre com o aumento da produtividade, indicando que este nutriente foi o mais limitante à produtividade nas regiões do sul do Maranhão e sudoeste do Piauí.

Os índices DRIS para ferro e manganês, foram mais positivos nas produtividades mais baixas, indicando excesso. O ferro apresentou índices DRIS próximos de zero nas classes de produtividade superiores. Para manganês houve uma diminuição nos valores dos índices DRIS com o aumento da produtividade, porém distantes do equilíbrio nutricional (Tabela 22). Os índices positivos em todas as classes de produtividade para manganês provavelmente podem ser atribuídos às freqüentes aplicações foliares com este nutriente.

O zinco apresentou uma sensível deficiência nas menores produtividades e índices DRIS próximos de zero nas demais classes de produtividade. Não houve relação significativa entre os índices DRIS deste nutriente e a produtividade.

Os índices DRIS de maneira geral foram mais positivos e/ou mais negativos nas menores produtividades, o que justificou um maior valor do IBN nestas condições. Estes resultados são indicativos da eficiência do método DRIS em avaliar o estado nutricional da soja nas regiões do sul do Maranhão e sudoeste do Piauí. 
Teoricamente, em plantas com adequado equilíbrio nutricional, todos os índices de diagnose seriam iguais a zero e as produções seriam elevadas, o que pode não ocorrer, segundo Beaufils (1973), por que um fator não nutricional pode estar limitando a produção.

Para avaliar o estado nutricional da soja nas regiões do sul do Maranhão e sudoeste do Piauí, utilizando os valores médios das classes de produtividade, os índices DRIS obtidos pelo método Jones (1981) foram subdivididos em três classes: deficiente, normal e excessivo (Tabela 23). Esta classificação utilizou um critério semelhante ao de Wadt (1996), considerando o índice de balanço nutricional médio, de modo que a ocorrência do índice DRIS em cada classe de diagnose indicou com que freqüência o nutriente se apresenta deficiente, normal ou excessivo.

Tabela 23. Avaliação do estado nutricional da soja nas regiões do sul do Maranhão e sudoeste do Piauí pelo DRIS (Jones, 1981) por classe de diagnose

\begin{tabular}{lcccccc}
\hline \multirow{2}{*}{ Nutriente } & \multicolumn{2}{c}{ Deficiente } & \multicolumn{2}{c}{ Normal } & \multicolumn{2}{c}{ Excessivo } \\
& Caso & $\%$ & Caso & $\%$ & Caso & $\%$ \\
\hline $\mathrm{N}$ & 0 & $0 \%$ & 12 & $100 \%$ & 0 & $0 \%$ \\
$\mathrm{P}$ & 1 & $8 \%$ & 9 & $75 \%$ & 2 & $17 \%$ \\
$\mathrm{~K}$ & 6 & $50 \%$ & 6 & $50 \%$ & 0 & $0 \%$ \\
$\mathrm{Ca}$ & 0 & $0 \%$ & 9 & $75 \%$ & 3 & $25 \%$ \\
$\mathrm{Mg}$ & 1 & $8 \%$ & 11 & $92 \%$ & 0 & $0 \%$ \\
$\mathrm{~S}$ & 1 & $8 \%$ & 10 & $83 \%$ & 1 & $8 \%$ \\
$\mathrm{~B}$ & 1 & $8 \%$ & 11 & $92 \%$ & 0 & $0 \%$ \\
$\mathrm{Cu}$ & 11 & $92 \%$ & 1 & $8 \%$ & 0 & $0 \%$ \\
$\mathrm{Fe}$ & 0 & $0 \%$ & 11 & $92 \%$ & 1 & $8 \%$ \\
$\mathrm{Mn}$ & 0 & $0 \%$ & 0 & $0 \%$ & 12 & $100 \%$ \\
$\mathrm{Zn}$ & 0 & $0 \%$ & 12 & $100 \%$ & 0 & $0 \%$ \\
\hline
\end{tabular}

Para a maioria dos nutrientes, as diagnoses predominantes se situaram na classe normal, com exceção para cobre e manganês. O cobre apresentou diagnóstico 
caracterizado por deficiência em $92 \%$ dos casos, evidenciando a limitação da produtividade.

Manganês foi $100 \%$ excessivo para todas as classes de produtividade, muito provavelmente devido às freqüentes aplicações foliares durante a fase vegetativa da cultura. O potássio apresentou $50 \%$ dos casos na classe normal e $50 \%$ dos casos na classe suficiente.

O diagnóstico nutricional obtido pelo método Jones (1981) para cada classe de produtividade da cultura da soja nas regiões do sul do Maranhão e sudoeste do Piauí foi comparado com as faixas de suficiência segundo Embrapa (2004) (Tabela 24).

Tabela 24. Comparação da diagnose nutricional para DRIS e o critério das faixas de suficiência para as regiões do sul do Maranhão e sudoeste do Piauí

\begin{tabular}{|c|c|c|c|c|c|c|c|}
\hline \multirow{2}{*}{ Nutriente } & \multicolumn{3}{|c|}{ DRIS } & \multicolumn{3}{|c|}{ FAIXA DE SUFICIÊNCIA ${ }^{1}$} & \multirow{2}{*}{$\begin{array}{c}\% \\
\text { Concordância }\end{array}$} \\
\hline & Deficiente & Normal & Excessivo & Deficiente & Normal & Excessivo & \\
\hline $\mathrm{N}$ & 0 & 12 & 0 & 5 & 7 & 0 & 58 \\
\hline $\mathrm{P}$ & 1 & 9 & 2 & 0 & 12 & 0 & 75 \\
\hline $\mathrm{K}$ & 6 & 6 & 0 & 0 & 12 & 0 & 50 \\
\hline $\mathrm{Ca}$ & 0 & 9 & 3 & 0 & 12 & 0 & 75 \\
\hline $\mathrm{Mg}$ & 1 & 11 & 0 & 0 & 12 & 0 & 92 \\
\hline $\mathrm{S}$ & 1 & 10 & 1 & 0 & 12 & 0 & 83 \\
\hline B & 1 & 11 & 0 & 0 & 12 & 0 & 92 \\
\hline $\mathrm{Cu}$ & 11 & 1 & 0 & 9 & 3 & 0 & 83 \\
\hline $\mathrm{Fe}$ & 0 & 11 & 1 & 0 & 12 & 0 & 92 \\
\hline $\mathrm{Mn}$ & 0 & 0 & 12 & 0 & 12 & 0 & 0 \\
\hline $\mathrm{Zn}$ & 0 & 12 & 0 & 0 & 12 & 0 & 100 \\
\hline
\end{tabular}

A diagnose nutricional observada para nitrogênio, potássio e manganês foi a mais discordante. Para nitrogênio verificou-se diagnose normal em todos os casos na avaliação do DRIS, enquanto que para o critério das faixas de suficiência, foram 
observadas cinco diagnoses deficientes, indicando uma menor rigidez do método DRIS na avaliação do estado nutricional.

Para potássio o método DRIS indicou seis diagnósticos deficientes e seis normais, enquanto que a avaliação pelo critério das faixas de suficiência indicou todas as diagnoses como normais, indicando neste caso um maior rigor na avaliação do estado nutricional pelo DRIS (Tabela 24).

A avaliação do estado nutricional para manganês diferiu totalmente entre os dois critérios. O DRIS considerou o manganês como excessivo em todas as classes de produtividade, enquanto que o critério das faixas de suficiência indicou como normal todas as concentrações de manganês. Verifica-se também um maior rigor na avaliação do estado nutricional pelo DRIS, para este nutriente (Tabela 24).

Para cobre o diagnóstico foi relativamente semelhante pela avaliação dos dois métodos. O maior número de diagnoses deficientes ocorreu para cobre e potássio nas regiões do sul do Maranhão e sudoeste do Piauí. O mesmo ocorreu na avaliação do estado nutricional da cultura da soja no sul do Mato Grosso do sul, cobre e potássio foram os nutrientes que apresentaram maior freqüência de limitação pelo método DRIS (Maeda, 2002).

\subsection{Estado nutricional da soja no Mato Grosso}

Da mesma forma que para as regiões do sul do Maranhão e sudoeste do Piauí, os índices DRIS, IBN e IBNm para o Mato Grosso foram obtidos a partir das concentrações médias dos nutrientes por classe de produtividade (Tabela 25).

O nitrogênio apresentou índices DRIS próximos de zero para a maioria das classes de produtividade, com valores mais elevados entre as classes de 2101 e 3000 $\mathrm{kg} \mathrm{ha}^{-1}$ porem não maiores que o IBNm. Como foi verificado no estudo da relação entre 
a produtividade e o índice DRIS para nitrogênio, não houve significância estatística entre estas variáveis. Estes resultados são indicativos de que este nutriente não representa limitação para a produtividade na avaliação do estado nutricional pelo DRIS e, que a fixação simbiótica é eficiente no suprimento de nitrogenio para a cultura da soja no Mato Grosso.

Tabela 25. Índices DRIS (Jones, 1981), Índice de Balanço Nutricional (IBN), Índice de Balanço Nutricional Médio (IBNm) por classe de produtividade da soja no Mato Grosso

\begin{tabular}{|c|c|c|c|c|c|c|c|c|c|c|c|c|c|}
\hline \multirow{2}{*}{$\begin{array}{c}\text { Classes de } \\
\text { produtividade } \\
\qquad\left(\mathrm{kg} \mathrm{ha}^{-1}\right)\end{array}$} & \multicolumn{13}{|c|}{ Índices DRIS (Jones, 1981) } \\
\hline & $\mathbf{N}$ & $\mathbf{P}$ & $\mathrm{K}$ & $\mathrm{Ca}$ & $\mathbf{M g}$ & $\mathrm{s}$ & B & $\mathrm{Cu}$ & $\mathrm{Fe}$ & $M n$ & $\mathrm{Zn}$ & IBN & IBNm \\
\hline $5101-5400$ & 0,5 & $-0,9$ & $-1,4$ & 1,7 & $-0,1$ & 1,1 & $-0,4$ & 0,7 & $-1,2$ & 1,0 & $-1,1$ & 10,2 & 0,9 \\
\hline $4801-5100$ & 0,0 & 0,2 & $-0,6$ & $-0,5$ & $-0,8$ & 0,0 & 0,5 & 0,1 & 0,3 & 0,4 & 0,3 & 3,8 & 0,3 \\
\hline $4501-4800$ & $-0,1$ & $-0,8$ & $-0,2$ & $-0,3$ & $-0,6$ & $-0,4$ & 0,9 & $-0,3$ & 1,5 & 0,3 & 0,1 & 5,3 & 0,5 \\
\hline $4201-4500$ & $-0,3$ & $-1,0$ & $-0,4$ & 0,0 & $-0,3$ & $-0,2$ & 0,4 & $-0,3$ & 1,4 & 0,3 & 0,3 & 4,9 & 0,4 \\
\hline $3901-4200$ & $-0,5$ & $-1,3$ & $-1,5$ & 0,7 & $-0,9$ & 0,9 & $-0,4$ & $-1,0$ & 1,1 & 1,6 & 1,1 & 10,8 & 1,0 \\
\hline $3601-3900$ & 0,1 & $-1,5$ & $-2,7$ & 1,2 & $-1,3$ & 1,3 & $-1,1$ & $-1,5$ & 1,7 & 2,2 & 1,8 & 16,3 & 1,5 \\
\hline $3301-3600$ & $-0,3$ & $-1,7$ & $-3,1$ & 0,8 & $-2,1$ & 1,5 & $-1,0$ & $-0,9$ & 1,9 & 2,4 & 2,6 & 18,2 & 1,7 \\
\hline $3001-3300$ & $-0,3$ & $-2,3$ & $-3,9$ & 1,2 & $-2,6$ & 1,4 & $-1,1$ & $-0,3$ & 1,4 & 3,3 & 3,3 & 21,2 & 1,9 \\
\hline $2701-3000$ & 1,1 & $-3,0$ & $-5,1$ & 2,6 & $-3,3$ & 2,1 & $-2,1$ & $-1,3$ & 1,6 & 4,3 & 3,1 & 29,7 & 2,7 \\
\hline $2401-2700$ & 1,8 & $-4,2$ & $-5,5$ & 3,5 & $-3,3$ & 2,6 & $-2,6$ & $-1,3$ & 0,9 & 4,8 & 3,2 & 33,6 & 3,1 \\
\hline $2101-2400$ & 1,4 & $-5,3$ & $-6,5$ & 3,5 & $-1,9$ & 2,8 & $-1,1$ & $-1,0$ & 0,1 & 4,7 & 3,3 & 31,6 & 2,9 \\
\hline $1801-2100$ & 0,7 & $-5,3$ & $-6,5$ & 3,3 & $-1,2$ & 1,9 & 0,2 & $-0,8$ & 0,6 & 4,5 & 2,5 & 27,7 & 2,5 \\
\hline $1501-1800$ & $-0,5$ & $-4,5$ & $-8,9$ & 3,8 & 0,4 & 2,2 & 0,2 & $-1,6$ & 1,4 & 5,1 & 2,3 & 31,0 & 2,8 \\
\hline $1201-1500$ & $-0,3$ & $-4,4$ & $-12,3$ & 4,5 & 1,5 & 1,7 & 1,4 & $-2,7$ & 2,6 & 3,4 & 4,5 & 39,4 & 3,6 \\
\hline $901-1201$ & $-0,3$ & $-8,8$ & $-6,4$ & 2,8 & 0,0 & 1,5 & 1,2 & $-2,7$ & 4,6 & 2,3 & 5,8 & 36,5 & 3,3 \\
\hline $601-900$ & $-0,4$ & $-7,7$ & $-4,3$ & 1,5 & $-1,9$ & 3,7 & 1,1 & $-3,8$ & 4,4 & 0,4 & 7,0 & 36,2 & 3,3 \\
\hline $301-600$ & 0,4 & $-13,5$ & $-4,3$ & 3,9 & $-0,4$ & 1,9 & 2,4 & $-1,8$ & 2,8 & 2,7 & 5,8 & 39,9 & 3,6 \\
\hline $0-300$ & $-0,3$ & $-17,7$ & $-5,1$ & $-1,1$ & $-2,2$ & 6,5 & 4,4 & $-2,0$ & 11,2 & $-1,8$ & 8,0 & 60,3 & 5,5 \\
\hline
\end{tabular}

Fósforo e o potássio apresentaram comportamento semelhante, onde os índices DRIS mais negativos se encontraram nas classes de produtividade mais baixas. Os índices DRIS tenderam a zero com o aumento da produtividade indicando 
que houve limitação por estes nutrientes nas classes de menor produtividade (Tabela 25).

Para cálcio observa-se índices DRIS mais elevados e positivos nas produtividades menores e que tendem a aproximar-se de zero com o aumento da produtividade, o que indica que nas produtividades menores pode estar ocorrendo excesso. O magnésio apresentou a maioria dos índices negativos, principalmente na classe de produtividade intermediária.

O cálcio e o magnésio tem papel importante na fixação simbiótica do nitrogênio, por esse motivo, é fundamental a presença destes nutrientes em solos sob cultivo de soja (Rosolem, 1980). Entretanto um excesso poderá induzir em deficiência de outros elementos como fósforo, ferro e potássio, a imobilidade do cálcio exige um suprimento constante para manter um ótimo desenvolvimento e a deficiência de magnésio poderá interferir na redistribuição do fósforo da parte vegetativa para as sementes (Bataglia \& Mascarenhas, 1982).

Os índices DRIS para enxofre foram positivos e maiores nas classes de menor produtividade e, tenderam ao equilíbrio com o aumento da produtividade, o que indica que houve excesso de enxofre nas produtividades menores (Tabela 25).

O boro apresentou índices DRIS variáveis com o aumento da produtividade. Nas menores produtividades os índices foram positivos, nas classes intermediárias verificou-se deficiência e nas produtividades mais altas os índices DRIS foram mais próximos do equilíbrio nutricional.

O cobre apresentou índices DRIS negativos em praticamente todas as classes, com exceção das duas classes com maior produtividade. Entretanto, estes não foram superiores aos valores em módulo do IBNm. Verificou-se que houve uma tendência de equilíbrio nutricional para cobre com o aumento da produtividade. Ferro e manganês 
apresentam índices DRIS predominantemente positivos em todas as classes de produtividade (Tabela 25 ).

Para zinco, os índices DRIS foram predominantemente positivos e diminuíram com o aumento da produtividade, indicando excesso nas classes de produtividade intermediárias e baixas. Cabe destacar que o zinco foi o nutriente que apresentou a melhor relação índices DRIS e produtividade

As classes de maior produtividade, principalmente a partir $3901 \mathrm{~kg} \mathrm{ha}^{-1}$, apresentaram índices DRIS mais próximos de zero, indicando um melhor equilíbrio nutricional. Verifica-se também que o IBN diminuiu com o aumento da produtividade, demonstrando que a norma refletiu o estado nutricional de uma faixa de produtividade consideravelmente alta.

Em termos gerais, verificou-se que houve maior limitação na produtividade pelo nutriente com menor índice DRIS. Considerando as classes de 0 a $1201 \mathrm{~kg} \mathrm{ha}^{-1}$ verifica-se que o mais limitante foi fósforo. Da classe de produtividade de $1201 \mathrm{~kg} \mathrm{ha}^{-1}$ até $4200 \mathrm{~kg} \mathrm{ha}^{-1}$ o potássio foi o mais limitante. Na classe 4801 a $5100 \mathrm{~kg} \mathrm{ha}^{-1} \mathrm{o}$ magnésio e o potássio apresentaram os menores índices DRIS. Das 18 classes de produtividade avaliadas, 11 apresentaram os menores índices DRIS para potássio e seis para fósforo. Estes dois nutrientes apresentaram os menores índices DRIS em praticamente todas as classes de produtividade (Tabela 25).

A avaliação do estado nutricional a partir da classificação dos nutrientes em deficiente, normal e excessivo, utilizando um critério semelhante ao de Wadt (1996) para as classes de produtividade avaliadas, é apresentada na Tabela 26.

Fósforo, potássio e magnésio, nesta ordem, apresentaram maior número de diagnoses na classe deficiente, evidenciando a forte limitação por estes nutrientes nas 
produtividades intermediárias e baixas. Nitrogênio, enxofre, boro e manganês não apresentaram nenhum diagnóstico considerado deficiente.

Tabela 26. Avaliação do estado nutricional da soja no Mato Grosso pelo DRIS (Jones, 1981) por classe de diagnose

\begin{tabular}{lcccccc}
\hline \multirow{2}{*}{ Nutriente } & \multicolumn{2}{c}{ Deficiente } & \multicolumn{2}{c}{ Normal } & \multicolumn{2}{c}{ Excessivo } \\
& Caso & $\%$ & Caso & $\%$ & Caso & $\%$ \\
\hline $\mathrm{N}$ & 0 & $0 \%$ & 18 & $100 \%$ & 0 & $0 \%$ \\
$\mathrm{P}$ & 16 & $89 \%$ & 2 & $11 \%$ & 0 & $0 \%$ \\
$\mathrm{~K}$ & 15 & $83 \%$ & 3 & $17 \%$ & 0 & $0 \%$ \\
$\mathrm{Ca}$ & 1 & $6 \%$ & 10 & $56 \%$ & 7 & $39 \%$ \\
$\mathrm{Mg}$ & 6 & $33 \%$ & 12 & $67 \%$ & 0 & $0 \%$ \\
$\mathrm{~S}$ & 0 & $0 \%$ & 15 & $83 \%$ & 3 & $17 \%$ \\
$\mathrm{~B}$ & 0 & $0 \%$ & 16 & $89 \%$ & 2 & $11 \%$ \\
$\mathrm{Cu}$ & 1 & $6 \%$ & 17 & $94 \%$ & 0 & $0 \%$ \\
$\mathrm{Fe}$ & 1 & $6 \%$ & 9 & $50 \%$ & 8 & $44 \%$ \\
$\mathrm{Mn}$ & 0 & $0 \%$ & 7 & $39 \%$ & 11 & $61 \%$ \\
$\mathrm{Zn}$ & 1 & $6 \%$ & 5 & $28 \%$ & 12 & $67 \%$ \\
\hline
\end{tabular}

Na região de Rio Verde-GO, fósforo também foi o nutriente mais limitante na avaliação do estado nutricional da soja pelo DRIS. O potássio, pelo contrário, foi o mais excessivo, justificado pelas elevadas adubações potássicas nas lavouras da região (Leandro, 1998).

O nitrogênio apresentou todas as diagnoses na classe normal, semelhante ao ocorrido nas regiões do sul do Maranhão e sudoeste do Piauí.

O cobre apesar de alguns índices DRIS negativos, apresentou a maior parte dos índices dentro da classe normal. Boro e enxofre também apresentaram a maioria dos diagnósticos dentro da classe normal. Os índices DRIS para zinco, manganês, ferro e cálcio apresentam algumas diagnoses dentro da classe deficiente. Contudo, zinco e manganês foram os nutrientes que mais se destacaram por apresentarem 
maior percentual dentro da classe excessivo. Para cálcio é importante considerar que o excesso ocorre principalmente nas classes onde potássio apresentou o menor índice DRIS (Tabela 26).

A avaliação do estado nutricional pelo DRIS (Jones, 1981) e a subdivisão em classes de diagnose (deficiente, normal e excessivo) foi comparada com a diagnose pelo critério das faixas de suficiência sugeridas pela Embrapa (2004). A concordância na avaliação do estado nutricional entre os dois métodos é apresentada na Tabela 27.

Tabela 27. Comparativo de diagnose nutricional da soja entre DRIS e critério das faixas de suficiência para o Mato Grosso

\begin{tabular}{|c|c|c|c|c|c|c|c|}
\hline \multirow{2}{*}{ Nutriente } & \multicolumn{3}{|c|}{ DRIS } & \multicolumn{3}{|c|}{ FAIXA DE SUFICIÊNCIA ${ }^{1}$} & \multirow{2}{*}{$\begin{array}{c}\% \\
\text { Concordância }\end{array}$} \\
\hline & Deficiente & Normal & Excessivo & Deficiente & Normal & Excessivo & \\
\hline $\mathrm{N}$ & 0 & 18 & 0 & 8 & 10 & 0 & 56 \\
\hline $\mathrm{P}$ & 16 & 2 & 0 & 13 & 5 & 0 & 83 \\
\hline $\mathrm{K}$ & 15 & 3 & 0 & 2 & 13 & 3 & 17 \\
\hline $\mathrm{Ca}$ & 1 & 10 & 7 & 0 & 18 & 0 & 56 \\
\hline $\mathrm{Mg}$ & 6 & 12 & 0 & 0 & 18 & 0 & 67 \\
\hline$S$ & 0 & 15 & 3 & 3 & 15 & 0 & 67 \\
\hline$B$ & 0 & 16 & 2 & 0 & 17 & 1 & 83 \\
\hline $\mathrm{Cu}$ & 1 & 17 & 0 & 0 & 18 & 0 & 94 \\
\hline $\mathrm{Fe}$ & 1 & 9 & 8 & 0 & 18 & 0 & 50 \\
\hline $\mathrm{Mn}$ & 0 & 7 & 11 & 0 & 18 & 0 & 39 \\
\hline $\mathrm{Zn}$ & 1 & 5 & 12 & 0 & 18 & 0 & 28 \\
\hline
\end{tabular}

'Embrapa (2004).

Para nitrogênio os métodos foram concordantes em $56 \%$ dos casos, onde pelo DRIS todas as diagnoses foram classificadas como normais, enquanto que pelo critério das faixas de suficiência oito diagnoses se encontraram na classe deficiente. Este resultado indica um maior rigor para o critério das faixas de suficiência na avaliação do 
estado nutricional da soja para o nitrogênio. O mesmo ocorreu também para as regiões do sul do Maranhão e sudoeste do Piauí.

As maiores similaridades no diagnóstico do estado nutricional foram verificadas para cobre, boro e fósforo, que apresentaram 94,83 e $83 \%$ de concordância entre os métodos respectivamente (Tabela 27).

Para potássio foi pequena a concordância entre os métodos (17\%), onde pelo DRIS a predominância de diagnoses se encontrou na classe deficiente, enquanto que para o critério das faixas de suficiência a maioria das diagnoses se encontraram na classe normal. De forma semelhante ao que ocorreu nas regiões do sul do Maranhão e sudoeste do Piauí, houve um maior rigor para potássio na avaliação do estado nutricional.

O magnésio apresentou seis diagnósticos deficientes pelo método DRIS, sendo que para as faixas de suficiência todas as diagnoses foram consideradas normais.

Para o enxofre houve concordância em $100 \%$ das diagnoses para a classe normal, entretanto o DRIS identificou três diagnoses como excessivas, enquanto que o critério das faixas de suficiência três diagnoses como deficientes.

Para ferro e manganês houve pouca concordância. O critério das faixas de suficiência considerou as concentrações de todas as classes como normais, enquanto que o método identificou parte das amostras na classe excessiva.

O zinco foi o nutriente que mais apresentou diagnósticos classificados como excessivo pelo DRIS, sendo que o critério das faixas de suficiência considerou as concentrações das classes de produtividade como normais (Tabela 27).

Com exceção do nitrogênio, a avaliação do estado nutricional da soja no Mato Grosso foi mais severa pelo método DRIS quando comparado ao critério das faixas de suficiência. 


\section{CONCLUSÕES}

- A relação entre a produtividade e o IBN apresentou melhor ajuste quando as normas DRIS foram estabelecidas utilizando a população de referência com produtividade $\geq 3600 \mathrm{~kg} \mathrm{ha}^{-1}$ para as regiões do sul do Maranhão e sudoeste do Piauí e $\geq 4800 \mathrm{~kg} \mathrm{ha}^{-1}$ para o Mato Grosso;

- O cobre foi o nutriente mais limitante para a produtividade da soja nas regiões do sul do Maranhão e sudoeste do Piauí.

- Fósforo foi o nutriente mais limitante para a produtividade da soja no Mato Grosso;

- As metodologias de cálculo das funções DRIS (Beaufils, 1973; Jones, 1981; Elwali \& Gascho, 1984) apresentaram resultados semelhantes no diagnóstico nutricional da soja nas regiões do sul do Maranhão, sudoeste do Piauí e Mato Grosso;

- O método DRIS, utilizando normas especificas para as regiões do sul do Maranhão e sudoeste do Piauí e para o Mato Grosso, foi eficiente no diagnóstico nutricional da soja. 


\section{REFERÊNCIAS BIBLIOGRÁFICAS}

AB'SÁBER, A.N. A organização natural das paisagens inter e subtropicais brasileiras. In: SIMPÓSIO SOBRE CERRADOS, 3., São Paulo, 1971. Proceedings. São Paulo: USP, 1971. p.1-14.

ADÁMOLI, J.; MACEDO, J.; AZEVEDO, L.G.; MADEIRA, N.J.S. Caracterização da região dos Cerrados. In: GOEDERT, W.J. (Ed.). Solos dos Cerrados: tecnologias e estratégias de manejo. São Paulo: Nobel, 1985. p. 33-74.

ALVAREZ V., V.H.; LEITE, R.A. Fundamentos estatísticos das fórmulas usadas para cálculo dos índices DRIS. Boletim informativo da Sociedade Brasileira de Ciência do Solo, v.24, 1999. p.20-25.

ARBOLEDA, C.; ARCILA, J.P.; MARTINEZ, R.B. Sistema integrado de recomendación y diagnosis: Una alternativa para la interpretación de resultados del análisis foliar en café. Agronomia Colombiana, v.5, p. 17-30, 1988.

BAILEY, J.S. BEATTIE, J.A.M.; KILPATRICK, D.J. The diagnosis and recomendation integrated system (DRIS) for diagnosing the nutrient status of grassland swards: I. Model establishment. Plant and Soil, v.197, p.127-135, 1997.

BALDOCK, J.O.; SCHULTE, E.E. Plant analysis with standardized scores combines DRIS and sufficiency range approaches of corn. Agronomy Journal, v.88, p.448456, 1996. 
BASSO, C.; WILMS, F.W.W.; SUZUKI, A. Fertilidade do solo e nutrição de plantas. In: EMPRESA CATARINENSE DE PESQUISA AGROPECUÁRIA. Manual da cultura da macieira. Florianópolis: EMPASC-DID, 1986. p.236-265

BATAGLIA, O.C. DRIS-Citros: uma alternativa para avaliar a nutrição das plantas. Laranja, v.10, p.565-576, 1989.

BATAGLIA, O.C.; MASCARENHAS, H.A.A. Nutrição mineral da soja. In: A soja no Brasil Central 2.ed. São Paulo: FUNDAÇÃO CARGILL, 1982. p.115-132.

BATAGLIA, O.C.; DECHEN, A.R. Critérios alternativos para diagnose foliar. In: SIMPÓSIO AVANÇADO DE QUÍMICA E FERTILIDADE DO SOLO. Campinas, 1986. Anais. Campinas: Fundação Cargill, 1986. 179p.

BATAGLIA, O.C.; SANTOS, W.R. Efeito do procedimento de cálculo e da população de referência nos índices do sistema integrado de diagnose e recomendação (DRIS). Revista Brasileira de Ciência do Solo, v. 14, p. 339-344, 1990.

BATAGLIA, O.C.; DECHEN, A.R. Princípios da diagnose foliar. In: ALVAREZ, V.H.; FONTES, L.E.; FONTES, M.P.F. (Ed.). O solo nos grandes domínios morfológicos do Brasil e o desenvolvimento sustentável. Viçosa: Sociedade Brasileira de Ciência do Solo/Universidade Federal de Viçosa, 1996. p.646-659.

BATAGLIA, O.C.; FURLANI, A.M.C.; TEIXEIRA, J.P.F.; FURLANI, P.; GALLO, J.R. Métodos de análise química de plantas. Campinas: Instituto Agronômico, 1983. 48p. (Boletim Técnico, 78).

BEAUFILS, E.R. Phisiological diagnosis - a guide for improving maize production based on principles developed for rubber trees. Fertilizer Society of South African Journal, v.1, p.1-30, 1971. 
BEAUFILS, E.R. Diagnosis and recomendation integrated system (DRIS). A general scheme for experimentation and calibration based on principles developed from research in plant nutrition. Pietermararitzburg: University if Natal, 1973. 132p. (Soil Science Bulletin,1).

BEVERLY, R.B. A practical guide to the diagnosis and recomendation integrated system (DRIS). Athens: Micro-macro publishing, 1991. 87p.

BEVERLY, R.B.; STARK, J.C.; OJALA, J.C.; EMBLETON, T.W. Nutrient diagnosis of Valencia oranges by DRIS. Journal of American Society Horticulture Science, v.109, p.649-654, 1984.

BEVERLY, R.B.; SUMNER, M.E.; LETZSCH, W.S.; PLANCK, C.O. Foliar diagnosis of soybean by DRIS. Communication in Soil Science and Plant Analysis, v.17, p.237-256, 1986.

BLACK, R.J. Complexo soja: fundamentos, situação atual e perspectiva. In: CÂMARA, G. M. E. de S. (Ed.). Soja: tecnologia da produção II. Piracicaba: Escola Superior Agricultura "Luiz de Queiroz", 2000. 450p.

BRASIL. Ministério das Minas e Energia. PROJETO RADAM BRASIL. Folha SB.23 Teresina e SB.24 Jaguaribe. Rio de Janeiro, 1973a.

BRASIL. Ministério das Minas e Energia. PROJETO RADAM BRASIL. Folha SC.23 Rio São Francisco e SC.24 Aracajú. Rio de Janeiro, 1973b.

BRASIL. Ministério das Minas e Energia. PROJETO RADAM BRASIL. Folha SD.21 Cuiabá. Rio de Janeiro, 1982.

BRASIL. Ministério das Minas e Energia. PROJETO RADAM BRASIL. Folha SE.22 Goiânia. Rio de Janeiro, 1983. 
CAMARGO, M.N.; KLAMT, E.; KAUFFMAN, J.H. Sistema brasileiro da classificação de solos. Boletim informativo da Sociedade Brasileira de Ciência do Solo, v.12, p.11-33, 1987.

COMPANHIA NACIONAL DE ABASTECIMENTO (CONAB). Indicadores da agropecuária. http://conab.gov.br (Jan. de 2005).

COSTA, A.N. Uso do sistema integrado de diagnose e recomendação (DRIS), na avaliação do estado nutricional do mamoeiro (Carica papaya L.) no estado do Espírito Santo. Viçosa, 1995. 95p. Tese (Doutorado) - Universidade Federal de Viçosa.

CRESTE, J.E. Uso do DRIS na avaliação do estado nutricional do Limoeiro Siciliano. Botucatu, 1996. 120p. Tese (Doutorado) - Faculdade de Ciências Agronômicas do Campus de Botucatu, Universidade Estadual Paulista.

DIAS, B.F.S. Cerrado: uma caracterização. In: DIAS B.F. de S. Alternativas de desenvolvimento dos Cerrados: manejo e conservação de recursos naturais renováveis. Brasília: IBAMA, 1992. p.11-25.

ELWALI, A.M.O.; GASCHO, G.J. Soil testing, foliar analysis and DRIS as guides for sugarcane fertilization. Agronomy Journal, v.76, p.466-470, 1984.

ELWALI, A.M.O.; GASCHO, G.J.; SUMNER, M.E. Sufficiency levels and DRIS norms for 11 nutrients in corn. Agronomy Journal, v.77, p.506-508, 1985.

EMPRESA BRASILEIRA DE PESQUISA AGROPECUÁRIA. Manual de análises químicas de solos, plantas e fertilizantes, SILVA, F.C (ed). Brasilia: Embrapa Comunicação para Transferência de Tecnologia, 1999. 421p.

EMPRESA BRASILEIRA DE PESQUISA AGROPECUÁRIA. Tecnologias de produção de soja: região central do Brasil 2005. Londrina: Embrapa Soja, 2004. $239 p$. 
ESCANO, C.R.; JONES C.A.; UEHARA, G. Nutrient diagnosis in corn on Hydric Dystrandepts: II. Comparison of two systems of tissue diagnosis. Soil Science Society American Journal, v.45, p.1140-1144, 1981.

FERRI, M.G. Plantas do Brasil: espécies de cerrado. São Paulo: Edgard Blücher, 1969. 238p.

GOEDERT, W.J. LOBATO, E. WAGNER, E. O potencial agrícola da região dos Cerrados brasileiros. Pesquisa Agropecuária Brasileira, v.15, p.1-17, 1980.

HALLMARK, W.B.; DEMOOY, C.J.; PESEK, J. Comparison of two DRIS methods for diagnosing nutrient deficiencies. Journal of Fertilizer Issues, v.4, p.151-158, 1987. HALLMARK, W.B.; BEVERLY, R.B.; PARKER, M.B.; ADAMS, J.F.; BOSWELL, F.C.; OHKI, K.; SHUMAN, L.M.; WILSON, D.O. Evaluation of zinc and manganese requirements by the M-DRIS and sufficiency range methods. Agronomy Journal, v.81, p.770-776, 1989.

HANSON, R.G. DRIS evaluation on N, P, K, status of determinants soybeans in Brazil. Communication in Soil Science and Plant Analysis, v. 12, p.933-948, 1981.

HANWAY, J.J.; WEBER, C.R. N, P and $\mathrm{K}$ percentages in soybean plant parts. Agronomy Journal, v.63, p.286-290, 1971.

JONES, C.A. Proposed modifications of the diagnosis and recommendation integrated system (DRIS) for interpreting plant analysis. Communication in Soil Science and Plant Analysis, v.12, p.785-794, 1981.

JONES, J.B.; WOLF, B.; MILLS, H.A. Plant analysis handbook: a practical sampling, preparation, analysis and interpretation guide. Athens: Micro-macro publishing, 1991. 213p. 
KURIHARA, C.H. Demanda de nutrientes pela soja e diagnose de seu estado nutricional. Viçosa, 2004. 101p. Tese (Doutorado) - Universidade Federal de Viçosa.

LANTMANN, A.F.; PEREIRA, L.R.; ZOBIOLE, L.H.S.; CASTRO, C.; ORTIZ, F.R. Normas DRIS regionalizadas para avaliação do balanço nutricional da soja no estado do Paraná. In: REUNIÃO DE PESQUISA DE SOJA DA REGIÃO CENTRAL DO BRASIL, 24., São Pedro, 2002. Resumos. Londrina: Embrapa Soja, 2002. $128 p$.

LEANDRO, W.M. Sistema integrado de diagnose e recomendacao (DRIS) para a cultura da soja (Glycine max L. Merril) na região de Rio Verde-GO. Goiânia, 1998. 159p. Tese (Doutorado) - Universidade Federal de Goiás.

LEITE, R.A. Avaliação do estado nutricional do cafeeiro Conilon no Estado do Espírito Santo utilizando diferentes métodos de interpretação de análise foliar, 1993. 87p. Dissertação (Mestrado) - Universidade Federal de Viçosa.

LETZSCH, W.S. Computer program for selection of norms for use in the diagnosis and recommendation integrated system (DRIS). Communication in Soil Science and Plant Analysis, v.16, p.339-347, 1985.

LETZSCH, W.S.; SUMNER, M. E. Effect of population size and yield level in selection of diagnosis and recommendation integrated system (DRIS) norms. Communication in Soil Science and Plant Analysis, v.15, p.997-1006, 1984.

LOPES, A.S. Solos sob cerrado: características, propriedades e manejo. Piracicaba:Instituto da Potassa \& Fosfato: Instituto Inernacional da Potassa, 1983. $162 p$.

LOURENÇO FILHO, R.C.B. Controle estatístico de qualidade. Rio de Janeiro: LTC Livros Técnicos e Científicos, 1982. p.35-47. 
MAEDA, S. Interpretação do estado nutricional de soja pelo DRIS no Mato Grosso do Sul. Curitiba, 2002. 107p. Tese (Doutorado) - Universidade Federal do Paraná.

MAIA, C. E. Análise crítica da fórmula original de Beaufils no cálculo dos índices DRIS: a constante de sensibilidade. In: POTAFOS. (Org.). Monitoramento nutricional para a recomendação da adubação de culturas. Piracicaba, 1999, v.1, $3 p$.

MALAVOLTA, E. A diagnose foliar: passado, presente e futuro. In: WADT, P.G.S.; MALAVOLTA, E. (Ed.). Monitoramento nutricional para a recomendação de adubação para as culturas. Piracicaba: POTAFOS, 1999. p.20-25.

MALAVOLTA, E.; MALAVOLTA, M.L. Diagnose foliar: princípios e aplicações. In: BULL, L.T.; ROSOLEM, C. Interpretação de analise química de solo e planta para fins de adubação. Botucatu: Fundação de Estudos e Pesquisas Agrícolas, 1989. p.227-308.

MALAVOLTA, E.; VITTI, G.C.; OLIVEIRA, S.A. Avaliação do estado nutricional das plantas: princípios e aplicações 2.ed. Piracicaba: Associação Brasileira para Pesquisa da Potassa e do Fosfato, 1997. 319p.

MARTINEZ, H.E.P.; CARVALHO, J.G. de; SOUZA, R.B. Diagnose foliar. In: RIBEIRO, A.C.; GUIMARÃES, P.T.G.; ALVAREZ V, V.H. Recomendações para o uso de corretivos e fertilizantes em Minas Gerais: $5^{\mathrm{a}}$ aproximação. Viçosa: Comissão de Fertilidade do Solo do Estado de Minas Gerais, 1999. p.143-144.

MASCARENHAS, H.A.A.; NEPTUNE, A.M.L.; MUROAKA, T.; BULISANI, E.A.; HIROCE, R. Absorção de nutrientes por cultivares de soja. Revista Brasileira de Ciência do Solo, v.4, p.92-96, 1980. 
McCLUNG, A.C.; FREITAS, L.M.M.; GALLO, J.R.; QUINN, L.R.; MOTT, G.O. Preliminary fertility studies on "Campos Cerrados"soils in Brazil. New York: IBEC Research Institute, 1958.19p. (IBEC Research Institute. Bulletin 13).

MELDAL-JOHNSEN, A.; SUMNER, M.E. Foliar diagnostic norms for potatoes. Journal of Plant Nutrition, v.2, p.569-576, 1980.

MILLER, R.J.; PESEK, J.T.; HANWAY, J.J. Relathionship between soybean yield and concentration of phosphorus and potassium fertilizers. Agronomy Journal, v.53, p.393-396, 1961.

MOURÃO FILHO, F.A.A. DRIS em laranjeira 'Valência' sobre três porta-enxertos. Piracicaba, 2000. 105p. Tese (Livre-Docência) - Escola Superior de Agricultura "Luiz de Queiroz".

MIYASAKA, S. A soja no Brasil Central (compact disc). Biblioteca Virtual de Publicações Técnicas, São Paulo: FUNDAÇÃO CARGILL, 1986.

NACHTIGALL, G.R. Sistema integrado de diagnose e recomendação (DRIS) para avaliação do estado nutricional da macieira no sul do Brasil. Piracicaba, 2004. 141p. Tese (Doutorado) - Escola Superior de Agricultura "Luiz de Queiroz".

NICK, J.A. DRIS para cafeeiros podados. Piracicaba, 1998. 86p. Dissertação (Mestrado) - Escola Superior de Agricultura "Luiz de Queiroz".

OHLROGGE, A.J. Mineral nutrition of soybean. Advances in Agronomy, v.12, p.126160, 1960.

OLIVEIRA, J.B.; JACOMINE, P.K.T; CAMARGO, M.N. Classes gerais de solos do Brasil: guia auxiliar para seu reconhecimento. Jaboticabal: Funep, 1992. 210p.

OLIVEIRA, S.A. Avaliação do balanço nutricional no sistema solo-planta. In: CONGRESSO BRASILEIRO DE CIÊNCIA DO SOLO, 24., Goiânia, 1993. Resumos: Goiânia, Sociedade Brasileira de Ciência do Solo, 1993. p.43-44. 
PALUDZYSZYN FILHO, E. A cultura da soja no Sul do Maranhão. Balsas: EMBRAPA-CNPSo, 1995. 34p. (Documentos, 84).

PAYNE, G.G.; RECHCIGL, J.E.; STEPHENSON, R.L. Development of diagnosis and recomendation integrated system norms for Bahiagrass. Agronomy Journal, v.82, p.930-934, 1990.

RAGHUPATHI, H.B.; BHARGAVA, B.S. Preliminary nutrient norms for 'Alphonso' mango using diagnosis and recommendation integrated system. Indian Journal of Agricultural Sciences, v.69, p.648-650, 1999.

RAMALHO FILHO, A.; BEEK, K.J. Sistema de avaliação da aptidão agrícola das terras. Rio de Janeiro: EMBRAPA-CNPS, 1994. 65p.

RATHFON, R.A.; BURGER, J.A. Diagnosis and recomendation integrated system (DRIS) nutrient norms for Fraser Christmas trees. Forest Science, v.37, p.9981010, 1991.

REIS JUNIOR, R.A.; Diagnose nutricional da cana-de-açúcar com o uso do sistema integrado de diagnose e recomendação (DRIS). Campos de Goytacazes, 1999. 141p. Tese (Doutorado) - Universidade Estadual do Norte Fluminense.

REIS JUNIOR, R.A. Dris Norms Universality In The Corn Crop. Communication in Soil Science and Plant Analysis, v.33, p.711-735, 2002.

REIS JUNIOR, R.A.; CORRÊA, J.B.; CARVALHO, J.G. de; GUIMARÃES, P.T.G. Estabelecimento de normas DRIS para o cafeeiro no sul de Minas Gerais: $1^{\text {a }}$ aproximação. Ciência Agrotécnica, v.26, p.269-282, 2002.

ROSOLEM, C.A. Nutrição mineral e adubação da soja. Piracicaba: Instituto da Potassa (EUA e Suiça), 1980. 80p. (Boletim técnico). 
SALVO, J.G. Uso do DRIS na avaliação do estado nutricional de plantas cítricas afetadas pela clorose variegada dos citros. Piracicaba, 2001. 108p. Dissertação (Mestrado) - Escola Superior de Agricultura "Luiz de Queiroz".

SANTOS, W.R. Avaliação do equilíbrio nutricional dos macronutrientes em citros com diferentes adubações. Piracicaba, 1997. 112p. Dissertação (Mestrado) - Escola Superior de Agricultura "Luiz de Queiroz".

SARRUGE, J.R.; HAAG, H.P. Análises químicas em plantas. Piracicaba: ESALQ. 1974. 56p.

SAS Institute inc. SAS/STAT. SAS user's guide for windows environment, 8.2 ed. Cary: SAS Institute, 1999. 956p.

SCHALLER, K.; LÖHNERTZ, O.; MICHEL, H. Improvements of the DRIS-Sistem and first experiences in gravepine nutrition with special consideration of the compositional nutrient diagnosis approach. Acta Horticulturae, n.383, p.171-189, 1995.

SCHUTZ, C.J.; VILLIERS, J.M. Foliar diagnosis and fertilizer prescription in forestry the DRIS system and its potential. South African Forestry Journal, v.141, p.6-12, 1987.

SILVA, J.E.; LEMANSKI, J.; RESCK, D.V.S. Perdas de matéria orgânica e suas relações com a capacidade de troca catiônica em solos da região de Cerrados do Oeste Baiano. Revista Brasileira de Ciência do Solo, v.18, p.541-547, 1994.

SOUSA, D.M.G.; MIRANDA, L.N.; LOBATO, E. CASTRO, L.H.R. Métodos para determinar as necessidades de calagem em solos dos Cerrados. Revista Brasileira de Ciência do Solo, v.13, p.193-198, 1989.

SUMNER, M.E. Preliminary N, P, and $\mathrm{K}$ foliar diagnostic norms for soybeans. Agronomy Journal, v.69, p.226-230, 1977a. 
SUMNER, M.E. Effect of corn leaf sampled on N, P, K, Ca and Mg content and calculated DRIS Index. Communication in Soil Science and Plant Analysis, v.8, p.269-280, 1977b.

SUMNER, M.E. Interpretation of foliar analysis for diagnostic purposes. Agronomy Journal, v.71, p.343-348, 1979.

SUMNER, M.E. Diagnosis of súlfur requirements of corn and wheat using foliar analysis. Soil Science Society of America Journal, v.45, p.87-90, 1981.

SZÜCS, E.; KÁLLAY, T.; SZENCI, G. Determination of DRIS indices for apple (Malus domestica Borkh). Acta Horticulturae, n.274, p.443-453, 1990.

ULRICH, A.; HILLS, F.J. Principles and practices of plant Analysis. In: HARDY, G.W. (Ed.) Soil testing and plant analysis. Madison:Soil Science Society American, 1967. p.11-24. (Special Publication,2).

VIGIER, B.; MACKENZIE, A.F.; CHEN, Z. Evaluation of diagnosis and recomendation integrated system (DRIS) on early maturing soybeans. Communication in Soil Science and Plant Analysis, v.20, p.685-693, 1989.

WADT, P.G.S. Os métodos da chance matemática e do sistema integrado de diagnose e recomendação (DRIS) na avaliação do estado nutricional de plantios de eucalipto. Viçosa, 1996. 123p. (Tese) Doutorado) - Universidade Federal de Viçosa.

WALWORTH, J.L.; SUMNER, M.E. The diagnosis and recomendation integrated system (DRIS). Advances in Soil Science, v.6, p.149-188, 1987.

WALWORTH, J.L.; WOODDARD, H.J.; SUMNER, M.E. Generation of corn tissue norms from a small, high-yield data base. Communications in Soil Science and Plant Analysis, v.19, p.563-577, 1988. 
ZAMBELLO JUNIOR, E. Aplicação do sistema integrado de diagnose e recomendação para diferentes solos e épocas de amostragem foliar em soqueiras de cana-deaçucar (Saccharum spp). Piracicaba, 1979. 95p. Dissertação (Mestrado) - Escola Superior de Agricultura "Luiz de Queiroz". 